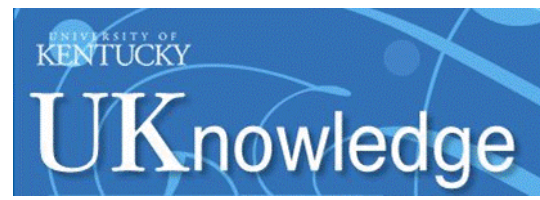

University of Kentucky

UKnowledge

\title{
FACTORS THAT INFLUENCE MATERNAL FEEDING DECISIONS FOR TODDLERS: EXTENDING THE THEORY OF PLANNED BEHAVIOR
}

\author{
Elizabeth Lucas Combs \\ University of Kentucky, elmars2@uky.edu \\ Author ORCID Identifier: \\ (iD) https://orcid.org/0000-0001-6167-3901 \\ Digital Object Identifier: https://doi.org/10.13023/etd.2019.056
}

Right click to open a feedback form in a new tab to let us know how this document benefits you.

\section{Recommended Citation}

Combs, Elizabeth Lucas, "FACTORS THAT INFLUENCE MATERNAL FEEDING DECISIONS FOR TODDLERS: EXTENDING THE THEORY OF PLANNED BEHAVIOR" (2019). Theses and Dissertations--Kinesiology and Health Promotion. 58.

https://uknowledge.uky.edu/khp_etds/58

This Doctoral Dissertation is brought to you for free and open access by the Kinesiology and Health Promotion at UKnowledge. It has been accepted for inclusion in Theses and Dissertations--Kinesiology and Health Promotion by an authorized administrator of UKnowledge. For more information, please contact UKnowledge@lsv.uky.edu. 


\section{STUDENT AGREEMENT:}

I represent that my thesis or dissertation and abstract are my original work. Proper attribution has been given to all outside sources. I understand that I am solely responsible for obtaining any needed copyright permissions. I have obtained needed written permission statement(s) from the owner(s) of each third-party copyrighted matter to be included in my work, allowing electronic distribution (if such use is not permitted by the fair use doctrine) which will be submitted to UKnowledge as Additional File.

I hereby grant to The University of Kentucky and its agents the irrevocable, non-exclusive, and royalty-free license to archive and make accessible my work in whole or in part in all forms of media, now or hereafter known. I agree that the document mentioned above may be made available immediately for worldwide access unless an embargo applies.

I retain all other ownership rights to the copyright of my work. I also retain the right to use in future works (such as articles or books) all or part of my work. I understand that I am free to register the copyright to my work.

\section{REVIEW, APPROVAL AND ACCEPTANCE}

The document mentioned above has been reviewed and accepted by the student's advisor, on behalf of the advisory committee, and by the Director of Graduate Studies (DGS), on behalf of the program; we verify that this is the final, approved version of the student's thesis including all changes required by the advisory committee. The undersigned agree to abide by the statements above.

Elizabeth Lucas Combs, Student

Dr. Melinda Ickes, Major Professor

Dr. Melinda Ickes, Director of Graduate Studies 


\title{
FACTORS THAT INFLUENCE MATERNAL FEEDING DECISIONS FOR TODDLERS: EXTENDING THE THEORY OF PLANNED BEHAVIOR
}

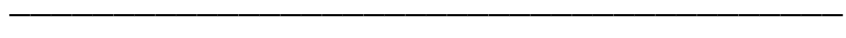 \\ DISSERTATION \\ A dissertation submitted in partial fulfillment of the \\ requirements for the degree of Doctor of Education in the \\ College of Education \\ at the University of Kentucky \\ By \\ Elizabeth Lucas Combs \\ Lexington, Kentucky \\ Director: Dr. Melinda Ickes, Associate Professor of Kinesiology and Health Promotion \\ Lexington, Kentucky \\ 2019
}

Copyright () Elizabeth Lucas Combs 2019

https://orcid.org/0000-0001-6167-3901 


\section{ABSTRACT OF DISSERTATION}

\section{FACTORS THAT INFLUENCE MATERNAL FEEDING DECISIONS FOR TODDLERS: EXTENDING THE THEORY OF PLANNED BEHAVIOR}

Establishing healthy eating behaviors is vital in the early years to help combat the development of obesity and other chronic diseases. Mothers play an invaluable role in shaping their children's eating habits through controlling what and when children eat as well as the overall food environment, which is why a better understanding of what influences mothers' decisions about these behaviors is important.

The purpose of the dissertation was to gain a better understanding of what impacts maternal feeding decisions regarding toddler nutrition behaviors. This was a two-phased mixed methods study. The aim of the initial study was to explore, using a Theory of Planned Behavior (TPB) framework, the influences on mothers' toddler feeding decisions. These included attitude, subjective norms, and perceived behavioral control. These constructs were derived from discussions about what sources of nutrition information mothers use and trust. The aim of the subsequent study was to use the TPB to assess factors affecting a mother's behavioral intention to provide their toddler with a healthy diet and to see if the addition of the parental role construction variable strengthened the TPB's ability to significantly predict the mother's behavioral intention.

The first study used a qualitative approach to gather data from three focus groups that consisted of mothers of toddlers $(N=15)$. Qualitative thematic analysis was used to define prominent themes. Four major themes emerged from the data analysis: (1) attitudes (subthemes: positive towards maternal role of feeding and negative towards the maternal role of feeding); (2) subjective norms positively accepted (subthemes: social media, pediatricians, and registered dietitians); (3) subjective norms negatively accepted (subthemes: pediatricians and registered dietitians); (4) perceived behavioral control (subthemes: acceptance, scarcity of time and outside influences).

An online survey was created using data gathered from the focus groups and a previously validated survey that fit the theoretical basis of the study. The survey utilized the TPB to assess the connections between the constructs and the mothers' behavioral intentions surrounding toddler feeding. The final sample consisted of 148 mothers. The mean age was $32.83(S D=6.16)$ years. The majority of participants were married $(87.2 \%)$, had earned a college degree or higher $(79.7 \%)$, held part-time or fulltime employment, (60.8\%), and were White $(90.3 \%)$. The TPB model predicted $53 \%$ of the variance in mother's behavioral intention surrounding the behavior of providing meals that include a wide variety of the five food groups in appropriate amounts. The addition of the parental role construction variable added $6 \%$ more predictive power to the model. 
The most salient predictors included attitude, perceived behavioral control, and parental role construction.

Mothers positively and negatively receive information from a variety of sources, they have many strong emotions associated with feeding that are deeply rooted in their roles as mothers, and their feeding decisions were strongly influenced by the TPB constructs. Health promotion efforts should aim to increase the mother's sense of behavioral control and parental responsibility rather than focusing on the benefits of healthy eating. Programs should provide tangible ways to help mothers overcome perceived barriers and, in turn, increase mothers' beliefs in their ability to provide toddlers with a balanced diet.

KEYWORDS: Theory of Planned Behavior, Parental Role Construction, Mothers, Toddlers, Nutrition, Sources of Nutrition Information 
Elizabeth Lucas Combs

(Name of Student)

03/12/2019

Date 
FACTORS THAT INFLUENCE MATERNAL FEEDING DECISIONS FOR TODDLERS: EXTENDING THE THEORY OF PLANNED BEHAVIOR

By

Elizabeth Lucas Combs

Dr. Melinda Ickes

Director of Dissertation

Dr. Melinda Ickes

Director of Graduate Studies

$03 / 12 / 2019$

Date 


\section{DEDICATION}

To my family. From the time that I was young, you instilled in me the idea that anything was possible. It is from your inspiration that I sought out this goal and it is from your support that it was made possible. Thank you. 


\section{ACKNOWLEDGMENTS}

This dissertation would not have been possible without the incredible amount of dedication and support from several individuals. I cannot say thank you enough to my Dissertation Chair, Dr. Melinda Ickes, whose level of commitment, expertise in the research area, and unwavering support allowed me to grow and produce a quality product. I was always amazed at the level of detail provided in the helpful comments and review at every stage of the dissertation. Thank you for your steadfast commitment to the process, for your countless edits, and for your consistent care. I am incredibly grateful and hope to inspire future students to meet their goals, like you inspired me to meet mine.

Thank you to the George and Betty Blanda Endowed Professorship awarded to Dr. Melody Noland for kindly providing incentives for part of this study. Next, I wish to thank the complete Dissertation Committee, and outside reader, respectively: Dr. Melody Noland, Dr. Kristen Mark, Dr. Janet Mullins, and Dr. Scott Black. The entire committee has provided thoughtful feedback and insight that has been appreciated and has helped produce a stronger end product.

In addition to the academic assistance above, I received equally important support from family and friends. My husband, Brandon Combs, provided on-going support throughout the entire graduate school process. During this timeframe, we have had two children and he has been adaptable and supportive every step of the way. He has quietly and consistently handled home life and taken wonderful care of our kids. I would also like to say thank you to my parents for their steady support throughout my entire academic career. They always allowed me to dream bigger and go farther, all while

saying that I could do it. Also, thank you to my parents-in-law for continuously being 
willing to step in and lend a helping hand and to my brother for leading the way and being a great "Uncle D" to my children. Additionally, thank you to my kiddos, Will and Ellie for providing joy on a daily basis. You are amazing and I hope that you will pursue your own goals with abandon, whatever they may be.

I would also like to thank my friends and colleagues that helped me along the way. My best friends, Becca Jump, Emily Andrews, and Erin Ferguson have provided supportive, listening ears for the past 20+ years and this type of constant friendship is much appreciated, especially in times of stress. Rachel Harrington has provided encouragement, patient support, and accountability every step of the way. The hours spent at Panera, the frequent texts/emails, and the deep understanding provided have all served as invaluable resources during this time. Finally, thank you to my colleagues at UK for serving as a sounding board for my many ideas and questions. You have all provided wise counsel, been a supportive team, and delivered words of encouragement just when I needed them the most. Thank you for believing in me. 


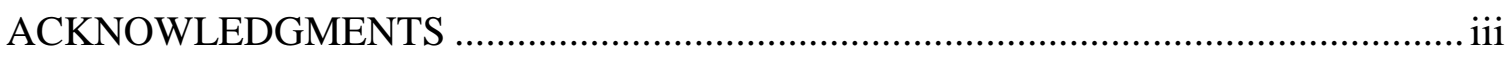

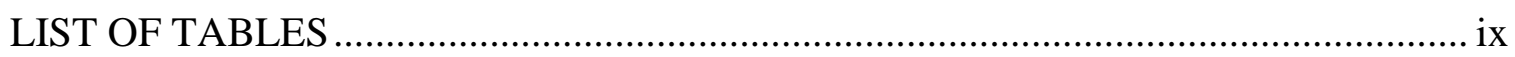

LIST OF FIGURES ………………………………….......................................

CHAPTER 1. INTRODUCTION AND STATEMENT OF PROBLEM............................ 1

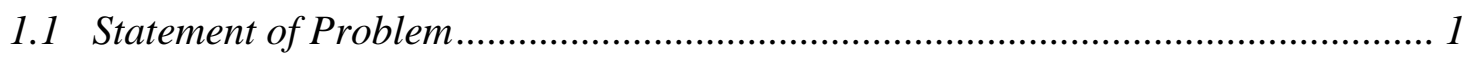

1.2 Theoretical Framework …………………………................................... 3

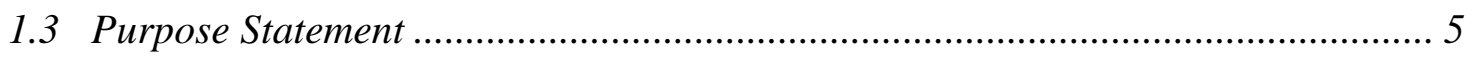

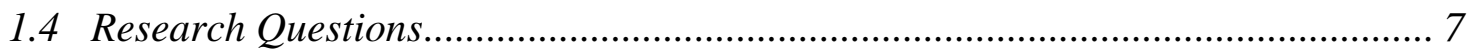

1.5 Significance of the Study to Health Promotion ....................................................... 8

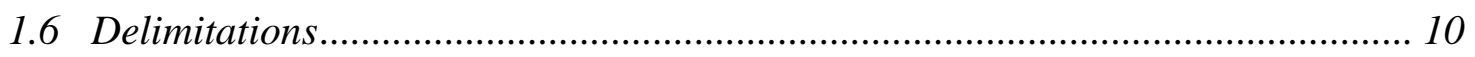

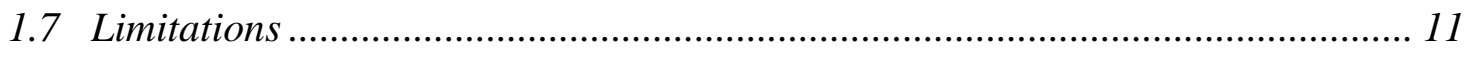

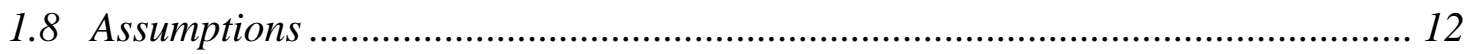

1.9 Operational Definitions .............................................................................. 12

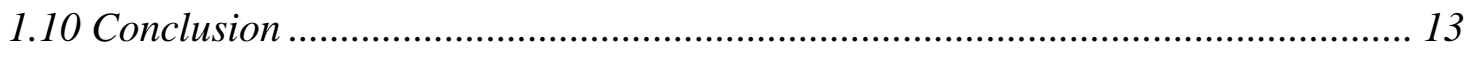

CHAPTER 2. REVIEW OF THE LITERATURE ………….................................... 15

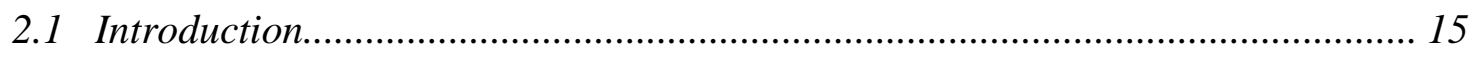

2.2 Purpose of Current Review ........................................................................ 17

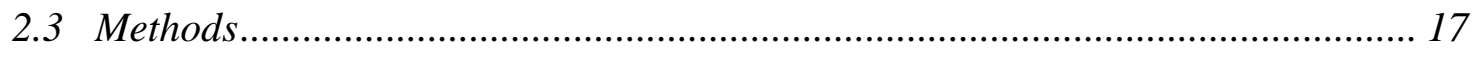

2.4 Current Toddler Nutrition Guidelines ............................................................. 18

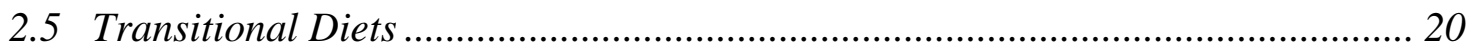

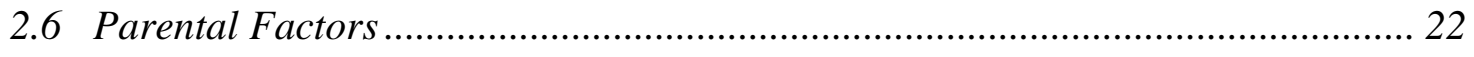

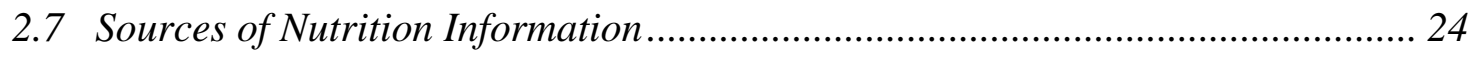

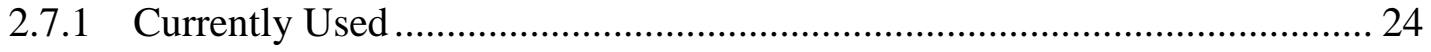

2.7.2 Preferred Methods............................................................................. 26

2.8 Current Concerns with Sources of Nutrition Information ……………………....... 27

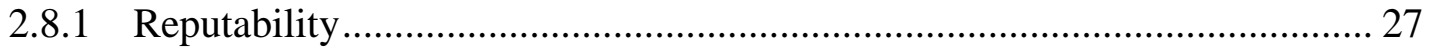

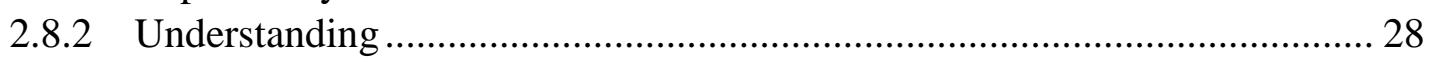

2.8.3 Trust and Reliability .......................................................................... 30

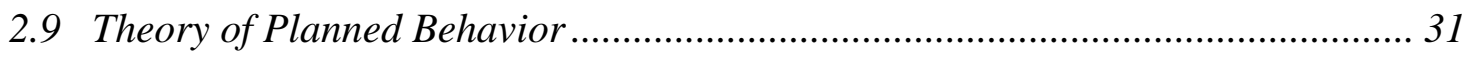




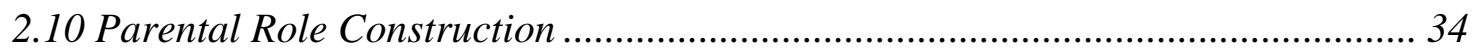

2.11 Applying the Theoretical Basis to the Current Study......................................... 35

2.12 Need for Additional Research ............................................................................. 37

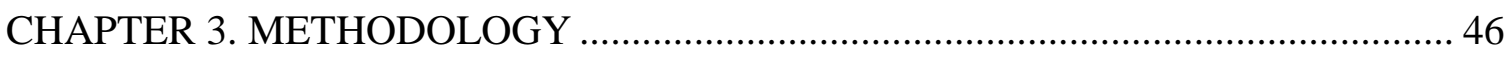

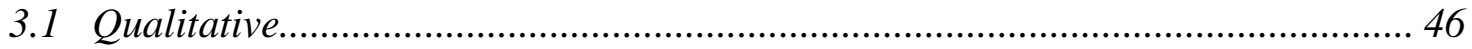

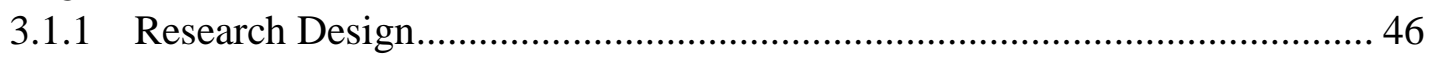

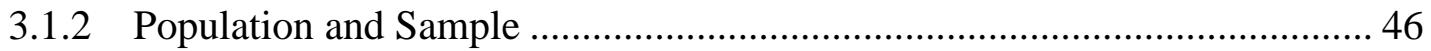

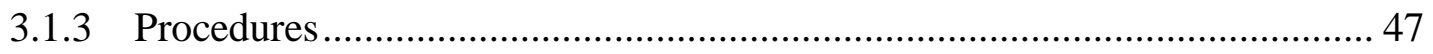

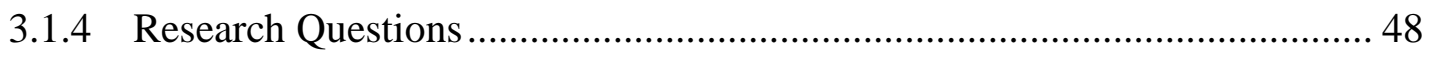

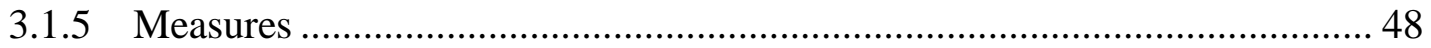

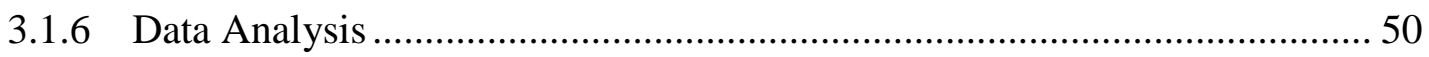

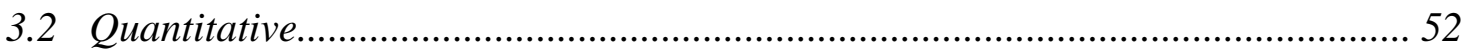

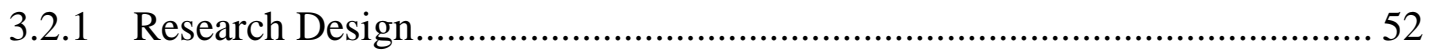

3.2.2 Population and Sample ………………………....................................... 53

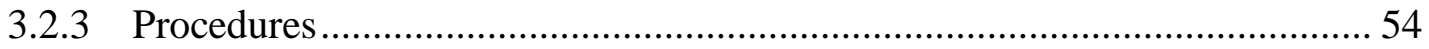

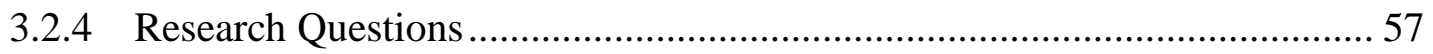

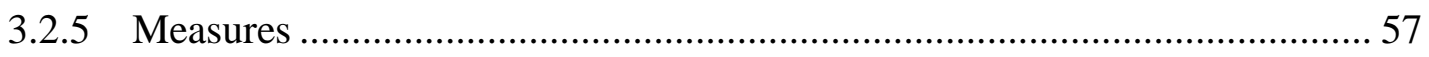

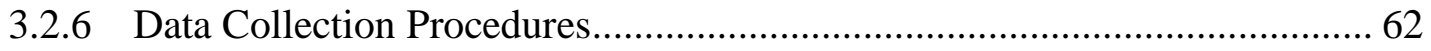

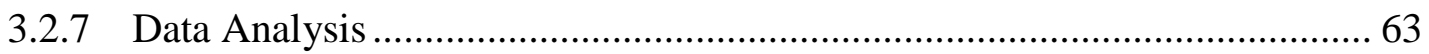

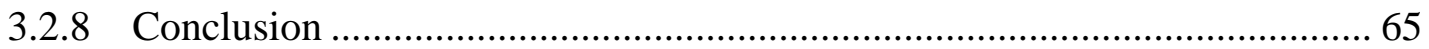

CHAPTER 4. INFLUENCES ON MATERNAL FEEDING DECISIONS FOR TODDLERS: FOCUS GROUP FINDINGS BASED ON THE THEORY OF PLANNED

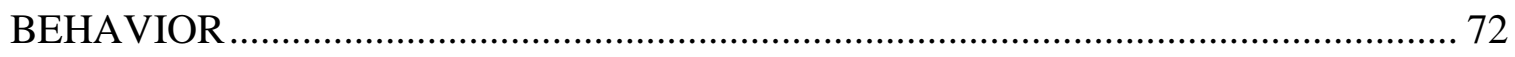

4.1 Introduction

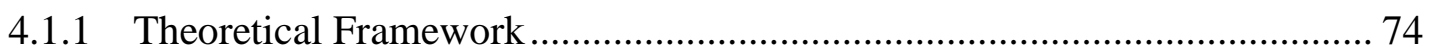

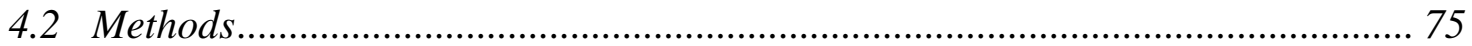

4.2.1 Study Design and Population.................................................................... 75

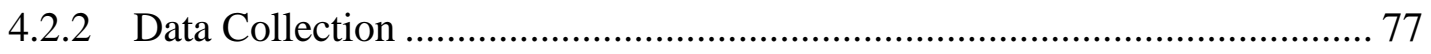

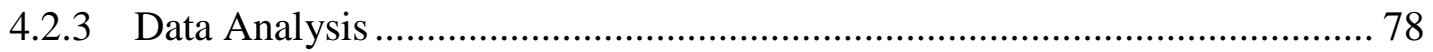

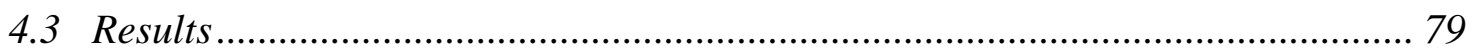

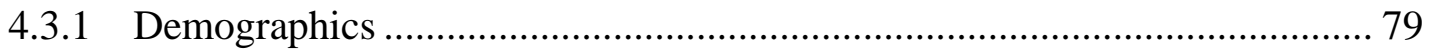

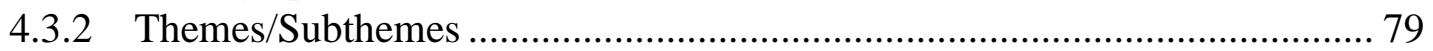

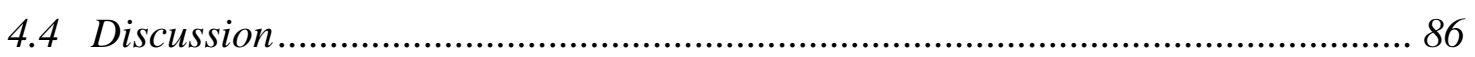

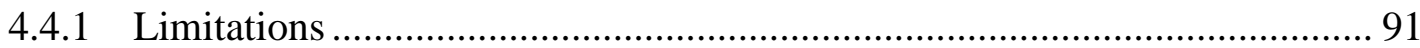

4.5 Implications for Research and Practice …………….................................... 91 
CHAPTER 5. FACTORS THAT INFLUENCE MATERNAL FEEDING DECISIONS FOR TODDLERS: EXTENDING THE THEORY OF PLANNED BEHAVIOR ........ 100

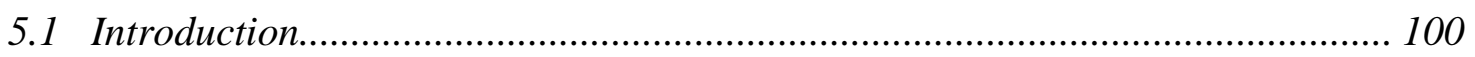

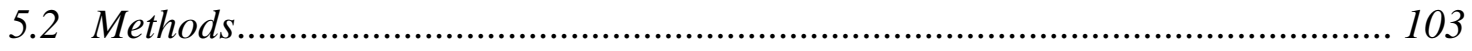

5.2.1 Research Design and Participants ............................................................ 103

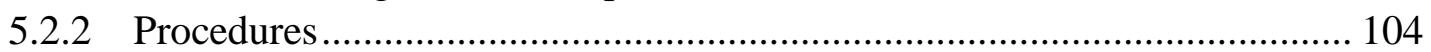

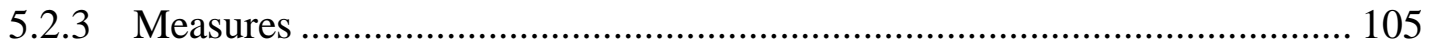

5.2.4 Statistical Analysis................................................................................. 108

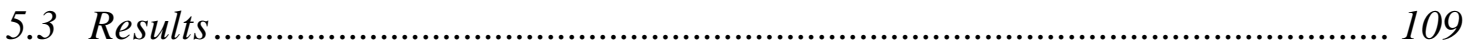

5.3.1 Participant Characteristics ...................................................................... 109

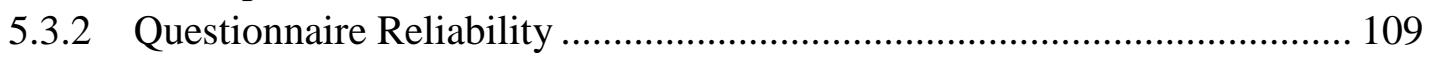

5.3.3 Theory of Planned Behavior Constructs ................................................. 110

5.3.4 Multivariate Linear Regression................................................................. 110

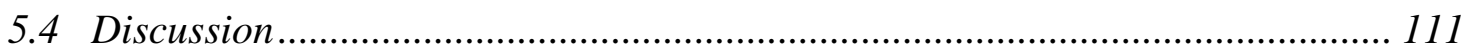

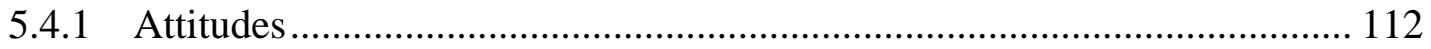

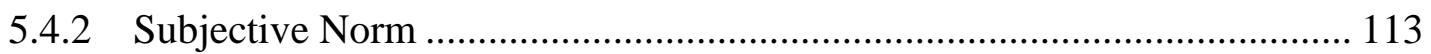

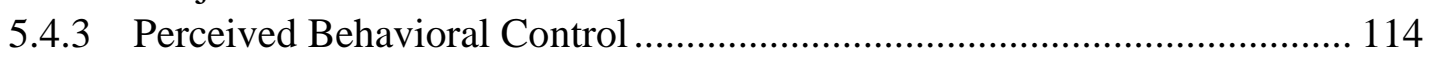

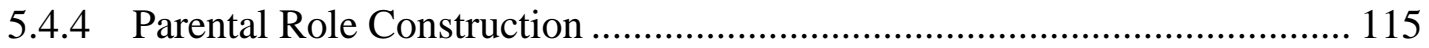

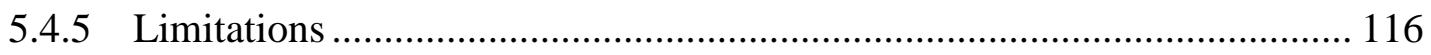

5.5 Implications for Research and Practice ………....................................... 116

CHAPTER 6. CONCLUSIONS AND RECOMMENDATIONS …………………...... 126

6.1 Summary of Results.................................................................................. 126

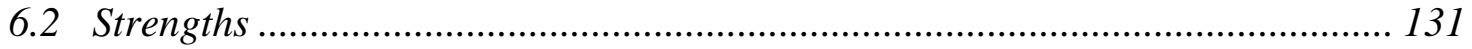

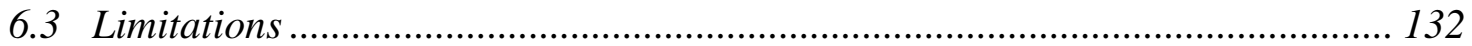

6.4 Implications for Researchers and Health Promotion Professionals .................. 134

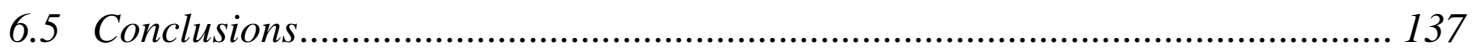

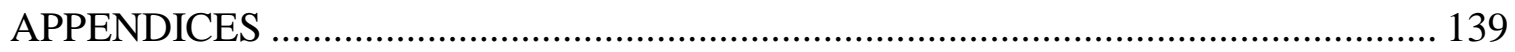

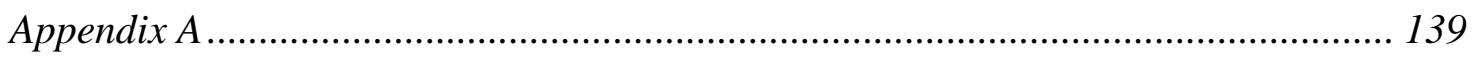

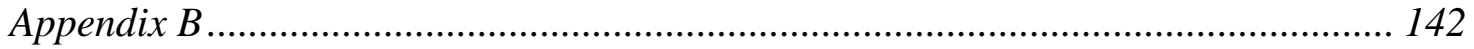

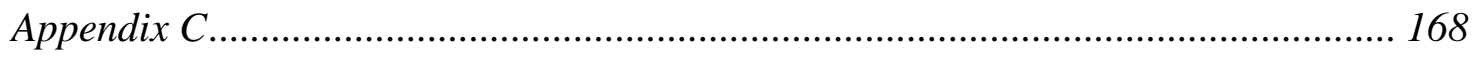

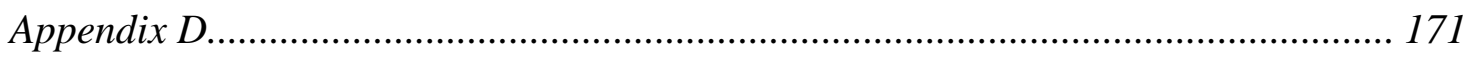

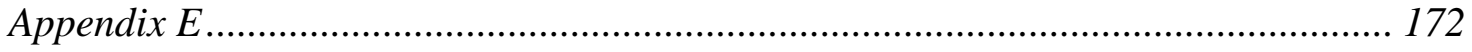

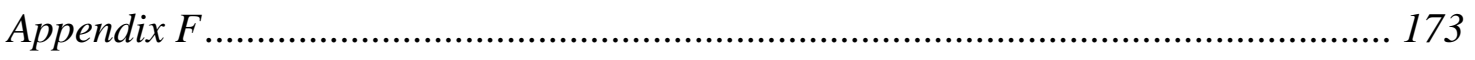

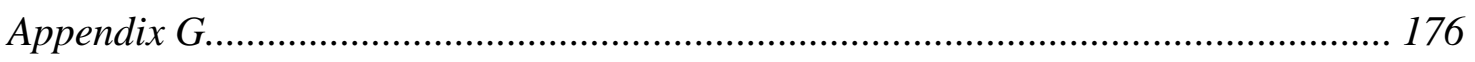




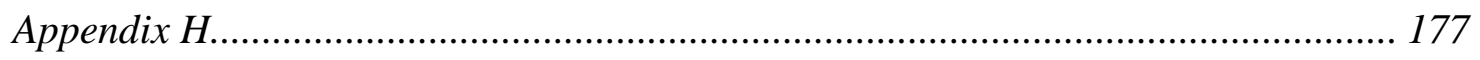

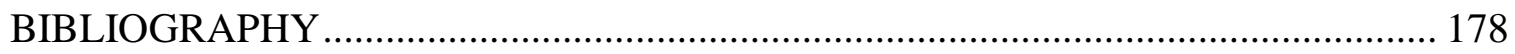

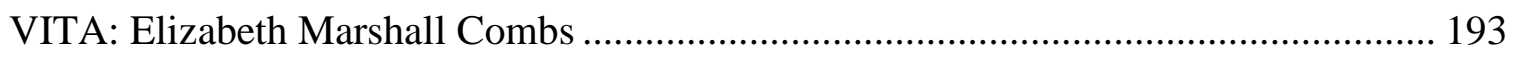




\section{LIST OF TABLES}

Table 2.1 Articles Specific to Sources of Nutrition Information Used by Parents 40 Table 3.1 Question Guide for Semistructure Focus Groups 66

Table 3.2 Sociodemographic Characteristics of Study Participants 68

Table 3.3 Constructs of the Theory of Planned Behavior 70

Table 4.1 Question Guide for Semistructured Focus Groups 94

Table 4.2 Sociodemographic Characteristics of Study Participants 96

Table 4.3 Quotes by Theme $\quad 97$

Table 5.1 Sociodemographic Characteristics of Study Participants 118

Table 5.2 Means and Standard Deviations of TPB Constructs 121

Table 5.3 Bivariate Correlations among Variables 124

Table 5.4 Summary of Regression Analysis for Variables Predicting Mothers' Intentions to Feed Their Toddler a Balanced Diet 125 


\section{LIST OF FIGURES}

Figure 1.1 Theory of Planned Behavior 


\section{CHAPTER 1. INTRODUCTION AND STATEMENT OF PROBLEM}

\subsection{Statement of Problem}

Many different factors are involved in the development of eating behaviors in infants and toddlers. Eating behaviors are shaped early in life and are one of the cornerstones in the developmental process. From one to two years of age toddlers transition from a primarily milk-based diet to an adult-modified diet. This may be a particularly important time in establishing eating behaviors as it represents the first experience children have in consuming foods that they may eat throughout their lifetime (Stang, 2006). It has been shown that foods offered during the first two years of life can predict what items are accepted later in childhood (Coulthard, Harris, \& Emmett, 2010; Skinner, Carruth, Bounds, Zeigler, \& Reidy, 2002).

Establishing healthy eating behaviors is vital in the early years to help combat the development of obesity and other chronic diseases (Birch \& Ventura, 2009). Unfortunately, the obesity epidemic has already impacted even the youngest Americans. National data show that $8.1 \%$ of children under age two years have high weight-forlength (at or above the 95th percentile) and $22.8 \%$ of children age two to five years are categorized as overweight or obese (Ogden, Carroll, Kit, \& Flegal, 2014). These numbers are of specific concern because it has been found that obesity during the early years increases the risk for obesity later in life (Freedman et al., 2005; Ong et al., 2009). From a different perspective, health officials have warned that today's children could be the first generation to have a predicted lower life expectancy than that of their parents due to the impact of obesity on longevity and quality of life (Olshanskey et al., 2005). 
The importance of parents establishing a healthy eating environment early on is reiterated in a Institute of Medicine (2011) Consensus Statement, which says, "Preventing obesity in infants and young children holds promise toward both reversing the epidemic of childhood obesity and reducing obesity in adulthood... [However] efforts must begin before children ever enter the school system" (p. 1). Therefore, parents serve as the first line of defense against the development of childhood obesity by establishing healthy eating habits early in their children's lives.

The importance of starting healthy eating habits during the transitional diet period needs to be shared with parents and well understood by them to make an impact on the health of their children. However, nutrition guidelines for the first few years of life can be difficult for parents to find since the Dietary Guidelines for Americans only provides advice for those ages two years and older (USDA, n.d.). In the past, these guidelines were limited to this age range because of the specific eating patterns, developmental milestones, and nutrient needs of toddlers. This can make finding reputable nutrition guidelines and advice for the 12-24 month period very difficult for parents to find. Because of this need, the United States Department of Agriculture has committed to expand the Dietary Guidelines for Americans to include infants and toddlers beginning in 2020 (USDA, n.d.). Until that time parents are left searching for reputable dietary guidance for their toddlers. Mothers especially carry the burden of trying to learn about healthy diet choices and how to establish such habits for their toddlers, as they are the dominant parent regarding food decisions and purchases in the home (Byrd-Bredbenner, Abbott, \& Cussler, 2008). 
Mothers have reported that they receive nutrition information from a variety of sources, including healthcare professionals, family members, friends, and the media (Carruth \& Skinner, 2001; Caton, Ahern, \& Hetherington, 2011; Gage et al., 2012; Gildea, Sloan, \& Stewart, 2009). However, research indicates that many describe nutrition guidance as too strict, confusing, or conflicting (Caton et al., 2011; Moore, Milligan, Rivas \& Goff, 2012; Swift 2009). In addition, mothers have shared that they do not traditionally trust most messages and sources of nutrition information (O'Key \& Hugh-Jones, 2010). By discovering which sources of toddler nutrition information mothers use and trust and attitudes and perceptions surrounding the toddler feeding experience, the dietary guidelines and other important feeding information can be prioritized and shared using the most effective avenue of communication. If trustworthy nutrition information was able to reach mothers via their preferred method and meet their needs then it could potentially increase maternal knowledge and self-efficacy regarding toddler feeding.

\subsection{Theoretical Framework}

The Theory of Planned Behavior (TPB) served as the theoretical basis for the study. The TPB is a modification of a previously established Theory of Reasoned Action (Ajzen, 2002). According to the theory, behavior is the direct result of intention. In turn, intention is impacted by attitude toward the behavior, subjective norms, and perceived behavioral control (Ajzen, 2002). It has also been defined as an "Expectancy Value Model.” This type of theory focuses on factors such as knowledge, attitudes, feelings, and beliefs of the individual (McKenzie, Neiger, \& Thackeray, 2013), which are very pertinent to the current study. More than likely, a mother intends to feed her child 
properly, but actually doing so depends greatly on ability and circumstances. This is reinforced by a study that reviewed parents' perceptions of child feeding, which found that parents believed that optimal nutrition is important but very difficult to achieve (Duncanson, Burrows, Holman, \& Collins, 2013).

The main constructs of this theory include: attitude toward the behavior, subjective norm, perceived behavioral control, intentions and behavior and are illustrated in Figure 1.1 (Ajzen, 2002). Intentions are influenced when there are strong attitudes toward a behavior, when subjective norms are favorable towards a behavior, and when individuals believe they are able to perform the behaviors correctly. These variables come together to impact whether or not an individual will change their behavior. For example, the TPB would predict that mothers of toddlers would provide a nutritious diet and healthy eating environment if they have a positive attitude towards healthy eating, think others whom they value believe it would be good to provide appropriate nutrition to their toddler, and perceive that they have control over providing a healthy diet to their toddler. Additionally, the mother would also need actual behavioral control, which is impacted by skills and resources needed to carry out the behavior.

The TPB has been applied to a range of health-related behaviors among parents of young children (Spinks \& Hamilton, 2016; Swanson et. al, 2011; Kahlor, Mackert, Junker, \& Tyler, 2011; Hamilton, Cleary, White, \& Hawkes, 2015); however, to date, no studies could be found that utilized this theory with the specified target population and topic. The constructs from the TPB were explored in both studies because the concepts that a mother sees, hears, and reads regarding nutrition messages could impact her attitude towards feeding behaviors. Attitude toward a behavior can be influenced by 
receiving accurate and through information. A mother could develop normative beliefs based on her family, friends, peers, and healthcare providers, especially if they serve as a main source of nutrition information. Her perceived behavioral control over feeding her toddler could be impacted by accessibility, outside influences, and situational factors. The source of information used and the resulting knowledge from the sources could greatly impact a mother's intention to change her actual behavior regarding appropriately feeding her toddler.

\subsection{Purpose Statement}

Mothers have access to information about toddler nutrition from many sources, including formal (healthcare providers), informal (family members and friends), through the internet and other written materials, and watching television. Even if not actively searching for nutrition information, they are regularly exposed to public health messages, advertisements from food companies, and the opinions of experts and peers. It is important to understand what sources of nutrition information mothers are most readily accessing and which forms they trust the most. These data could help shape future health promotion campaigns and the dissemination of sound nutrition information.

The overall purpose of the dissertation was to gain a better understanding of what factors impact maternal feeding decisions regarding toddler nutrition behaviors. This was a two-phased mixed methods study. The study assessed maternal sources of toddler nutrition information, influences on maternal feeding decisions, and the relationship of TPB constructs and the concept of parental role construction on mothers' intentions for feeding behaviors for their toddlers. 
Initially, qualitative methods were used for exploratory research to discover major themes and concepts surrounding where mothers of toddlers get their nutrition information and what influences their decisions surrounding feeding their children. Influences and perceptions can be hard to quantify, which is why it was important to complete this stage of research as a qualitative study. A TPB framework was used to create the discussion guide used for the focus groups. From qualitative findings, theories can be supported and hypotheses can be deduced and tested with subsequent quantitative research (Patten, 2009). Based on the emerging themes and concepts identified in the focus groups, questions were refined and a quantitative survey was distributed to a much larger sample size of mothers. This quantitative method was used so more direct associations could be drawn between variables in the study, such as demographics, constructs from the TPB, parental role construction, and mothers' intentions.

The purpose of the first manuscript was to explore, using a TPB framework, the influences on mothers' toddler feeding decisions. These influences included factors related to attitudes, subjective norms, and perceived behavioral control. These constructs were derived from discussions about what sources of nutrition information mothers use and what sources of nutrition information mothers trust. Additionally, the research aimed to use the TPB to learn more about mothers' perceptions and assessment of their behaviors and decisions about toddler feeding. Concepts from the TPB guided the focus group sessions and analysis.

The primary purpose of the second manuscript was to use the TPB to assess factors affecting mothers' behavioral intentions to provide their toddlers with a healthy diet. The secondary purpose of the study was to see if the addition of the parental role 
construction variable strengthened the TPB's ability to significantly predict the mother's behavioral intention to provide her toddler with a healthy diet. Using the TPB and past research, it was hypothesized that attitude, subjective norm, perceived behavioral control, and parental role construction would predict a mother's intention to provide a healthy diet for her toddler.

\subsection{Research Questions}

The two manuscripts are described in detail in Chapter IV and Chapter V. Research questions for each manuscript are listed below.

Research questions for the first manuscript (Chapter IV) include:

RQ1: What attitudes do mothers associate with the act of toddler feeding?

RQ2: What are the primary subjective norms that influence mothers' toddler feeding decisions?

RQ3: How much control do mothers of toddlers perceive they have over the act of toddler feeding?

RQ4: What sources of information do mothers use regarding toddler nutrition?

RQ5: What sources of information do mothers trust regarding toddler nutrition and why do they trust these sources?

Research questions for the second manuscript (Chapter V) include:

RQ1: Which constructs of the Theory of Planned Behavior (attitude toward the behavior, subjective norms, and perceived behavioral control) significantly predict the mother's behavioral intention surrounding the toddler feeding behavior of providing meals that include a wide variety of the five food groups in appropriate amounts? Which is the most salient predictor of this behavioral intention? 
RQ2: Does the addition of the parental role construction construct strengthen the Theory of Planned Behavior's ability to significantly predict the mother's behavioral intention surrounding the toddler feeding behavior of providing meals that include a wide variety of the five food groups in appropriate amounts?

\subsection{Significance of the Study to Health Promotion}

Researching the sources of nutrition information mothers use, maternal attitudes about toddler feeding behaviors, subjective norms surrounding toddler feeding, and maternal perceived behavioral control about their ability to provide a healthy diet to their toddlers may help provide a more complete picture of the decisions surrounding toddler feeding practices. This information can help fill a gap in the literature about this very important timeframe of the transitional diet for toddlers as they move from a milk-based diet to a typical food-based diet.

Even though several studies regarding sources of nutrition information for parents have been completed (Carruth \& Skinner, 2001; Chezem, Friesen, \& Clark, 2001; Gildea et al., 2009; O'Key \& Hugh-Jones, 2010), research is greatly lacking in the area of what sources of nutrition information mothers of toddlers use to guide their feeding decisions during the specific transitional diet period of toddlerhood. The majority of the studies conducted explored either the first year of life or the school years and beyond. Additionally, the majority of the studies have been completed in Australia or Europe rather than in the United States. The only study that purposefully reviewed the entire first few years of life (Carruth \& Skinner, 2001) was completed 16 years ago and did not include the internet as an option for participants to select as a source. The internet is reported as being used by $84.7 \%$ to search for medical conditions for themselves or 
family members (Bianco, Zucco, Nobile, Pileggi, \& Pavia, 2013), which demonstrates the clear need to take another look at this topic since the internet is so pervasive in today's society.

Additionally, the current study makes a unique contribution to the health promotion literature by assessing not only which sources of nutrition information mothers of toddlers use, but also which sources of information mothers trust. Only one study was found that reviewed which sources of dietary information mothers trusted, and it was a qualitative study that reviewed only 12 mothers' accounts (O'Key \& Hugh-Jones, 2010). By including trust as a variable in the study, more information was able to be discovered about mothers' attitudes toward certain sources.

Furthermore, by using a theoretical framework and measuring constructs from the TPB, potential relationships were able to be examined between mothers' attitudes, subjective norms, and perceived behavioral control surrounding their behavioral intention for toddler feeding. These results could be used to highlight potential barriers to proper nutrition, and health educators could highlight areas of importance to mothers on how to overcome such barriers. Information gathered through this research could provide future interventions with data on what behaviors, attitudes, and perceptions to target to be the most impactful. By using multiple regression analysis, it was possible to know which constructs had the greatest impact on behavioral intentions, which would allow future health educators to focus interventions on certain areas that would have the strongest influence on the target behavior. Additionally, the research provides support for additional health education and services for mothers since it was found that there were many negative attitudes associated with the act of feeding. At a broader health promotion 
level, these data could help shape the direction of future health campaigns and the dissemination of sound nutrition information for mothers of toddlers.

The current study is unique in the fact that it appears to be the first of its kind in two ways. First, it examined the main sources of information used and trusted by mothers for toddler nutrition information. This information can provide nutrition and health promotion professionals with relevant data on which avenues of information dissemination seem to be the most effective and valuable. Second, the study used the TPB to guide the research. To date, no studies could be found that utilized this theory with the specified target population and topic. By using the TPB, these results can be used to develop theoretically driven and evidence-based health messages that are relevant to mothers of toddlers.

\subsection{Delimitations}

Delimitations are conscious choices that a researcher makes in regards to boundaries that they set for the study. These types of restrictions can include choices and justifications about the literature, methods, population, and other aspects. There are several delimitations for the study, which include:

- The research included only mothers of young children (ages 12-48 months of age). Mothers were selected because they have been found to be the main decision makers surrounding a child's diet in the home. The age range of the child was limited to $12-48$ months because this is the timeframe where children advance from a milk-based diet to an adult-modified diet and parents have greater control of their child's diet during this period. 
- The sampling frame for this research is not a traditional sampling frame because snowball sampling was used. The entry points for sampling were LexingtonFayette County Health Department, Community Action Council, a Northern KY Mothers' Group, and ResearchMate. One reason for this type of sampling is because if random sampling was used, then the researcher would have to first identify if participants were mothers of toddlers. By using snowball sampling, it helped identify the exact type of respondent that was to be studied. It also builds credibility since the person contacting new participants would be a friend, family member, or acquaintance.

\subsection{Limitations}

Limitations are circumstances that impact the methods and analysis of research that are out of the researcher's control. These restrictions can be placed on methodology and conclusions of the findings. Limitations for the current study include:

- Because the sampling was not randomized, the findings cannot be generalized to the larger population.

- Mothers that are interested in health and nutrition might have been more likely to participate in the research since sampling was not randomized. This interest could influence the knowledge and resources the mother uses in regards to nutrition information, which could impact the results.

- Because the survey was distributed via the internet, respondents could have been more likely to be comfortable using the internet and might have used it more often as their main source of information. 
- Limited funding existed, which allowed for few incentives for participation. This could have impacted the number of participants that took part in the focus groups and that completed the survey.

\subsection{Assumptions}

Assumptions in research are concepts that are out of the researcher's control, yet the research is dependent upon the concepts occurring. For example, in the current study it was assumed that the participants answered the survey truthfully. This assumption is supported by the ideas that confidentiality was preserved at all times and that the participants were volunteering to take the survey and could withdraw from the study at any time. Additionally, any incentives were distributed in a timely manner.

\subsection{Operational Definitions}

1. Actual behavioral control: Extent to which a person has the skills, resources, and other prerequisites necessary to perform a given behavior (Ajzen, 2007).

2. Attitude toward behavior: Positive or negative feelings or expectations towards a certain behavior or the outcomes from that behavior (Ajzen, 2007).

3. Parental role construction: Parents' beliefs about their role in relation to their children's development (Hoover-Dempsey \& Sandler, 1995).

4. Perceived behavioral control: People's perceptions of their ability to perform a certain behavior (Ajzen, 2007).

5. Subjective norms: What someone perceives others are doing in regards to a health behavior (Simmons-Morton, McLeroy, \& Wendel, 2012). The traditional definition of the source of the subjective norm component is someone who is seen 
as trustworthy or experienced regarding the behavior of interest (Hamel \& Smith, 2013).

6. Transitional feeding: the time period between 4 and 24 months as a child transitions from a milk-based diet to an adult-modified diet (Abbott Nutrition, n.d.).

\subsection{Conclusion}

There are a variety of factors that impact a toddler's diet during the transitional feeding time period. Mothers have a pivotal role in establishing dietary patterns and the feeding environment during this timeframe. The current study examined influences on mothers' decisions surrounding toddler feeding using a TPB framework. This information can provide nutrition and health promotion professionals with sound data on what strongly impacts mothers' behavioral intentions and which ways of information dissemination seem to be the most effective and valuable. Additionally, the information can help focus the areas that nutrition interventions should address to be the most impactful. Professionals could then invest more resources in certain methods of communication and in the development of messages on specific topics, which could in turn improve nutrition behaviors of toddlers and their long-term health outcomes. 


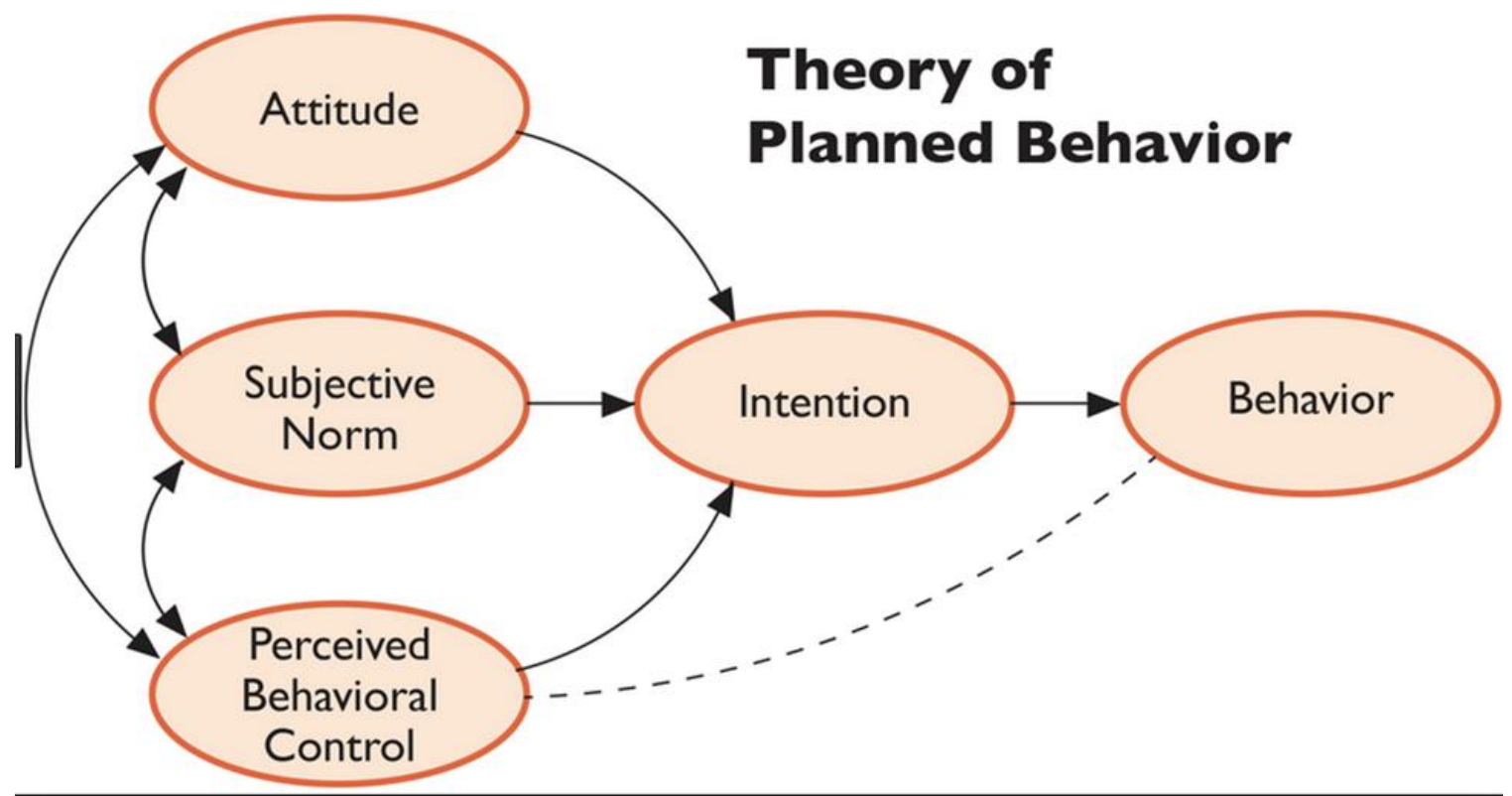

Figure 1.1 Theory of Planned Behavior 


\section{CHAPTER 2. REVIEW OF THE LITERATURE}

\subsection{Introduction}

Establishing healthy eating behaviors is vital in the early years to help combat the development of obesity and other chronic diseases (Birch \& Ventura, 2009).

Unfortunately, the obesity epidemic has already impacted even the youngest Americans. National data show that $8.1 \% \%$ of children under age 2 years have high weight-for-length (at or above the 95th percentile) and $22.8 \%$ of children aged 2-5 are categorized as overweight or obese (Ogden, Carroll, Kit, \& Flegal, 2014). These numbers are of specific concern because it has been found that obesity during the early years increases the risk for obesity later in life (Freedman et al., 2005; Ong et al., 2009). From a different perspective, health officials have warned that today's children could be the first generation to have a predicted lower life expectancy than that of their parents due to the impact of obesity on longevity and quality of life (Olshanskey et al., 2005).

Preventing excessive weight gain in the early years is important because the psychological, physiological, and social consequences of childhood obesity have been well documented. Many diseases used to be considered adult-specific, however recently the following prevalence rates of specific diseases were found children and adolescents: hypertension (2-4\%); atherosclerosis (50\%); dyslipidemia (5-10\%); metabolic syndrome (4\% overall, $30 \%$ among obese); obstructive sleep apnea (1-5\%, 25\% in obese); nonalcoholic fatty liver disease (3-8\%, 50\% in obese); and depression (3-5\%) (Daniels, 2006). It appears that chronic disease are developing in the young as a result of excess weight. 
Characteristics that have been shown to be related to excess weight in early childhood include coming from a low income family (Wang \& Zhang, 2006), having a sedentary lifestyle, watching television (Christakis \& Garrison, 2009), and not getting adequate sleep (Iglowstein, Jenni, Molinari, \& Largo, 2003). Parents are key players in the fight against childhood obesity because they have the ability to impact the environment in which the child lives. Parents have some control over the majority of the variables that impact childhood obesity, including diet, activity level, screen time, and amount of sleep.

Eating and activity patterns established early in life also persist into adulthood supporting the importance of early intervention to develop and maintain healthy behaviors and normal weight throughout life. Additionally, the medical costs of an obese child are substantial compared to that of a normal weight child. Recently it was estimated that childhood obesity comes with an approximate cost increase of $\$ 19,000$ per obese child when comparing lifetime medical costs to those of a normal weight child (Finkelstein, Graham, \& Malhotra, 2014). For this, and many other reasons, the Institute of Medicine (IOM) strongly recommends that obesity prevention intervention begins in early childhood and focuses on prevention efforts among children from birth to five years (IOM, 2011).

The importance of parents establishing a healthy eating environment early on is reiterated in a recent Institute of Medicine (2011) Consensus Statement, which says, "Preventing obesity in infants and young children holds promise toward both reversing the epidemic of childhood obesity and reducing obesity in adulthood... [However] efforts must begin before children ever enter the school system" (p. 1). Therefore, 
parents serve as the first line of defense against the development of childhood obesity by establishing healthy eating habits from early in their children's lives.

\subsection{Purpose of Current Review}

The transitional diet period for infants and toddlers has undergone a great deal of study; however, where caregivers find nutrition information during this time is not as well researched. This review will explore the current guidelines for optimal toddler nutrition, current sources of health information used by parents, and current toddler feeding behaviors used by parents. It will also examine which sources of health information individuals tend to trust in comparison to the ones they use the most. Using current, available information, this review will synthesize what is presently known about sources of toddler nutrition information used by parents and how this information impacts current feeding behaviors. This review will also summarize current research on toddler feeding decisions based on the constructs from the TPB. Finally, the review will describe possible areas for future research based on the research that has currently been completed to date.

\subsection{Methods}

A variety of methods were utilized to locate the literature on this topic. The database PubMed was predominantly used to find and access peer-reviewed journal articles. The terms "nutrition information," "sources of nutrition information," "toddler," "transitional diet," and "maternal nutrition knowledge" were used to locate relevant sources. Google Scholar was also used to locate peer-reviewed journal articles that were not accessible by the PubMed database. National health organizations' websites were 
frequented to locate general nutrition information and statistics. Examples of these websites include the United States Department of Agriculture, the Academy of Nutrition and Dietetics, and the American Academy of Pediatrics. The dates included in the search were broad because of the small number of research articles available about this specific topic. The date range used for the search included the years $2000-2018$. Limited research was found on the topic at hand because not many research studies have focused on this particular age range.

\subsection{Current Toddler Nutrition Guidelines}

Information about establishing healthy eating habits during the transitional diet period needs to be shared with parents and well understood to make an impact on the health of a child. However, nutrition guidelines for the first few years of life can be difficult for parents to find since the Dietary Guidelines for Americans only provides advice for those ages 2 years and older (USDA, n.d.). In the past, these guidelines were limited to this age range because of the specific eating patterns, developmental milestones, and nutrient needs of toddlers. This can make finding reputable nutrition guidelines and advice for the 12-24 month period very difficult for parents to find. Because of this need, the United States Department of Agriculture has committed to expand the Dietary Guidelines for Americans to include infants and toddlers beginning in 2020 (USDA, n.d.). Until that time parents are left searching for reputable dietary guidance for their toddlers.

A recent systematic review of the current feeding guidelines for young children (one to three years) was conducted to compare the broad recommendations to long-term 
health risks. This review found support for limiting sodium and rapidly absorbed (simple) carbohydrates, using a meal pattern, and reducing saturated fat and trans fatty acids. However, the authors also concluded that there were many inconsistencies in current recommendations, which caused challenges in analysis (Zalewski et al., 2015). This article supports the need for more specific nutrition guidelines for young children.

Even without set feeding guidelines, many researchers have tried to identify positive and negative aspects of toddlers' diets. The Feeding Infants and Toddlers Study 2008 was a cross-sectional study that looked at the diets and feeding patterns of children ages birth through the third year of life. A random sample was compiled of 3,273 children, however only 701 cases had completed food records. The major findings included the fact that although most diets in the sample were adequate, unhealthy patterns started to emerge in infants as young as 9 to 11 months. These unwanted behaviors included occasional fruit and vegetable consumption, increased consumption of calorically-dense foods, and increase in sugary beverages. It was also found that most of the subjects' diets met or exceeded energy and protein requirements from the 24-hour recall data. Typical intakes of most vitamins and minerals were also adequate, however iron, zinc, vitamin E, and potassium were all lacking in a small subset of children (Briefel et al., 2010; Butte et al., 2010).

Without guidelines it can be challenging for parents to gauge the quality of their child's diet. It's important that parents have a realistic perception of the quality of their child's diet so they can make appropriate diet-related decisions. In a study completed by Kourlaba and colleagues in 2009 , only $0.2 \%$ of preschoolers in the study were deemed to have a "good" diet. More surprisingly is the fact that $83 \%$ of mothers overestimated the 
quality of their child's diet. Clearly there is a need for parents to better understand what a nutritious diet is for children as well as to have a realistic way to gauge if their child's diet is optimal for growth and wellbeing.

\subsection{Transitional Diets}

Parental knowledge and feeding behaviors surrounding infant and toddler nutrition can impact a child from the beginning of the transitional diet phase. An optimal transition to food at the time of weaning for an infant can have an impact on the development of healthy eating habits, both in the short and long term. The timing of the introduction of a variety of foods could be important. Various studies show that the ease of accepting new foods changes with age (Beauchamp \& Mennella, 2009; Maier, Chabanet, Schaal, Leathwood, \& Issanchou, 2008) and the first two years of life are reported to be essential in the development of healthy eating habits later in life (Coulthard, Harris, \& Emmett, 2010; Skinner, Carruth, Bounds, Zeigler, \& Reidy, 2002).

Many different factors are involved in the development of eating behaviors in infants and toddlers. Eating behaviors are shaped very early on in an infant's life and are one of the cornerstones in the developmental process. The time of 1 to 2 years of age, during which toddlers transition from a primarily milk-based diet to an adult-modified diet, may be a particularly important period in influencing eating behaviors as it represents the first experience children have in consuming foods that they may eat lifelong (Stang, 2006). It has been shown that foods offered during the first two years of life can predict what foods are accepted later in childhood (Coulthard, Harris, \& Emmett, 2010; Skinner, Carruth, Bounds, Zeigler, \& Reidy, 2002). 
In addition to the timing of food exposure, the nutrient content of the food is also important. Infants that were routinely fed diets high in sugar and salt were found to have a greater risk of developing nutrient deficiencies, dental carriers, and hypertension (Ruottinen et al., 2004; Ruottinen et al., 2009). Overall, early exposure to salty and sugary foods may lead to long-term health consequences.

These health consequences are important to note because the choice to feed sugary and salty foods could be directly tied to parents' nutrition knowledge. It has been shown that young children prefer sweet and salty foods to sour and bitter foods (Birch, 1999; Schwartz, Issanchou, \& Nicklaus, 2009). This detail could affect what foods parents routinely offer because the infants and toddlers more readily accept sweet and salty foods compared to other flavors. If a parent was aware of this fact then they might be more likely to offer a variety of flavor profiles.

It can also be said that there are critical periods for the introduction of texture during the weaning process. It has been found that the most drastic change in oral skill development occurs between 6 and 10 months (Gisel, 1991). Children who were introduced to lumpy textures after 10 months of age had more feeding problems at 15 months and 7 years of age (Coulthard et al., 2009). If a parent is not familiar with the suggested food introductory guidelines, it could impact a child's acceptance of food textures well into their adolescence.

In addition to the introduction of taste and texture, the mere exposure to a new food can increase an infant's or toddler's acceptance of that food. Sullivan \& Burch (1994) concluded that a new foods need to be served several times before they might be fully accepted. This concept was demonstrated by the fact that in one study young 
children consumed produce more often when those foods were introduced early in life (Cooke et al., 2004).

Maier and colleagues (2007) found that it took at least 8 attempts before a toddler would accept a previously rejected vegetable. This concept is not usually practiced by parents, since, according to the same study, mothers gave up feeding a refused food after 1-5 meals. If a parent had a good understanding of the necessity of repeated exposure in some children, they might be more successful when introducing new foods and increasing the variety in their child's diet.

\subsection{Parental Factors}

Cluss and colleagues (2013) examined the idea that parents' lack of nutrition knowledge may negatively impact children's health outcomes, most specifically weight status. They concluded that black race, lower education level, and very low income are associated with poorer nutrition knowledge and increased weight status in children. Some variables that have been associated with a higher number of positive feeding behaviors for infants and toddlers include higher maternal education level, ever being breastfed, married parents, older parents, and living in the western part of the U.S. (Hendricks, Briefel, Novak, \& Ziegler, 2006; Vereecken \& Maes, 2010). Additionally, maternal nutrition knowledge and maternal nutrition attitudes have both been shown to be positively associated with improved diet quality in toddlers (Vereecken \& Maes, 2010)

Parents play an invaluable role in shaping their children's eating habits through controlling what and when children eat as well as the overall food environment (Mitchell, Farrow, Haycraft \& Myer, 2013). Children are more willing accept a healthy diet if that 
type of eating is modeled by their parents, if healthy foods are readily available at home, and if parents use encouraging behavior at meal times (Schwartz, Scholtens, Lalanne, Weenen, \& Nicklaus, 2011; Horodynski, Strommel, Brophy-Herb, Xie, \& Weatherspoon, 2010). However, parents need to be provided with the appropriate skills to actually create such an environment. It has been found that even though parents believe that optimal nutrition is important for their family, it is difficult to achieve because of a lack of perceived control over child feeding (Duncanson, Burrows, Holman, \& Collins, 2013).

In addition to the timing and type of foods provided, many other factors impact the quality of a toddler's diet, which could impact their weight status. Currently in the United States, toddler's diets are not well balanced and may contribute to excessive weight gain in the first few years of life (Briefel et al., 2010; Butte et al., 2010; Siega-Riz et al., 2010). It appears that toddlers are establishing unhealthy eating behaviors that could potentially last a lifetime.

In order to combat excess weight gain in the toddler years, parents need a strong understanding of the factors that contribute to obesity in the childhood population. One study looked at how parents of 2- to 5-year old children ranked factors associated with obesity. It was found that many parents felt like the largest perceived barrier towards healthy weight included outside caregivers offering unhealthy food options (Hernandez, Thompson, Cheng, \& Serwint, 2012). Another study found that parents' perceived behavioral control was most strongly impacted by food advertising, extended family, and negative peer influences (Duncanson et al., 2013). These findings suggest the need to provide parents with accurate information regarding obesity prevention and ways to establish an overall healthy environment. 


\subsection{Sources of Nutrition Information}

\subsubsection{Currently Used}

In addition to the factors listed above, several other barriers to providing a healthful diet are perceived by parents. One being that the majority of healthcare professionals do not discuss nutrition guidance with their patients. Even though the family physician represents the main source of health-related nutrition information for parents (Chezem, Friesen, \& Clark, 2001; Bianco, Zucco, Nobile, Pileggi, \& Pavia, 2013) it was found that most healthcare professionals do not discuss nutrition and feeding with parents unless they assess that there is a problem with growth (Paul et al., 2009). This is especially true in children younger than 3 years of age, even if there is a weight problem (Hernandez, Cheng, \& Serwint, 2010). If a parent feels that a physician does not value nutrition, then they might perceive that diet is not an important factor in contributing to their child's overall health. If healthcare professionals are not readily discussing nutrition with parents, then it is important to understand other sources that parents are using when seeking out nutritional guidance for their toddlers.

In a survey completed by the Academy of Nutrition and Dietetics (2011) top sources of nutrition information for American adults were TV (67\%), magazines (41\%), internet (40\%), newspapers (20\%), doctors (16\%), family and friends (16\%). One fact to note is that $40 \%$ of people got their information from the internet in 2011 , which had increased $16 \%$ since only 2008 (AND, 2011). This number was even higher in a survey completed in 2014 where $63 \%$ of respondents stated that they had previously used the internet to find nutrition information (Cash, Desbrow, Leveritt, \& Ball, 2014). This number has continued to grow as reliable internet and access to computers and 
smartphones has increased. According to the Pew Research Center (2017), in 2016, 96$99 \%$ of women between the ages of 18-49 use the Internet regularly.

Even though the internet was cited as being used by most adults, it was found that the family physician still represented the main source of health-related nutrition information for parents (Chezem et al., 2001; Bianco et al., 2013). Considering other health professionals, it was found that $2 \%$ of adults get information from nutritionists, $1 \%$ from nurses, and $1 \%$ from registered dietitians (AND, 2011). It is interesting that parents cite physicians as being the main source of nutrition information since Paul and colleagues (2009) found that most healthcare professionals do not discuss nutrition and feeding with parents unless they assess that there is a problem with growth.

One study found that $65 \%$ of parents (Bianco et al., 2013) stated that the pediatrician (or doctor) was the most used source of nutrition information, which is much higher than the previously noted $16 \%$ in the general population (AND, 2011). This difference could be because parents visit their child's pediatrician often throughout the first years of life. However, as children grow, parents report that they rely less on information from health professionals regarding nutrition. After 24 months of age, newspapers, television, and friends were reported to be used more frequently by mothers and the use of healthcare professionals as a nutrition resource steadily decreased from 2 to 54 months. It was found that the use of advice by family as a nutrition resource stayed consistent throughout the first few years of life (Carruth \& Skinner, 2001).

One source of child nutrition information that is consistently named as being valuable by parents in a variety of studies is family. Family is a commonly used resource for nutrition information regarding breastfeeding, weaning, and other feeding skills 
(Carruth \& Skinner, 2001; Caton, Ahern, \& Hetherington, 2011; Gage et al., 2012;

Gibbons, Graham, Marraffa \& Henry, 2000). In one study, it was found that younger mothers and those with lower educational status were more likely to be influenced by advice from family (Moore, Milligan, Rivas \& Goff, 2012). Advice from family and friends has been shown to be more important than official government guidelines when it comes to feeding decisions (Caton et al., 2011; O'Key \& Hugh-Jones, 2010). Also, mothers are more likely to initiate a conversation about feeding their child with family and friends than with a healthcare professional (Chezem et al., 2001).

These findings are consistent from a study completed in Australia in 2000. Gibbons and colleagues (2000) found that parents of young children utilize family, friends, nurses, and books the most as sources of nutrition information. Additionally, the majority of parents in this study replied that current nutrition information was not adequate for this age group. They requested additional information regarding amounts and types of foods required at varying stages of child development along with practical advice on cooking for young children (Gibbons et al., 2000).

\subsubsection{Preferred Methods}

Over $40 \%$ of adults in the U.S. surveyed stated that they actively seek out nutrition related information (AND, 2011). While it has also been found that the majority of individuals' health information seeking behavior is often accidental and informal in nature (Marquis, Dubeau, \&Thibault, 2005), several preferred methods of information dissemination have been identified. Parents have shared that they are interested in receiving this type of information from a wide variety of locations, including in-person venues like doctors' offices and shopping centers (Gibbons et al., 2000). However, since 
the internet has become more prevalent over $80 \%$ of parents in a 2016 study reported that online reading in their home was there preferred manner and setting to receive nutrition information This study also found that handouts were the second most popular method of preferred information (Dexter, Frank, \& Seguin, 2016).

A study from Australia in 2014 found that individuals preferred and trusted information provided by dietitians, nutritionists, and doctors the most compared to other sources (Cash et al., 2014). However, even though healthcare professionals might be preferred and trusted, it is important to note that parents prefer to receive nutrition information from home (86\%) compared to healthcare offices (34\%) (Dexter et al., 2016). Therefore, healthcare professionals need to provide evidence-based nutrition websites to parents so credible information can be shared at parents' preferred location where they might be more receptive to receiving it.

\subsection{Current Concerns with Sources of Nutrition Information}

\subsubsection{Reputability}

Although the pervasiveness of the internet as a source of health-related information continues to increase, it is important to examine which online resources parents are accessing. Sebelefsky and colleagues (2015) found that while $94.4 \%$ of parents used the internet to obtain childhood health information, the two of the most common resources used were Google $(91.4 \%)$ and Wikipedia $(84.7 \%)$. The trustworthiness and reputability of such sources are important considerations for parents when deciding whether or not to act on such information. The results from the 
Sebelefsky study (2015) did contrast former findings specific to the internet usage of parents in their study was independent of parental education level.

\subsubsection{Understanding}

The Academy of Nutrition and Dietetics (2011) reviewed where adults obtained their information and their level of understanding of the information itself. It was found that $49 \%$ of all adults said they were "doing all they can" to achieve a healthy diet and overall lifestyle. This is in comparison to only $42 \%$ of adults with children that say they are "doing all they can," which could point to the fact that the responsibilities of childrearing could make healthy lifestyles more difficult to achieve. From the same study, $46 \%$ of all adults were actively seeking information about nutrition and diet. However, $40 \%$ of those surveyed responded that one reason why they did not make healthy changes was because they did not understand the guidelines for food and nutrition (AND, 2011).

In order to establish healthy dietary habits, the expert guidelines on a wellbalanced diet need to be shared and well understood by parents. Mothers have reported that they receive nutrition information from a variety of sources, including healthcare professionals, family members, friends, and the media (Carruth \& Skinner, 2001; Caton, Ahern, \& Hetherington, 2011; Gage et al., 2012; Gildea, Sloan, \& Stewart, 2009). However, research indicates that many describe nutrition guidance as too strict, confusing, or conflicting (Caton et al., 2011; Moore et al., 2012; Swift, 2009). In addition, mothers have shared that they do not traditionally trust most messages and other sources of nutrition information (O'Key \& Hugh-Jones, 2010). 
In comparison, one study completed specifically with parents in 2013 , found that $84.7 \%$ of parents reported using the internet to search for medical conditions for themselves or family members and $40.7 \%$ of parents reported looking for diet, weight, or physical activity information. The overwhelming majority of parents (81.2\%) said that the use of the internet improved their understanding of health care issues. Parents who looked for health-related information online were more likely to be female, educated, younger, with chronic conditions, and not satisfied with information provided by the doctor (Bianco et al., 2013). However, one study found that the internet was cited as being less influential on dietary choices in those mothers that had higher education levels (Moore et al., 2012).

In a recent study completed in Australia, parents from economically disadvantaged families utilized the internet and families less often than their wealthier counterparts. This same group of individuals also cited more difficulties in accessing, understanding, and applying the health information that they did receive. This can be seen as a large barrier to applying correct nutrition and health guidelines considering the fact that children from these families regularly consumed more sweetened drinks, packaged foods, and watched more than 4 hours of TV a day compared to children of wealthier families (Myers, Gibbons, Arnup, Volders, \& Naughton, 2015). Therefore, socially and economically disadvantaged families report greater difficulty understanding and applying health advice. 


\subsubsection{Trust and Reliability}

In addition to not understanding guidelines, the majority of consumers (78\%) said that they encounter conflicting information about what to eat or avoid. From those individuals, $56 \%$ said the conflicting information makes them question the food choices they make (International Food Information Council Foundation, 2017). This concept is congruent with other research that found that many describe nutrition guidance as too strict, confusing, or conflicting (Caton et al., 2011; Moore et al., 2012; Swift, 2009). Even if parents seek out child nutrition information, they have reported that they still have trouble accessing, understanding, and putting the information into practice (Myers et al., 2015).

Another aspect to consider when reviewing a source is if an individual trusts it. According to a survey completed in $2017,77 \%$ of adults surveyed indicated that they rely on family and friends for nutrition information, however only $29 \%$ of those have high trust in the information they receive from family and friends (International Food Information Council Foundation, 2017). It appears that the trust and credibility of a source could impact how it is received.

Just because the use of healthcare professionals as the source of nutrition advice appears to decrease by age, it does not necessarily mean that it is not wanted. As mentioned before, it has been found that individuals preferred and trusted information provided by dietitians, nutritionists, and doctors the most compared to other sources (Cash et al., 2014). However, even though the medical professionals were deemed to be the most trustworthy and credible, they were not utilized the most. The most commonly 
used sources of nutrition information were the internet, friends, and family. In this study, parents admitted to not using the most credible sources because they experienced barriers such as lack of time to attend face-to-face appointments with the medical professionals. This supports the idea that trusted and credible nutrition sources need to be easily accessed by parents to be considered useful.

Mothers receive information about toddler nutrition from many sources, including formally (healthcare providers), informally (family members and friends), through the internet and other written materials, and watching television. Even if not actively searching for nutrition information, they are regularly exposed to public health messages, advertisements from food companies and the opinions of experts and peers. It is important to understand what sources of nutrition information mothers are most readily accessing and which forms they trust the most. These data could help shape future health campaigns and the dissemination of sound nutrition information. By discovering which sources of toddler nutrition information mothers use and trust the most, the dietary guidelines can be shared using the most effective avenue of communication, which could hopefully increase parental knowledge and self-efficacy regarding toddler feeding.

\subsection{Theory of Planned Behavior}

The TPB is a modification of a previously established Theory of Reasoned Action (Ajzen, 2002). According to the theory, behavior is the direct result of intention. In turn, intention is impacted by attitude toward the behavior, subjective norms, and perceived behavioral control (Ajzen, 2002). It has also been defined as an "Expectancy Value Model". This type of theory focuses on factors such as knowledge, attitudes, feelings, 
and beliefs of the individual (McKenzie, Neiger, \& Thackeray, 2013), which are very pertinent to the study. More than likely, a mother intends to feed her child properly, but actually doing so would depend greatly on ability and circumstances. This is reinforced by a study that reviewed parents' perceptions of child feeding, which found that parents believed that optimal nutrition is important but very difficult to achieve (Duncanson et al., 2013).

The main constructs of this theory include: attitude toward the behavior, subjective norm, perceived behavioral control, intentions, and behavior (Ajzen, 2002). Intention can really be seen as an outcome of motivation, meaning in regards to the current study, did a mother actively seek out nutrition information or did they receive it passively? This simple designation could impact whether or not they change their behavior.

These concepts connect to the study because the concepts that a mother sees, hears, and reads regarding nutrition messages could impact her attitude towards the behavior. Attitude toward a behavior can be influenced by receiving accurate and through information. If the mother is properly educated on the benefits of a healthful diet, then she may develop a more positive attitude towards producing that outcome. Attitude is also impacted by the anticipated outcomes (behavioral beliefs) and the positive or negative implications of those outcomes (outcome evaluations). Attitude has been found to significantly impact eating behaviors in several different population groups in previous studies (Backman, Haddad, Lee, Johnston, \& Hodgkin, 2002; Patrick \& Nicklaus, 2005). Specific to mothers, attitude has been found to be one of the strongest 
predictors of controlling young children's sugary snack behaviors (Astrom \& Kiwanuka, 2006; Vinchayanrat et al, 2018).

Subjective norms are what someone perceives others are doing in regards to a health behavior (Simmons-Morton, McLeroy, \& Wendel, 2012). A mother could develop normative beliefs based on her family, friends, peers, and healthcare providers, especially if they serve as a main source of nutrition information. Typically when people feel social pressure to act in a certain way they tend to engage in the specific behavior that is desirable. Past research has shown that subjective norm has been found to significantly influence eating intentions and behaviors (Backman et al., 2002). The traditional definition of the source of the subjective norm component is someone who is seen as trustworthy or experienced regarding the behavior of interest (Hamel \& Smith, 2013), which sources that mothers trust were measured.

Perceived behavioral control takes into account what barriers an individual sees toward performing a behavior and how much control that barrier might possess in deterring the individual from completing the behavior in question. Based off of a mother's attitude and subjective norm towards the behavior, she could increase her perceived behavioral control over feeding her toddler. Perceived behavioral control has been found to significantly influence eating intentions and behaviors in past research (Backman et al., 2002; Patrick \& Nicklas, 2005). The actual, reputable resources regarding toddler nutrition that a mother uses could influence the mother's perceived behavioral control by impacting the severity of the barriers to toddler feeding. 
A recent TPB study examining factors that impact mothers' decisions towards healthy eating for their children found that attitude, subjective norm, and perceived behavioral control predicted intention and behavior for healthy eating. The addition of a variable, parental role construction, was also a significant predictor in that study of maternal intentions to feed their children a healthy diet (Spinks \& Hamilton, 2016). When considering other heath behaviors, it was found the addition of the parental role construction variable to the TPB constructs strengthened the theory's ability to explain the variance in parental decisions to limit child screen time (Hamilton, Spinks, White, Kavanagh, \& Walsh, 2016) and to use sun-protective behaviors (Thomson, White, \& Hamilton, 2012).

\subsection{Parental Role Construction}

Parental role construction is derived from the model of parental involvement and it describes how a parent views their role of personal responsibility and beliefs about child rearing (Hoover-Dempsey \& Sandler, 1995). This differs from subjective norm, which is external pressure, as parental role construction is internal pressure to behave in a certain manner that meets the expectations attached to being a good parent. These pressures are socially constructed attitudes or beliefs that influence parents' decisions surrounding their child's behavior.

Parental role construction has been shown to be influential in a wide variety of topics for parental decision-making regarding their children's health behaviors (Hamilton, Spinks, White, Kavanagh, \& Walsh, 2016; Keech, Hatzis, Kavanagh, White, \& Hamilton, 2018; Spinks \& Hamilton, 2016; Thomson, White, \& Hamilton, 2012). If a 
parent believes that their role is active and important in the promotion of health behaviors for their children then they are more likely to partake in the protective behaviors (Hamilton, Kirkpatrick, Rebar, White, \& Haggar, 2017; Ice, Neal, \& Cottrell, 2014; Thomson et al, 2012).

This construct was added to the study because of findings from focus groups in the initial stage of research that demonstrated how seriously mothers see the job of feeding their child as a central tenant of maternal responsibility. The mothers described a deep level of commitment and strong emotions when talking about their role in regard to feeding their child. The consensus was that feeding a toddler a nutritious diet was a central duty of mothering and if they did not meet this requirement then they had failed in one of their basic maternal roles (Combs, Ickes, \& McMullen, 2019). It is important to study the importance of role construction on mothers' decision-making because these roles seem to be associated with health behaviors.

\subsection{Applying the Theoretical Basis to the Current Study}

A theory should be selected based on the target population and the topic at hand. The Theory of Planned Behavior (TPB) served as the theoretical basis for the current study. This theory was selected because its constructs most thoroughly support the objectives of the study and the information that was researched in the study.

The TPB was the best fit for the study on maternal nutrition knowledge regarding toddler nutrition because it is considered an intrapersonal level theory and these types of theories consider factors within the individual such as knowledge, attitudes, beliefs, motivation, skills, and behaviors (McKenzie et al., 2013). The TPB has been shown to 
reliably predict intentions and behavior for a range of behaviors (Albarracin, Johnson, Fishbein, \& Muellerleile, 2001; Hamel \& Smith, 2013; Spinks \& Hamilton, 2016). Furthermore, the TPB has been applied to a range of health-related behaviors among parents of young children (Spinks \& Hamilton, 2016; Swanson et. al, 2011; Kahlor, Mackert, Junker, \& Tyler, 2011; Hamilton, Cleary, White, \& Hawkes, 2015); however, to date, no studies could be found that utilized this theory with the specified target population and topic.

Additionally, the TPB has commonly been used to study dietary behaviors in several population groups. Specific to prediction of diet, a recent meta-analysis found that the constructs of the theory could explain $21.2 \%$ of the variance found in diet behaviors. The meta-analysis also found that short-term behaviors and those assessed by self-report were also better predicted, which are both characteristics of the current study (Rosemary, McEachan, Conner, Taylor, \& Lawton, 2011). In comparison, a different review identified 19 studies that focused on different healthy eating behaviors, including increasing fruit and vegetable consumption and reducing sugar and fat intake. According to this review, $41 \%$ of variance in intention and $16 \%$ of variance in eating behavior was statistically predicted in all of the studies (Conner \& Sparks, 2005).

The TPB can help explain the relationship between behavioral intention and actual behavior. It has been found that even though parents believe that optimal nutrition is important for their family, it is difficult to achieve because of a lack of perceived control over child feeding (Duncanson et al., 2013). Therefore, a mother could have full intention to feed her toddler correctly, however outside factors such as lack of knowledge or lack of support from others could impact her actual behavior. 
This study aimed to see if the sources a mother used impacted her nutrition knowledge, increased her attitude toward nutrition, impacted her subjective norms, or perceived behavioral control over feeding her toddler. Additionally the support and advice given by healthcare professionals, family members, friends, and media represent a part of the subjective norms surrounding toddler feeding. This study examined if a mother receives dietary advice from multiple sources, does that increase her attitude toward healthy nutrition, the subjective norms impacting toddler feeding, or her level of perceived behavioral control, which could in turn increase the behavioral intention for proper toddler nutrition. Overall, this study aimed to find if sources of nutrition information and the TPB constructs impact a mother's behavioral intention of properly feeding her toddler.

\subsection{Need for Additional Research}

Even though several studies regarding sources of child health information for parents were mentioned in the review above, research is greatly lacking in the area of what sources of nutrition information mothers of toddlers use to guide their feeding decisions during the specific transitional diet period of 12-24 months. The majority of

the studies listed were looking at either the first year of life or the preschool years and beyond. Additionally, the majority of the studies have been completed in Australia or Europe rather than in the United States. Table 2.1 provides information about the studies reviewed for this research and includes the main concepts, subjects, country where research was conducted, pertinent methods, and any recommendations the authors had for future studies. 
The only study completed in America that purposefully reviewed the entire first few years of life in regards to nutrition information (Carruth \& Skinner, 2001) was completed 14 years ago and did not include the internet as an option for participants to select as a source. As mentioned before, $84.7 \%$ of parents reported using the internet to search for medical conditions for themselves or family members (Bianco et al., 2013), which demonstrates the clear need to take another look at this topic since the internet is so pervasive in today's society.

Additionally, the current study made a unique contribution to the literature by assessing not only which sources of nutrition information mothers of toddlers use, but also which sources of information mothers trust. Only one study was found that reviewed which sources of dietary information mothers trusted, and it was a qualitative study that reviewed only 12 mothers' accounts (O'Key \& Hugh-Jones, 2010). By including trust as a variable in the current study, more information was able to be discovered about how mothers feel about certain sources.

Finally, the current study is unique in the fact that it appears to be the first of its kind in three ways. First, it looked at currently used, preferred, and trusted sources of information used by mothers and how these impacted their knowledge of general toddler nutrition guidelines. This information will provide nutrition professionals with very good data on which avenues of information dissemination seem to be the most effective and valuable. Professionals could then invest more in certain sources, which could in turn improve nutrition behaviors. Second, the study used the TPB to guide the research. To date, no studies could be found that utilized this theory with the specified target 
population and topic. Finally, the study extends the TPB by adding the variable of parental role construction to see if this strengthens the predictive power of the model. 
Table 2.1 Articles Specific to Sources of Nutrition Information Used by Parents

\begin{tabular}{|c|c|c|c|c|c|}
\hline Article & Main concept & Subjects & Country & Methods & $\begin{array}{l}\text { Recommend } \\
\text { ations }\end{array}$ \\
\hline $\begin{array}{l}\text { Academy of } \\
\text { Nutrition and } \\
\text { Dietetics. (2011). } \\
\text { Nutrition and you: } \\
\text { Trends 2011. } \\
\text { Retrieved from } \\
\text { http://www.eatright } \\
\text {.org/nutritiontrends }\end{array}$ & $\begin{array}{l}\text { Measure current } \\
\text { attitudes and } \\
\text { behaviors toward } \\
\text { diet and health. }\end{array}$ & $\begin{array}{l}754 \\
\text { adults }\end{array}$ & $\begin{array}{l}\text { United } \\
\text { States }\end{array}$ & $\begin{array}{l}\text { Eight } \\
\text { surveys } \\
\text { conducted } \\
\text { since } 1991\end{array}$ & $\begin{array}{l}\text { None } \\
\text { provided. }\end{array}$ \\
\hline $\begin{array}{l}\text { Bianco, A., Zucco, } \\
\text { R., Nobile, C.G., } \\
\text { Pileggi, C., \& } \\
\text { Pavia, M. (2013). } \\
\text { Parents seeking } \\
\text { health-related } \\
\text { information on the } \\
\text { internet: Cross- } \\
\text { sectional study. } \\
\text { Journal of Medical } \\
\text { Internet Research. } \\
\text { 15, e204. }\end{array}$ & $\begin{array}{l}\text { Establish the } \\
\text { extent of Internet } \\
\text { access and usage } \\
\text { to gather child } \\
\text { health } \\
\text { information. }\end{array}$ & $\begin{array}{l}1,039 \\
\text { parents } \\
\text { of } \\
\text { children } \\
\text { (age not } \\
\text { specifie } \\
\text { d) }\end{array}$ & Italy & $\begin{array}{l}\text { Cross- } \\
\text { sectional } \\
\text { survey sent } \\
\text { to parents of } \\
\text { a public } \\
\text { school } \\
\text { system. }\end{array}$ & $\begin{array}{l}\text { None } \\
\text { provided. }\end{array}$ \\
\hline $\begin{array}{l}\text { Carruth, B.R., \& } \\
\text { Skinner, J.D. } \\
\text { (2001). Mothers' } \\
\text { sources of } \\
\text { information about } \\
\text { feeding their } \\
\text { children ages } 2 \\
\text { months to } 54 \\
\text { months. Journal of } \\
\text { Nutrition } \\
\text { Education, 33, 143- } \\
\text { 147. }\end{array}$ & $\begin{array}{l}\text { Determine what } \\
\text { sources and types } \\
\text { of information } \\
\text { about child } \\
\text { feeding practices } \\
\text { that were } \\
\text { received by } \\
\text { mothers and to } \\
\text { see how it } \\
\text { changes over } \\
\text { time. }\end{array}$ & $\begin{array}{l}62 \\
\text { mothers } \\
\text { of } \\
\text { children } \\
\text { aged 2- } \\
54 \\
\text { months. }\end{array}$ & $\begin{array}{l}\text { United } \\
\text { States }\end{array}$ & $\begin{array}{l}10 \text { or } 11 \text { in- } \\
\text { home } \\
\text { interviews }\end{array}$ & $\begin{array}{l}\text { None } \\
\text { provided. }\end{array}$ \\
\hline $\begin{array}{l}\text { Cash, T., Desbrow, } \\
\text { B., Leveritt, M., \& } \\
\text { Ball, L. (2014). } \\
\text { Utilization and } \\
\text { preference of } \\
\text { nutrition } \\
\text { information sources } \\
\text { in Australia. Health } \\
\text { Expectations, 18, } \\
\text { 2288-2295. }\end{array}$ & $\begin{array}{l}\text { Investigate } \\
\text { individuals' } \\
\text { utilization and } \\
\text { preference of } \\
\text { nutrition } \\
\text { information } \\
\text { sources, as well } \\
\text { as perceptions of } \\
\text { trustworthiness, } \\
\text { credibility, and } \\
\text { effectiveness of } \\
\text { sources. }\end{array}$ & $\begin{array}{l}94 \\
\text { adults }\end{array}$ & Australia & $\begin{array}{l}\text { Cross- } \\
\text { sectional } \\
\text { online } \\
\text { survey }\end{array}$ & $\begin{array}{l}\text { Further } \\
\text { research is } \\
\text { needed on } \\
\text { the impact } \\
\text { of the } \\
\text { sources used } \\
\text { vs. preferred } \\
\text { sources on } \\
\text { overall } \\
\text { nutrition- } \\
\text { related } \\
\text { health }\end{array}$ \\
\hline
\end{tabular}


Table 2.1 (continued)

Chezem, J.,
Friesen, C., \&
Clark, H. (2001).
Sources of infant
feeding information
used by pregnant
women. The
Journal of
Perinatal
Education, 10, 20-
26.

$\begin{array}{lll}\begin{array}{l}\text { Sources of } \\ \text { information }\end{array} & 89 & \text { United } \\ \text { used during } & \text { women } & \text { States } \\ \text { pregnancy for } & & \\ \text { infant feeding. } & \\ & \end{array}$

Dexter, B., Frank, S., \& Seguin, L. (2016). How and where parents of infants and young children want to receive information. Canadian Journal of Dietetic Practice and Research, 77, 203-205.

Parental
preferences of
how to receive
nutrition
information

529

parents of children

$0-5$ at communit $y$ health centers

\section{Canada}

.

\section{Cros}

Cross- $\quad$ No differences sectional were found in survey the type of recruited resources used from by women who medical planned to practices. breastfeed, formula feed, or combination feed. Women in the study were four times more likely to initiate a conversation about infant feeding methods with a family member or friend than with a health care provider.

Cross- A limitation of sectional the study is that survey at it did not ask communi parents to ty health identify their centers. main source of nutrition information. Future research could determine where, what, why and whey parents access online nutrition information; their ability to discern its credibility; and its

effectiveness compared with other methods such as handouts and classes. 
Table 2.1 (continued)

\begin{tabular}{|c|c|c|c|c|c|}
\hline $\begin{array}{l}\text { Gage, H., } \\
\text { Williams, P., Von } \\
\text { Rosen-Von } \\
\text { Hoewel, J., } \\
\text { Laitinen, K., } \\
\text { Jakobik, V., } \\
\text { Martin-Bautista, E., } \\
\ldots \text { Raats, M. } \\
\text { (2012). Influences } \\
\text { on infant feeding } \\
\text { decisions of first- } \\
\text { time mothers in } \\
\text { five European } \\
\text { countries. }\end{array}$ & $\begin{array}{l}\text { Investigate } \\
\text { influences on } \\
\text { infant feeding } \\
\text { decisions, } \\
\text { including } \\
\text { sources of } \\
\text { information. }\end{array}$ & $\begin{array}{l}2,071 \\
\text { first-time } \\
\text { mothers of } \\
\text { infants. }\end{array}$ & $\begin{array}{l}\text { England, } \\
\text { Finland, } \\
\text { Germany, } \\
\text { Hungary, } \\
\text { and Spain }\end{array}$ & $\begin{array}{l}\text { Cross- } \\
\text { sectional } \\
\text { questionn } \\
\text { aire } \\
\text { distribute } \\
\text { d shortly } \\
\text { after } \\
\text { birth and } \\
8 \text { months } \\
\text { later. }\end{array}$ & $\begin{array}{l}\text { Further } \\
\text { research is } \\
\text { required to } \\
\text { identify which } \\
\text { dissemination } \\
\text { strategies are } \\
\text { most effective, } \\
\text { including the } \\
\text { effect of health } \\
\text { professionals } \\
\text { and the } \\
\text { growing } \\
\text { importance of } \\
\text { the internet. }\end{array}$ \\
\hline
\end{tabular}

European Journal

of Clinical

Nutrition, 66, 914-

919.

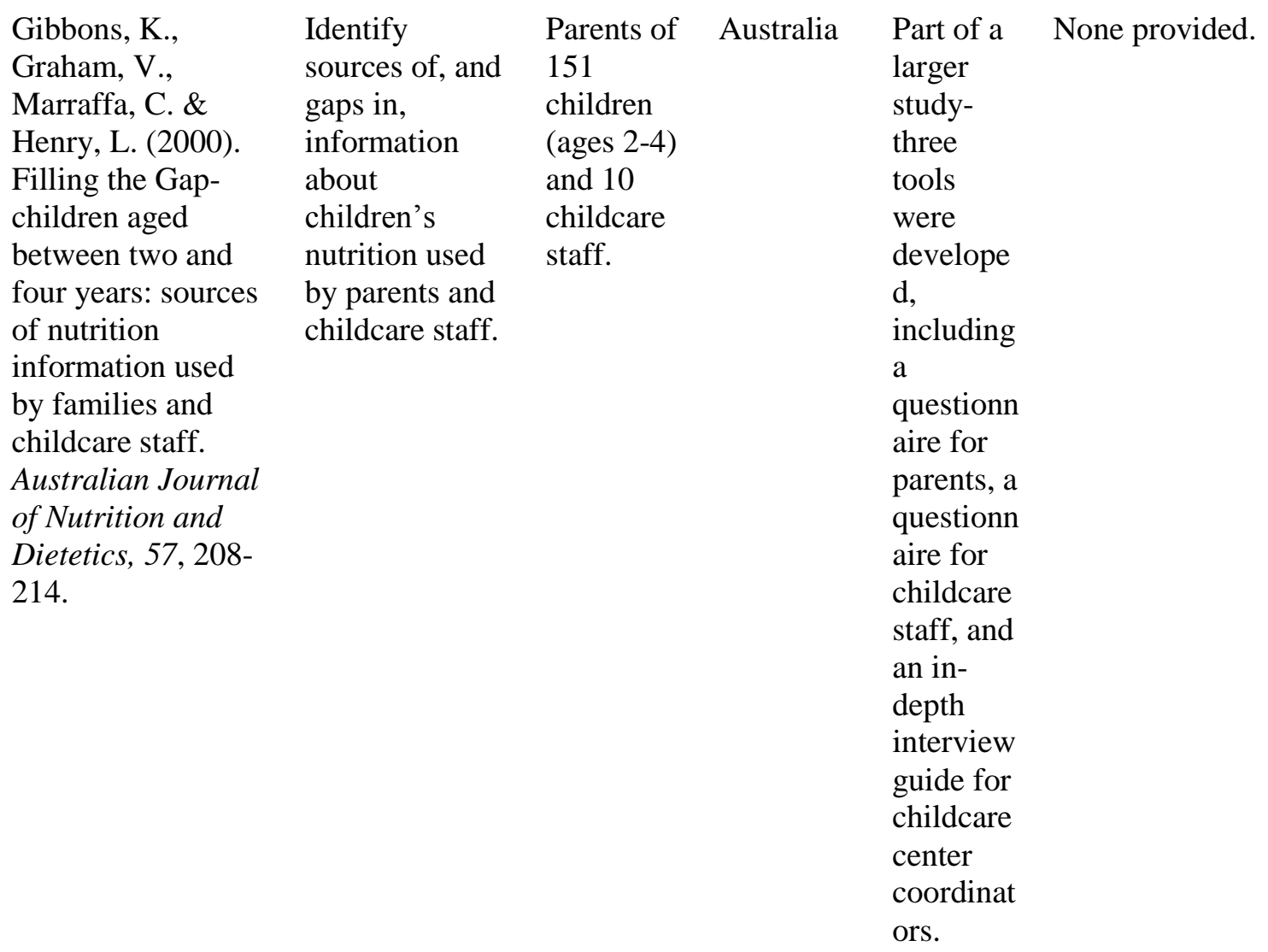


Table 2.1 (continued)

Gildea, A., Sloan, S., \& Stewart, M. (2009). Sources of feeding advice in the first year of life: Who do parents value? Community Practices, 82, 27 -

31.

International Food

Information

Council

Foundation. (2017).

2017 food and

health survey: "A

healthy

perspective:

Understanding

American Food

Values". Retrieved

from

http://www.foodins

ight.org/2017-food-

and-health-survey

Marquis, M.

Dubeau, C., \&

Determine the

principle

Thibault, I. (2005).

Canadians' level of

confidence in their

sources of nutrition

information.

Canadian Journal

of Clinical

Nutrition, 66, 170-

175. sources of

nutrition

information

and confidence

in these

sources.

\author{
Report on the \\ sources of \\ feeding advice \\ in the first year \\ of life.

215
parents
(both male
and
female)

Ireland

Semi- Qualitative

structure research would

d

interview in finding out

$\mathrm{s} \quad$ what sources

conducte parents want to

$\mathrm{d}$ in the use for feeding

home advice and how

during they would

health prefer to access

visits. them and their

perceptions of

them.

Annual None provided.

online

cross-

sectional

survey.

\section{0 adults Canada}

Canada

Cross

sectional

survey

posted to

Dietitians

of

Canada

websites

None provided. 
Table 2.1 (continued)

\begin{tabular}{|c|c|c|c|c|c|}
\hline $\begin{array}{l}\text { Moore, A.P., } \\
\text { Milligan, P., Rivas, } \\
\text { C., \& Goff, L.M. } \\
\text { (2012). Sources of } \\
\text { weaning advice, } \\
\text { comparisons } \\
\text { between formal and } \\
\text { informal advice, } \\
\text { and associations } \\
\text { with weaning time } \\
\text { in a survey of UK } \\
\text { first-time mothers. }\end{array}$ & $\begin{array}{l}\text { First-time } \\
\text { mothers' source } \\
\text { of knowledge } \\
\text { of weaning }\end{array}$ & $\begin{array}{l}1,348 \\
\text { first-time } \\
\text { mothers in } \\
\text { UK }\end{array}$ & $\begin{array}{l}\text { United } \\
\text { Kingdom }\end{array}$ & $\begin{array}{l}\text { Internet } \\
\text { survey } \\
\text { that was } \\
\text { linked to } \\
\text { parenting } \\
\text { websites. } \\
\text { Twenty- } \\
\text { one } \\
\text { questions } \\
\text { in } \\
\text { themed } \\
\text { sections. }\end{array}$ & $\begin{array}{l}\text { Recruitment } \\
\text { bias should be } \\
\text { considered } \\
\text { since the } \\
\text { current study } \\
\text { used internet- } \\
\text { sourced } \\
\text { sample. }\end{array}$ \\
\hline
\end{tabular}

Public Health

Nutrition, 15,

1661-1669.

Moseley, K.L.,

Freed, G.L., \&

Goold, S. D.

(2011). Which

sources of child

health advice to

parents follow?

Clinical Pediatrics,

50, 50-56.

\begin{tabular}{|c|c|}
\hline $\begin{array}{l}\text { Which sources } \\
\text { of child health } \\
\text { advice do } \\
\text { parents follow }\end{array}$ & $\begin{array}{l}543 \\
\text { parents } \\
\text { (no age } \\
\text { specified) }\end{array}$ \\
\hline
\end{tabular}

Cross- More work

sectional needs to be

survey in done to

pediatrici examine the

ans dynamics of

offices. the parent-

pediatrician

relationship for

African

Americans.

Myers, J., Gibbons,

Differences

between

"supported

playgroups"

and

(2015). Early

childhood nutrition,

active outdoor play

and sources of

information for

families living in

highly socially

disadvantaged

locations. Journal

of Pediatric and

Child Health,

51(3), 287-293. "mainstream"

of sources used

by parents (in

addition to

many other

variables)

\section{2}

parents of

children

$0-4$ years

Australia

Cross-

sectional

survey

from

childcare

centers. 
Table 2.1 (continued)

O'Key, V. \& Hugh-

Jones, S. (2010). I

don't need anybody

to tell me what I

Maternal trust

12

of nutrition

mothers

United
Kingdom

Semi-

None provided.

should be doing'. A

discursive analysis

of maternal

accounts of

(mis)trust of

healthy eating

sources

information.

Appetite, 54, 524-

532.

500

Internet health-

parents of

Karner, D., Voitl, J. seeking

children

Klein, F., Voitl, P., $\quad$ behavior of

(no age

Internet health

parents

specified)

structure

d

interview

$\mathrm{s}$

conducte

$\mathrm{d}$ in

participa

nts'

homes

(40-75

minutes)

in

England.

Austria

Cross-

None provided

sectional

survey

complete

$\mathrm{d}$ at a

general

pediatric

outpatien

$\mathrm{t}$ clinic. 


\section{CHAPTER 3. METHODOLOGY}

\subsection{Qualitative}

\subsubsection{Research Design}

This study used a non-experimental, exploratory design using focus groups. Focus groups were conducted with three groups of five to eight mothers. A qualitative methodology was selected to analyze concepts and themes derived from an investigation of mothers' influences, perceptions, and assessments about the sources of nutrition information they use and their toddler-feeding habits. A qualitative approach was most appropriate since this was an exploratory design to find out new knowledge about a topic where little is currently known. Qualitative design provides rich data that can help gain a deeper understanding of maternal perceptions and emotions, which can inform health professionals and future interventions. Additionally, findings from qualitative approaches can inform the development of future theoretically grounded measures.

\subsubsection{Population and Sample}

This study targeted mothers of at least one child between the ages of 12-48 months. Males (fathers) were excluded, because it is supported in the literature that mothers are the dominant parent regarding food decisions and purchases in the home (Byrd-Bredbenner, Abbott, \& Cussler, 2008). All participants were over the age of 18 and spoke English. 


\subsubsection{Procedures}

Recruitment took place over the span of two weeks and methods included flyers, postings on social media, and word of mouth. The recruitment took place at the Beaumont YMCA in Lexington, KY and at Asbury University in Wilmore, KY. At the time of enrollment, participants indicated a preferred focus group session to attend. A confirmation email was sent to all interested individuals that confirmed the date, time and location of the selected focus group.

Three different focus groups were held over the duration of four weeks in the summer months of 2016. Focus groups took place at a large YMCA, a private preschool, and a small liberal arts University. Focus group attendees were asked to respond to questions with particular reference to the study child and to focus on their experiences of child feeding when their children were currently between the ages of 12-48 months of age.

The number of participants ranged from four to six at each focus group and the length of the focus groups ranged from 30 minutes to 60 minutes. All took place in a private room with tables and chairs placed in a small circle to ease discussion. For incentives, participants in the first two focus groups received nutrition packets and participants in the final focus group received a meal and a $\$ 15$ gift card. This change in procedures was approved by the University's Institutional Review Board.

The focus groups were conducted by two researchers associated with the University. All three sessions were led by the same individual while the second individual took brief notes of the sessions and assisted with the collection of forms. 
Interviews were digitally recorded and transcribed by the lead researcher in a word document format. Interview transcripts were checked by two researchers before analysis. Ethical clearance was provided by the University of Kentucky's Intuitional Review Board.

\subsubsection{Research Questions}

Research questions for the first manuscript (Chapter IV) include:

RQ1: What attitudes do mothers associate with the act of toddler feeding?

RQ2: What are the primary subjective norms that influence mothers' toddler feeding decisions?

RQ3: How much control do mothers of toddlers perceive they have over the act of toddler feeding?

RQ4: What sources of information do mothers use regarding toddler nutrition?

RQ5: What sources of information do mothers trust regarding toddler nutrition and why do they trust these sources?

\subsubsection{Measures}

The semi-structured focus group qualitative technique enabled the researcher to comprehensively explore parental perceptions of toddler feeding, factors that influence behaviors surrounding toddler feeding, and sources of nutrition information used by the mother. Discussion topics and a question guide were developed and trialed in a mock session, conducted with University staff that had children aged 12-48 months $(n=3)$, to evaluate comprehension and suitability of discussion topics and probing techniques. After this pilot session, prompting suggestions for each of the sources of nutrition 
information were revised in the guide to support expansion of responses. Additionally, a more direct question was added about working with a registered dietitian since that experience seemed to be topic of debate among mothers in the pilot session.

The focus group guide was developed using the TPB as organizing framework and consisted of 13 questions (Table 3.1) that were based on previous research using the same theory (Duncanson, Burrows, Holman, \& Collins, 2013). The discussion guide sought to identify sources of nutrition information used, trust of sources of nutrition information used, and perceived facilitators and/or barriers to providing what participants believed to be a healthy diet for 12-48-month-old children. Each session employed a semi-structured format based on predetermined discussion prompts. The discussion guide is included in Appendix C. All three sections were led by the same moderator and a secondary researcher recorded field notes.

To collect demographic data, all participants completed a 10-question demographic survey along with their IRB informed consent form. In addition to demographic information, one question had mothers self-assess their maternal nutrition knowledge. All group sessions opened with introductions followed by the primary researcher initiating discussion with the generic question 'how important is nutrition to you when preparing or providing food for your child?' With no set question order, discussions were encouraged to evolve and many topics were covered without prompting. However, if discussion ceased then prompts were used to generate further input such as 'how have you handled those decisions in the past?' and 'what do you do in that situation?' 
Once a topic ended and did not naturally evolve into another area of discussion, open-ended questions related to attitude were offered such as: 1) How important are childhood eating habits and nutrition in terms of lifelong health? Why do you feel this way? 2) What are your responsibilities as a mother in feeding your toddler? And 3) what are some strengths of your toddler's current eating habits? Open-ended questions related to subjective norms were offered such as: 1) if you were to compare the eating habits of your toddler with the dietary guidelines, how do you think they would compare? Why did you say better or worse? And 2) if you were to compare the eating habits of your toddler with his or her peers, how do you think they would compare? Why did you say better or worse? Open-ended questions related to perceived behavioral control were offered such as: 1) what do you think are the main influences on what your toddler eats? And 3) what is the main challenge that you experience in regard to feeding your toddler?

Finally, open-ended questions related to sources of nutrition were asked such as: 1) Could you please describe where you look for toddler nutrition information? 2) Could you please describe whom you ask for toddler nutrition information? 3) What resources have you found to be extremely helpful in regard to information on feeding your toddler? and 4) How would you feel if your child was referred to a registered dietitian?

\subsubsection{Data Analysis}

Interview transcripts were reviewed for accuracy and completeness by both researchers before analysis. The transcripts were coded using QSR NVivo 11 software (QSR International) by one analyst. A combination of inductive and deductive coding was used to populate a matrix, with a priori codes for TPB constructs included with central theme codes that emerged as analysis progressed. The primary researcher initially 
analyzed the three focus group transcripts as they were produced and created the first version of the codebook with initial codes and definitions. A second, independent researcher then coded and organized the data to strengthen the analysis method by confirming the reliability of the coding scheme. The two researchers met in person and compared their findings and discussed main conclusions.

Qualitative thematic analysis was the analysis strategy used. Frequently used words, thoughts, and general concepts were gathered and organized into codes from the data themselves, which were then systemically applied. Data were then reduced from broader concepts and categories to subcategories and main themes, which helped identify important concepts and to make connections. These axial data were arranged based on these higher-level categories to clarify relationships and prominent themes discovered through the focus group findings.

The trustworthiness of the findings was ensured in several ways, including data coding by multiple analysts and debriefing by a faculty advisor to provide external validity. Member checking was used by soliciting two participants' views on the findings and interpretation of the discoveries. The reliability of the findings was strengthened by use of a good quality digital recorder, verbatim transcription, and detailed field notes. The field notes helped the researchers gain a better understanding of when a comment made was one of consensus with the group or if it was an individual point. 


\subsection{Quantitative}

\subsubsection{Research Design}

The analytic approach for the study was a two-step mixed methods approach and the results from each step were analyzed separately. The initial phase of qualitative research served as a backbone to provide comprehensive and individualized insight into the creation of the measure used for the second phase of quantitative research. By using a mixed methods approach, the study initially sought out meaning and understanding of the factors that impact toddler feeding choices and then employed quantitative methods to assess the frequency and importance of those factors on the mother's behavioral intention. Additionally, the quantitative method attempted to draw measurable associations between theoretical constructs. It has been suggested that combining qualitative and quantitative data collection can be advantageous because the weakness of one method can be covered by the strengths of the other method (McKenzie, Neiger, \& Thackeray, 2013). Using a mixed methods approach provided a more comprehensive understanding of the factors that impact a mother's choices surrounding her toddler's diet.

Based on the emerging themes and concepts identified in the first phase of the research project, an online quantitative survey was created and distributed to a larger sample of mothers. The design of the study was a non-experimental, cross-sectional design. This quantitative method was used to study the population at a single point in time to examine the relationship between variables. This design allowed for direct associations to be drawn between variables, such as the constructs in the TPB. Other benefits of this type of design included the fact that multiple outcomes were able to be 
studied, data on all variables were collected at once, and it works well for descriptive analyses (Barratt \& Kirwan, 2009).

\subsubsection{Population and Sample}

The study population included mothers that had at least one child between the ages of 12 months and 48 months. Selecting only mothers of children in this age range was important since the objectives of the study were specific towards toddler nutrition information and toddler feeding behaviors. Males (fathers) were excluded, because it is supported in the literature that mothers are the driving force of food decisions and purchases in the home (Byrd-Bredbenner, Abbott, \& Cussler, 2008).

All participants were over the age of 18 and spoke English. Participants were not excluded based on race/ethnicity or health status. These approaches sought out to provide a wide sample of participants from a variety of backgrounds and socioeconomic statuses. Additionally, the survey respondents were not limited to a particular geographical region because of the nature of the online survey.

The entry points for sampling were the Lexington-Fayette County Health Department, Central Kentucky Community Action Council sites, a Northern Kentucky Mother's Group, and ResearchMatch. The survey was distributed via these organizations' listservs and websites. A description of the population served specifically at the Lexington-Fayette County Health Department was not available. However, data from 2014 show that in Kentucky there are 251,978 individuals that participated in The Special Supplemental Program for Women, Infants, and Children (WIC), which is housed within the Health Department. WIC provides supplemental foods, health care referrals, and nutrition education for low-income pregnant and postpartum women and infants and 
children up to age five (USDA, 2017). When considering WIC participants within Kentucky, over $65 \%$ of the households included children between the ages of 1-5. From these participants, $72.9 \%$ reported their race as White, $10.9 \%$ reported Black/African American, 9.6\% reported as Hispanic, and 5.5\% reported multiple races (Altarum, 2017). A second recruitment site was the Central Kentucky Community Action Council. This program serves 2,199 total households. There are 802 children between the ages of 0-5 within these households. The majority of adults in the households served have an education of a high school level or less. Additionally, in regards to race, the population served is $36 \%$ African-American, $48 \%$ white, and $16 \%$ multi-racial (NASCSP Demographics, 2017). A description of the demographics of the population Northern Kentucky Mother's Group was not available. However, the group is a local non-profit organization with over 150 members.

The final sample consisted of 148 mothers. The mean age was $32.83(S D=6.16)$ years. The majority of participants were married (87.2\%), had earned a college degree or higher (79.7\%), held part-time or fulltime employment, $(60.8 \%)$, and were White (90.3\%). Women in the sample ranged in the number of children that they had with $30 \%$ having one child, $46 \%$ having two children, $17 \%$ having three children, and $7 \%$ having four children. The majority of women did not receive WIC benefits (91\%) and did not receive SNAP benefits (96\%). See Table 3.2 for detailed demographic information.

\subsubsection{Procedures}

Nonprobability, snowball sampling was used since it is an effective way to identify respondents who are difficult to find or identify. Since the population for this study was mothers with children in a specific age range, snowball sampling helped 
identify members of this specific group. To ensure an adequate response rate, it was possible for respondents to send the survey to other interested parties via email. This made the "snowball" part of the sampling method easier. Additionally, a few qualifying questions were included at the beginning of the survey and if individuals did not meet the criteria, they were not allowed to complete the remainder of the survey.

A power analysis using the $\mathrm{G}^{*}$ Power computer program indicated that a total sample of 129 people would be needed to detect small effects with 95\% power using multiple regression with 4 predictors. The survey was administered through Qualtrics, an online survey management system. The survey could have been taken using a variety of digital tools, including computers, tablets, or cell phones. Based on pilot testing and the recorded responses, the survey took 10-15 minutes to complete on average.

The survey distribution process included initiating pre-survey contact with the initial entry points, distribution of the online survey link, follow-up contact to the group, and a final second survey request to the group. Contact was made with key personnel at each site, which included the Health and Nutrition Manager at Community Action Council, the Business Services and Nutrition Team Leader with WIC, and a board member with the Northern Kentucky mothers group. They all agreed to participate and assist with recruitment and distribution of the survey at their respective facilities (J. Coffie, personal communication, September 5, 2017; C. Hiten, personal communication, September 5, 2017; A. Moellering, personal communication, August 4, 2017).

Specifically, an invitation email was sent to potential participants from key personnel at each site that included a summary of the study and an anonymous link to the web survey. There was also a message at the end of the email requesting that the 
participants forward the survey link to others they knew that fit the inclusion criteria. Participants were able to skip questions and/or withdraw from the survey at any time.

\subsubsection{Limitations of the Data Collection Methods}

There are several limitations to consider in regard to the collection methods. One limitation is the fact that the findings from the research will not be able to be extrapolated to a larger population because of the nonrandom sampling design, however they are acceptable for this research since it was exploratory. This type of design provided sufficient information to meet the purpose of the research, which pertains to the nonexperimental, exploratory design of the survey.

Additionally, access to a computer and the internet was required to complete the online survey, so this could have eliminated possible participants or certain groups resulting in non-response error. However, according to the Pew Research Center, in 2016 96-99\% of women between the ages of 18-49 use the Internet regularly (Pew Research Center, 2017). The use of snowball sampling could have produced a sample that is homogenous. Furthermore, self-administered surveys are not a viable method if a respondent has a learning disability or cannot read, which again could have resulted in non-response error. Finally, the fact that the survey is comprised of mostly closed-ended items could have limited possible responses. However, the survey was developed after qualitative data collection with a similar target population. Several open-ended responses questions were included, which allowed participants to expand, thus providing a more thorough understanding of the topic. 


\subsubsection{Research Questions}

Research questions for the second manuscript (Chapter V) include:

RQ1: Which constructs of the Theory of Planned Behavior (attitude toward the behavior, subjective norms, and perceived behavioral control) significantly predict the mother's behavioral intention surrounding the toddler feeding behavior of providing meals that include a wide variety of the five food groups in appropriate amounts? Which is the most salient predictor of this behavioral intention?

RQ2: Does the addition of the parental role construction construct strengthen the Theory of Planned Behavior's ability to significantly predict the mother's behavioral intention surrounding the toddler feeding behavior of providing meals that include a wide variety of the five food groups in appropriate amounts?

\subsubsection{Measures}

The survey for this study was developed using results from prior focus groups (Combs, Ickes, \& McMullen, 2018) and a previously validated survey (Spinks \& Hamilton, 2016) that fit the theoretical basis of this study. An initial phase of qualitative research was conducted that served as a backbone and provided individualized insight into the creation of the measure used for the quantitative research. The survey was pilot tested with a group of four mothers of toddlers before dissemination to check for face validity and to ensure that the survey had appropriate readability. The survey was also shared with two nutrition experts to ensure face and content validity. The survey can be found in Appendix B. 


\subsubsection{Theory of Planned Behavior Constructs}

The survey measured behavioral intention of mothers to provide meals that include a wide variety of the five food groups in appropriate amounts to their toddlers as the dependent variable. Independent variables of the TPB constructs (attitude, subjective norms, and perceived behavioral control) were measured based on procedures outlined by Ajzen (2007). Finally, the additional construct of parental role construction was included and measured based on procedures of prior research (Spinks \& Hamilton, 2016).

The main outcome behavior of the tool was modified slightly from "ensure that my child eats a wide variety of foods from the five food groups according to the recommended serves" to "ensure that my child eats a wide variety of foods from the five food groups in appropriate amounts." This change was made based on focus group findings (Combs et al., 2018) and based on the fact that the United States Dietary Guidelines do not have set serving size recommendations for children younger than 2 years of age.

The number of questions for each construct from the TPB varied. Each question was scored using a 7 point Likert-type scale on a "strongly disagree" to "strongly agree" or "bad" to "good" dimension. For each scaled question, higher scores indicated higher levels of agreement or more positive responses. The questions for each construct are listed in Table 3.3.

\subsection{ATTITUDE}

Four items comprised the attitude subscale. Participants ranked the specified behavior as being good/bad, favorable/unfavorable, desirable/undesirable, and 
beneficial/harmful. Participants evaluated each outcome on a 7-point scale from positive (7) to negative (1) with a possible range of $4-28$.

\subsection{SUBJECTIVE NORM}

Three questions comprised the subjective norm subscale. Participants responded to the following three questions: "Most people who are important to me would approve of me ensuring that my toddler eats a wide variety of foods from the five food groups in appropriate amounts EVERY DAY"; "The people in my life whose opinions I value would think that my ensuring my toddler eats a wide variety of foods from the five food groups in appropriate amounts EVERY DAY is desirable"; and "Those people who are important to me think that I should ensure my toddler eats a wide variety of foods from the five food groups in appropriate amounts EVERY DAY". Participants evaluated each outcome on a 7-point scale from strongly agree (7) to strongly disagree (1) with a possible range of $3-21$.

\subsection{PERCEIVED BEHAVIORAL CONTROL}

Two questions comprised the perceived behavioral control subscale, which included: "It is mostly up to me whether I ensure that my toddler eats a wide variety of foods from the five food groups in appropriate amounts EVERY DAY" and "I am confident that I will ensure that my toddler eats a wide variety of foods from the five food groups in appropriate amounts EVERY DAY". Participants evaluated each outcome on a 7-point scale from strongly agree (7) to strongly disagree (1) with a possible range of 2 14. 


\subsection{BEHAVIORAL INTENTION}

Three questions comprised the behavioral intention subscale. These questions included: "I intend to ensure that my toddler eats a wide variety of foods from the five food groups in appropriate amounts EVERY DAY"; "I plan to ensure that my toddler eats a wide variety of foods from the five food groups in appropriate amounts EVERY DAY"; and "I expect that I will ensure that my toddler eats a wide variety of foods from the five food groups in appropriate amounts EVERY DAY". Participants evaluated each outcome on a 7-point scale from strongly agree (7) to strongly disagree (1) with a possible range of $3-21$.

\subsection{PARENTAL ROLE CONSTRUCTION}

Three questions comprised the parental role construction subscale, which included: "I believe it is my responsibility as a parent to make sure that my child eats a wide variety of foods from the five food groups in appropriate amounts EVERY DAY in the next week"; "It is an important part of my role as a parent to make sure that my child eats a wide variety of foods from the five food groups in appropriate amounts EVERY DAY in the next week"; and "As a parent, it is my job to make sure that my child eats a wide variety of foods from the five food groups in appropriate amounts EVERY DAY in the next week". Participants evaluated each outcome on a 7-point scale from strongly agree (7) to strongly disagree (1) with a possible range of $3-21$.

\subsection{DEMOGRAPHICS}

A section of demographic questions was included to garner important information about the participants completing the survey. Information gathered included: maternal 
age, maternal education (high school diploma/GED, associate's degree, bachelor's degree, graduate/professional degree, or other), maternal employment (full-time, parttime, stay-at-home mom, student, or other), maternal relationship status (single (never married), married, divorced/separated, or other), household income, maternal race (American Indian/Alaska Native, Asian, Black/African American, Native Hawaiian/Pacific Islander, White, or other), current WIC participation (yes, no, or prefer not to answer), current SNAP participation (yes, no or prefer not to answer), maternal weight/height, child's weight/height, child's age, child's gender, and total number of children in the household.

\subsection{MOTHER'S NUTRITION KNOWLEDGE}

Additionally, a 10-item maternal knowledge scale specific to toddler nutrition guidelines was provided. The score for maternal nutrition knowledge was measured from these questions. The mothers answered if the statements were true of false. Correct answers were given a score of 1 and incorrect answers were given a score of zero. The higher the final score, out of a possible range of zero to 10 on the subscale, the higher the maternal nutrition knowledge. The ten questions were based on general guidelines provided from the American Academy of Pediatrics (AAP, n.d.). The questions were listed as follows:

1. Juice should be limited to $4-6$ ounces per day.

2. Toddlers need 2-3 snacks per day.

3. Meals and snacks should always be served seated.

4. When provided with healthy options, your toddler should be allowed to control the amount of food they eat. 
5. It can take up to 15 times before a toddler actually accepts a new food.

6. Toddlers should be drinking whole (full-fat) milk up until the age of 2 .

7. It is OK to watch TV while eating a meal with a toddler.

8. The recommended amount of protein per day for a toddler is 1-2 ounces.

9. An appropriate serving size for a toddler is $1 / 4^{\text {th }}$ of an adult portion.

10. A toddler's diet should contain $30-40 \%$ of calories from fat.

\subsection{SOURCES OF NUTRITION INFORMATION}

One aspect of this study was to initially explore the sources of nutrition information that a mother uses and which sources she trusts. A section on where mothers get their nutrition information and the trustworthiness of such sources was also included. Sources included in this section were based on past research (Gibbons, Graham, Marraffa \& Henry, 2000; Carruth \& Skinner, 2002; Gage et al., 2012). Twelve questions explored which sources were most often used, which sources were seen as trustworthy, which sources were preferred by participants, and which sources were perceived as being helpful. Sources listed on the survey included healthcare providers, family members, traditional media outlets, and social media. While most questions were exploratory in nature, one question had survey respondents select their main source of nutrition information.

\subsubsection{Data Collection Procedures}

The University of Kentucky Institutional Review Board (IRB) approved the study on March 30, 2018 after review. The approval letter can be found in Appendix G. Additionally, the Lexington-Fayette County Health Department Institutional Review 
Board approved the use of their facilities as a recruitment site and the project on January 24, 2018. The approval letter can be found in Appendix H.

\subsubsection{Data Cleaning}

Once data collection was complete, the data were reviewed for missing data and outliers. Two inclusion questions at the beginning of the study, which took individuals that were not mothers of children between $12-48$ months to the end of the survey helped identify cases in which the respondents were not from the target audience. There were 27 cases in which data came from those that met the exclusion criteria and were therefore removed from analysis.

\subsubsection{Data Analysis}

Descriptive statistics were used to identify the demographic data of the sample population. The determinants of intention per the TPB were explored using descriptive statistics and multiple linear regression. The measures of attitude, subjective norm, perceived behavioral control, parental role construction, and behavioral intention demonstrated acceptable levels of internal consistency reliability, with $\alpha$ coefficients of $0.885,0.838,0.501,0.949$, and 0.870 respectively. Initial analyses were completed to check that the assumptions of multiple linear regression were met. The VIF values were above 0.1 and the Tolerance values were well below 10, the Durbin-Watson statistic was within an acceptable range, and the scatterplot of standardized residual on standardized predicted value was acceptable. The software package used for these analyses was IBM SPSS Statistics for Windows, Version 24.0. For statistical testing, the significance level was set to 0.05 . 


\subsubsection{Assumptions of Statistical Tests}

With regression analysis, it is important to assess whether all assumptions for the analysis have been met. These are the specific areas that need to be addressed in order to make sure that all assumptions have been met. These include the assumptions of: 1) multicollinearity, 2) autocorrelation of residuals, 3) linearity, and 4) homoscedasticity.

For the assumption of multicollinearity, which is the high correlation between independent variables, it needed to be established that none of the collinearity tolerance statistics were below .01 and none of the VIF statistics were above 10. In the current data, the lowest collinearity tolerance was .563 and the highest VIF statistic was 1.776 . Therefore, the assumption of multicollinearity was satisfied.

For the assumption of no autocorrelation of residuals, which is a lack of correlation between the residuals of two observations, the Durbin-Watson statistic needed to fall within a desirable range that is dependent upon the number of independent variables and the number of participants. The Durbin-Watson $d=2.020$, which is between the two critical values of $1.5<\mathrm{d}<2.5$. Therefore, it can be assumed that there is no linear autocorrelation in the data.

For the assumptions of linearity, which is a linear relationship between independent and dependent variables and homoscedasticity, which is a similar variance of error terms across independent variables, the scatterplots were reviewed. The scatterplots of the relationship between each dependent variable and the independent variable indicated that the relationships were linear. Additionally, the scatterplot of standardized residuals on standardized predicted values was reviewed. It was found that the graph of 
the current dataset does not funnel or curve. Therefore, the assumptions of linearity and homoscedasticity were also met.

\subsubsection{Conclusion}

The two-step mixed methods approach was used and the results from each step were analyzed separately. In both stages, mothers with children between the ages of 1248 months were used to gain understanding influencers on decisions surrounding feeding their toddlers. The initial phase of qualitative research served to support the creation of the measure used for the second phase of quantitative research. Data gathered from the focus groups served as exploratory research to help create a survey that utilized the TPB to assess the connections between sources of nutrition information, mothers' nutrition knowledge, mothers' attitude, subjective norms, perceived behavior control, intentions, and perceived behaviors surrounding toddler feeding. 
1. Tell me about how important nutrition is to you when

Attitude toward behavior providing food to your toddler?

a. Why do you feel this way?

2. What are your responsibilities as a mother in feeding your toddler?

3. What are some of strengths of your toddler's current eating habits?

4. If you were to compare the eating habits of your toddler with the dietary guidelines, how do you think they would compare? Why did you say better or worse?

5. If you were to compare the eating habits of your toddler with other toddlers his/her age, how do you think they would compare? Why did you say better or worse?

6. Where does your main source of nutrition information come from?

Attitude toward behavior

Attitude toward behavior

Subjective norm

a. Can you list some sources where you look for toddler nutrition information?

i. Have you used any of the following sources of information about feeding your child?

1. Television (what programs)

2. Magazines (what magazines)

3. Internet (what sites)

4. Others

b. Can you list some people that you ask for toddler nutrition information?

i. Have you talked to any of the following persons about how to feed your child?

1. Relatives

2. Friends

3. Health professionals
a. Doctors
b. Nurses
c. Physician Assistant
d. Registered Dietitians

Subjective norm

7. Others (church, daycare, etc). 
Table 3.1 (continued)

8. How would you feel if your toddler was referred to a Subjective Norms registered dietitian?

9. What sources have you found to be extremely helpful Subjective Norms in regard to information on feeding your toddler?

10. What sources do you trust in regards to information Subjective Norms on feeding your toddler?

11. What do you think are the main influences on what your toddler eats?

Perceived behavioral control

12. What is the main challenge that you experience in regard to feeding your toddler?

Perceived behavioral control

13. What are some parts of your toddler's eating habits that you would like to change?

Behavioral intention 
Table 3.2 Demographics

\begin{tabular}{|c|c|}
\hline Age & $\mathrm{n}(\%)$ \\
\hline$<30 \mathrm{y}$ & $29(19)$ \\
\hline $30-39 y$ & $114(74)$ \\
\hline$>40 y$ & $10(7)$ \\
\hline Education Level & $\mathrm{n}(\%)$ \\
\hline High school diploma or GED & $20(13)$ \\
\hline Associate degree & $16(11)$ \\
\hline Bachelor's degree & $56(38)$ \\
\hline Graduate degree & $56(38)$ \\
\hline Employment Status & $\mathrm{n}(\%)$ \\
\hline Working (full-time) & $74(50)$ \\
\hline Working (part-time) & $21(14)$ \\
\hline Stay-at-home mom & $49(33)$ \\
\hline Student & $4(3)$ \\
\hline Ethnicity & $\mathrm{n}(\%)$ \\
\hline Hispanic, Latino, or Spanish Origin & $4(3)$ \\
\hline $\begin{array}{l}\text { Not of Hispanic, Latino, or Spanish } \\
\text { Origin }\end{array}$ & $143(97)$ \\
\hline Race & $\mathrm{n}(\%)$ \\
\hline American Indian or Alaska Native & $1(0.68)$ \\
\hline Asian & $1(0.68)$ \\
\hline Black or African American & $5(3)$ \\
\hline White & $138(93)$ \\
\hline Other & $4(3)$ \\
\hline Number of Children & $\mathrm{n}(\%)$ \\
\hline 1 & $45(30)$ \\
\hline 2 & $68(46)$ \\
\hline 3 & $25(17)$ \\
\hline 4 & $10(7)$ \\
\hline
\end{tabular}


Table 3.2 (continued)

\begin{tabular}{|c|c|}
\hline Marital Status & $\mathrm{n}(\%)$ \\
\hline Single (never-married) & $9(6)$ \\
\hline Married & $129(87)$ \\
\hline Divorced or separated & $6(4)$ \\
\hline Other & $4(3)$ \\
\hline Currently Receive WIC & $\mathrm{n}(\%)$ \\
\hline Yes & $13(9)$ \\
\hline No & $134(91)$ \\
\hline Currently Receive SNAP & $\mathrm{n}(\%)$ \\
\hline Yes & $5(3)$ \\
\hline No & $142(96)$ \\
\hline Current Nutrition Knowledge Rating & $\mathrm{n}(\%)$ \\
\hline Poor & $1(1)$ \\
\hline Fair & $18(11)$ \\
\hline Good & $60(38)$ \\
\hline Very Good & $56(36)$ \\
\hline Excellent & $21(14)$ \\
\hline Current Toddler Nutrition Rating & $\mathrm{n}(\%)$ \\
\hline Poor & $5(3)$ \\
\hline Fair & $17(11)$ \\
\hline Good & $57(37)$ \\
\hline Very Good & $66(42)$ \\
\hline Excellent & $11(7)$ \\
\hline
\end{tabular}


Table 3.3 Constructs of the Theory of Planned Behavior

\begin{tabular}{|c|c|c|}
\hline Construct & Questions & Scale \\
\hline Attitude & $\begin{array}{l}\text { Good/Bad, Favorable/Unfavorable, } \\
\text { Desirable/Undesirable, } \\
\text { Beneficial/Harmful }\end{array}$ & $\begin{array}{l}\text { Participants evaluate } \\
\text { each outcome on a } 7- \\
\text { point scale from } \\
\text { strongly agree (7) to } \\
\text { strongly disagree (1) } \\
\text { for three questions } \\
\text { with a possible total } \\
\text { of } 28 \text { points. }\end{array}$ \\
\hline \multirow[t]{2}{*}{ Subjective Norms } & $\begin{array}{l}\text { The people in my life whose } \\
\text { opinions I value would think that my } \\
\text { ensuring my toddler eats a wide } \\
\text { variety of foods from the five food } \\
\text { groups in appropriate amounts } \\
\text { EVERY DAY is desirable }\end{array}$ & \multirow[t]{2}{*}{$\begin{array}{l}\text { Participants evaluate } \\
\text { each outcome on a } 7 \text { - } \\
\text { point scale from } \\
\text { strongly agree ( } 7) \text { to } \\
\text { strongly disagree (1) } \\
\text { for three questions } \\
\text { with a possible total } \\
\text { of } 21 \text { points. }\end{array}$} \\
\hline & $\begin{array}{l}\text { Those people who are important to } \\
\text { me think that I should ensure my } \\
\text { toddler eats a wide variety of foods } \\
\text { from the five food groups in } \\
\text { appropriate amounts EVERY DAY. }\end{array}$ & \\
\hline $\begin{array}{l}\text { Perceived Behavioral } \\
\text { Control }\end{array}$ & $\begin{array}{l}\text { It is mostly up to me whether I } \\
\text { ensure that my toddler eats a wide } \\
\text { variety of foods from the five food } \\
\text { groups in appropriate amounts } \\
\text { EVERY DAY. }\end{array}$ & $\begin{array}{l}\text { Participants evaluate } \\
\text { each outcome on a } 7 \text { - } \\
\text { point scale from } \\
\text { strongly agree ( } 7) \text { to } \\
\text { strongly disagree (1) } \\
\text { for three questions } \\
\text { with a possible total } \\
\text { of } 14 \text { points. }\end{array}$ \\
\hline
\end{tabular}


Table 3.3 (continued)

Behavioral Intention I intend to ensure that my toddler Participants evaluate eats a wide variety of foods from the each outcome on a 7five food groups in appropriate point scale from amounts EVERY DAY. $\quad$ strongly agree (7) to

I plan to ensure that my toddler eats a strongly disagree (1) wide variety of foods from the five for three questions food groups in appropriate amounts EVERY DAY. with a possible total of 21 points.

I expect that I will ensure that my toddler eats a wide variety of foods from the five food groups in appropriate amounts EVERY DAY

Parental Role Construction

I believe it is my responsibility as a parent to make sure that my child eats a wide variety of foods from the five food groups in appropriate amounts EVERY DAY in the next week.

It is an important part of my role as a parent to make sure that my child eats a wide variety of foods from the five food groups in appropriate amounts EVERY DAY in the next week.

As a parent, it is my job to make sure that my child eats a wide variety of foods from the five food groups in appropriate amounts EVERY DAY in the next week.
Participants evaluate each outcome on a 7point scale from strongly agree (7) to strongly disagree (1) for three questions with a possible total of 21 points. 


\section{CHAPTER 4. INFLUENCES ON MATERNAL FEEDING DECISIONS FOR TODDLERS: FOCUS GROUP FINDINGS BASED ON THE THEORY OF PLANNED BEHAVIOR}

\subsection{Introduction}

Establishing healthy eating behaviors is vital in the early years to help combat the development of obesity and other chronic diseases (Birch \& Ventura, 2009).

Unfortunately, the obesity epidemic has already impacted even the youngest Americans. National data show that $8.1 \%$ of children under age 2 years have high weight-for-length (at or above the 95 th percentile) and $22.8 \%$ of children age 2-5 years are categorized as overweight or obese (Ogden, Carroll, Kit, \& Flegal, 2014). These numbers are of specific concern because obesity during the early years increases the risk for obesity later in life (Lakshman, Elks, \& Ong, 2012; Freedman et al., 2005; Ong et al., 2009). Health officials have warned that today's children could be the first generation to have a predicted lower life expectancy than their parents due to the impact of obesity on longevity, quality of life, and the development of co-morbidities (Dwyer-Lindgren et al, 2017; Olshanskey et al., 2005).

Eating behaviors are shaped early in life and are one of the cornerstones in the developmental process. From one to two years of age toddlers transition from a primarily milk-based diet to an adult-modified diet. This may be a particularly important time in establishing eating behaviors as it represents the first experience children have in consuming foods that they may eat throughout their lifetime (Stang, 2006). Mothers are the dominant parent regarding food decisions and purchases in the home (ByrdBredbenner, Abbott, \& Cussler, 2008). Foods that are offered during the first two years of life can predict what foods are accepted later in childhood (Coulthard, Harris, \& 
Emmett, 2009; Skinner, Carruth, Bounds, Zeigler, \& Reidy, 2002), which is why parents, especially mothers, need to help establish healthy eating habits during these formative years.

The importance of parents establishing healthy eating habits early on is reiterated in an Institute of Medicine (2011) Consensus Statement, which says, "Preventing obesity in infants and young children holds promise toward both reversing the epidemic of childhood obesity and reducing obesity in adulthood... [However] efforts must begin before children ever enter the school system" (p. 1). Therefore, parents serve as the first line of defense against the development of childhood obesity by establishing healthy eating habits early in their children's lives. However, parents need to be equipped with the proper skills and knowledge to serve in this important role.

Nutrition guidelines for the first few years of life can be difficult for mothers to find since the Dietary Guidelines for Americans only provides advice for those ages 2 years and older (USDA, n.d.). In the past, these guidelines were limited to this age range because of the specific eating patterns, developmental milestones, and nutrient needs of toddlers (1-3 years of age). With the lack of national guidelines, reputable nutrition recommendations and advice for the 12-24-month period is not readily available for mothers to access. Because of this need, the United States Department of Agriculture has committed to expand the Dietary Guidelines for Americans to include infants and toddlers beginning in 2020 (USDA, n.d.). Until that time mothers are left searching for reputable dietary guidance for their toddlers and could be making feeding decisions based on varying beliefs or attitudes towards nutrition rather than on trustworthy information. There is currently a gap in the understanding of what beliefs guide mothers' decisions 
about their toddlers' eating habits, which is why the Theory of Planned Behavior (TPB) was used to guide the current study to gain a better understanding of the behavior of mothers of toddlers. These beliefs can be used to develop theoretically based interventions and evidence-based health messages.

Research is greatly lacking in the area of what mothers of toddlers use to guide their feeding decisions during the specific transitional diet period of 1-3 years. Most of the studies reviewed looked at either the first year of life or the preschool years and beyond and none used a theoretical framework to guide the research methods. Additionally, the majority of previous studies on this topic have been completed in Australia or Europe rather than in the United States. It is important to understand the beliefs and sources that guide mothers' decisions about their toddler's eating habits and to apply this knowledge to strengthen other research endeavors and interventions. Therefore, formative research on beliefs is necessary to explore, using a TPB framework, to gain a better understanding of what guides the feeding decisions of mothers.

\subsubsection{Theoretical Framework}

Given the need to understand this issue from a theoretical perspective, the Theory of Planned Behavior (TPB) served as the theoretical basis for the study. The main constructs of the TPB include: attitude toward the behavior, subjective norm, perceived behavioral control, intentions, and behavior (Ajzen, 2002). According to the theory, behavior is the direct result of intention. In turn, intention is impacted by attitude toward the behavior, subjective norms, and perceived behavioral control (Ajzen, 2002). It has also been defined as an "Expectancy Value Model." This type of theory focuses on factors such as knowledge, attitudes, feelings, and beliefs of the individual (McKenzie, 
Neiger, \& Thackeray, 2013), which are very pertinent to the current study. The TPB has been applied to a range of health-related behaviors among parents of young children (Spinks \& Hamilton, 2016; Swanson et. al, 2011; Kahlor, Mackert, Junker, \& Tyler, 2011; Hamilton, Cleary, White, \& Hawkes, 2015); however, to date, no studies could be found that utilized this theory with the specified target population and topic. Formative research is needed to further understand these influences on this population. Themes that emerge from qualitative research can support previously established theories and generate new hypotheses to be tested on a larger scale. Additionally, the themes can be used to develop theoretically sound measures for future research.

The aim of the current study was to explore, using a TPB framework, the influences on mothers' toddler feeding decisions. These influences included attitude, subjective norms, and perceived behavioral control. These constructs were derived from discussions about what sources of nutrition information mothers use and what sources of nutrition information mothers trust. Additionally, the research aimed to use the TPB to learn more about mothers' perceptions and assessment of their behaviors and decisions about toddler feeding.

\subsection{Methods}

\subsubsection{Study Design and Population}

A qualitative methodology was selected to analyze concepts and themes derived from an investigation of mothers' influences, perceptions, and assessment about the sources of nutrition information they use and their toddler-feeding habits. A qualitative approach was most appropriate since this was an exploratory design to find out new 
knowledge about a topic where little is currently known. Qualitative design provides rich data that can help gain a deeper understanding of maternal perceptions and emotions which can inform health professionals and future interventions. Additionally, findings from qualitative approaches can inform the development of future theoretically grounded measures.

A non-experimental, exploratory design with focus groups was used. This study targeted mothers of at least one child between the ages of 12-48 months. Males (fathers) were excluded, because it is supported in the literature that mothers are the dominant parent regarding food decisions and purchases in the home (Byrd-Bredbenner et al., 2008). All participants were over the age of 18 and spoke English.

Nonprobability, snowball sampling was used to identify respondents who are difficult to find or identify. Participants were recruited from a local YMCA and a small liberal arts University, both in Central Kentucky, over the span of two weeks using flyers, postings on social media, and word of mouth. At the time of enrollment, participants indicated a preferred focus group session to attend. A confirmation email was sent to all interested individuals that confirmed the date, time and location of the focus group. Participants were then encouraged to share the study information with other mothers that fit the recruitment criteria. The final sample included individuals that all resided in the Central Kentucky region. The recruitment sites were in typically highly educated, affluent areas because they include several higher education institutions.

Ethical clearance was provided by the University's Institutional Review Board. Participants completed informed consent forms and were reminded of their rights and the voluntary nature of the study before the focus groups began. 


\subsubsection{Data Collection}

Three focus groups were held over four weeks during summer 2016. Focus groups convened in three locations: (1) a large YMCA, (2) a private preschool, and (3) a small University. The number of participants ranged from 4-6 at each focus group and the length of the focus groups ranged from 30 to 60 minutes. Participants in the first two focus groups received nutrition packets and participants in the final focus group received a meal and a $\$ 15$ gift card.

The focus group guide was developed using the TPB as organizing framework and consisted of 13 questions (Table 4.1) that were based on previous research using the same theory (Duncanson, Burrows, Holman, \& Collins, 2013). The guide was used in a mock session, conducted with university staff that had children aged 12-48 months $(n=$ 3), to evaluate comprehension and suitability of discussion topics and probing techniques. After this pilot session, prompting suggestions for each of the sources of nutrition information were revised in the guide to support expansion of responses. Additionally, a more direct question was added about working with a registered dietitian since that experience appeared to be topic of debate among mothers in the pilot session.

All three sessions were led by a trained facilitator while a second individual took brief field notes of the sessions and assisted with the collection of forms. All focus groups were digitally recorded and transcribed verbatim by the lead researcher in a word document format. 


\subsubsection{Data Analysis}

Interview transcripts were reviewed for accuracy and completeness by both researchers before analysis. The transcripts were coded using QSR NVivo 11 software (QSR International) by one analyst. A combination of inductive and deductive coding was used to populate a matrix, with a priori codes for TPB constructs included with central theme codes that emerged as analysis progressed. The primary researcher initially analyzed the three focus group transcripts as they were produced and created the first version of the codebook with initial codes and definitions. A second, independent researcher then coded and organized the data to strengthen the analysis method by confirming the reliability of the coding scheme. The two researchers met in person and compared their findings and discussed main conclusions.

Qualitative thematic analysis was the analysis strategy used. Frequently used words, thoughts, and general concepts were gathered and organized into codes from the data themselves, which were then systemically applied. Data were then reduced from broader concepts and categories to subcategories and main themes, which helped identify important concepts and to make connections. These axial data were arranged based on these higher-level categories to clarify relationships and prominent themes discovered through the focus group findings.

The trustworthiness of the findings was ensured in several ways, including data coding by multiple analysts and debriefing by a faculty advisor to provide external validity. Member checking was used by soliciting two participants' views on the findings and interpretation of the discoveries. The reliability of the findings was strengthened by use of a good quality digital recorder, verbatim transcription, and detailed field notes. 
The field notes helped the researchers gain a better understanding of when a comment made was one of consensus with the group or if it was an individual point.

\subsection{Results}

\subsubsection{Demographics}

A total of 15 individuals participated in the focus groups. All participants were married, spoke English in their home, and identified as non-Hispanic white. One participant received both WIC and SNAP benefits. Participant demographics can be found in Table 4.2.

\subsubsection{Themes/Subthemes}

Four major themes emerged from the data analysis: (1) attitudes (subthemes: positive towards maternal role of feeding and negative towards the maternal role of feeding); (2) subjective norms positively accepted (subthemes: social media, pediatricians, and registered dietitians); (3) subjective norms negatively accepted (subthemes: pediatricians and registered dietitians); (4) perceived behavioral control (subthemes: acceptance, scarcity of time and outside influences). Table 4.3 shows select participant quotations to highlight each identified theme.

\subsubsection{Theme 1: Attitudes}

Mothers in the study shared several outlooks surrounding the feeding responsibility that ranged from pride to stress to guilt. It emerged that preparing meals and feeding a family is a very maternal task that can be laden with emotion. It was clear 
that the majority viewed the task of feeding their child differently than other daily maternal responsibilities with both positive and negative lenses.

\subsection{Subtheme 1.1: Positive Maternal Role in FEeding}

It was clear that the participants felt that feeding their family was one of the basic responsibilities of being a mother. They took this very seriously and it made them feel "good" and "proud" when they deemed their efforts successful. "It does make you feel like you're doing something good when you're feeding your children nutritious foods, whole foods, things that you know are good for them and their body." Feeding their family was described as being a personal task and that it was very maternal to want to provide and keep their families well. "You want to think that you're providing well for your children and doing right... and with feeding, that's such a personal thing, especially with the mom. I think it is so maternal to want to provide and keep them well."

\subsection{SUBTHEME 1.2: NEGATIVE MATERNAL ROLE IN FEEDING}

Many of the mothers had strong feelings of guilt when it came to feeding their child (ren). It was shared that they mostly had a good understanding of what made a nutritious diet for a toddler, but many struggled to be able to provide this on a regular basis because of constraints of time and toddler acceptance of some foods. Some expressed stress over not being able to commit more time or energy to providing balanced meals. "In several areas of being a mom, I struggle with guilt... you know I feel like I only get, in the grand scheme of things in my daughter's life, I only get this little bit where I really get to control everything, you know what I mean?... So, when I'm giving her something and I find out that maybe it's not good or that there's something 
better like I do think that I struggle with guilt sometimes." Participants regularly used words such as "failed" and "bad mom" when describing their attitudes towards this parental responsibility.

\subsubsection{Theme 2: Subjective Norms: Positively Accepted}

Very few participants discussed actively seeking nutrition information in regard to toddler feeding. Many passively received information at well-child visits at their pediatrician's office and also from social media websites like Facebook and Pinterest. The majority of participants did not rely on family members for information and advice, but a few did look to friends that had children of similar ages for guidance about nutrition.

\subsection{SUBTHEME 2.1: SOCIAL MEDIA.}

Several participants mentioned that they passively read and reviewed nutrition articles and recipes that are posted on Facebook and other forms of social media. They stated that if an article caught their eye then they would read the information. It appeared that most participants enjoyed receiving information in this manner. Participants identified that they questioned the trustworthiness of social media posts. They valued the information based on the person that posted it and how that person takes care of their own family. "I don't have a whole lot of time to devote to research, so I often rely on things that friends have posted on Facebook and stuff like that. I'll see a link to an article, and I'll be like "oh" and go read it. I'll be like oh that was really good and I think it's valid. (Laughter from all). But yeah, I don't do a whole lot of original research, but I think that Facebook is a good place to find things." The consensus appeared to be that mothers 
only accepted the information if it was something that aligned with their prior thoughts on the topic and if they perceived the person that posted it valued health. "Some of it does have to do with the person that posted it and how I see that they're taking care of their family. Well, if they believe this then there must be something to it."

\subsection{SUbTheme 2.2: Pediatricians.}

The well-visit at the pediatrician's office was unanimously agreed upon as the number one source of information surrounding toddler nutrition. The majority of mothers received some type of handout regarding appropriate feeding and nutritional milestones at each child well-visit. "It would be the regular checkups at the doctor. They have a print out that they always give us. I'll keep all of those in a folder." Some pediatricians regularly discussed information from this handout with the family, while others did not address nutrition at all during visits. Two mothers did like the fact that their doctors openly discussed nutrition as a piece of the health continuum because their children were more likely to listen to the doctor about health related habits.

\subsection{SUBTHEME 2.3: REGISTERED DIETITIANS.}

Thoughts surrounding registered dietitians (RDs) were mostly positive in the focus groups. When asked about seeing a RD for toddler nutrition guidance, it was shared that RDs were the nutrition experts and would take the time to research individualized nutrition problems more than doctors. "So if there was a nutritionist that could say, "you need to eat this" or whatever or however they're good about doing that. I feel it just gives more clout or weight. You know, like they're the expert on foods!" 
They are seen as an additional resource and as approachable; however, they are not seen as a healthcare professional that would be sought out regularly by mothers.

\subsubsection{Theme 3: Subjective Norms: Negatively Accepted}

While pediatricians and RDs were viewed by the participants to be reputable healthcare providers, many of the mothers demonstrated a level of skepticism about following their guidelines blindly. The consensus was that recommendations from doctors and/or RDs would not necessarily be important influences on the mothers' feeding decisions for their toddlers. Many of the mothers relied more on their "motherly instinct" in regard to these types of decisions.

\subsection{SUbTheme 3.1: Pediatricians.}

While the pediatrician was seen as the medical expert, most mothers expressed that they did not see the pediatrician as an expert on nutrition, even though they were the most commonly used source of nutrition information. "They also look uncomfortable doing it [giving nutrition information]." While all participants agreed that the pediatrician was their number one source of information, the majority of participants did not believe that their pediatrician was well-educated on nutrition and feeding issues.

“Doctors are very well educated too. But I don't know how well they're educated on nutrition" and "you know I love my pediatrician for a lot of other things, but not nutrition." They discussed hearing what the doctor had to say, but going with their "motherly instinct" or searching out other information if they disagreed with what he or she had to say. "I'm not very doctor trusting, to be honest. It's kind of like if the doctor 
says it, it doesn't mean that much to me. I'd just rather kind of evaluate it for myself or look for more natural sources."

\subsection{SUBTHEME 3.2: REGISTERED DIETITIANS.}

One idea that was clearly conveyed through all three focus groups is that mothers viewed RDs as an extreme step in receiving care and guidance for their child. They felt that a referral to a RD would denote failure in caring for their child. "I've FAILED! (Laughs with others) No really, I've done something wrong if my child needs a specialist, someone who is trained in this. You know, I've done something wrong." There were very strong, emotional responses surrounding seeking care from a RD. Many shared they would only go if it was an extreme case and that they would seek a second opinion from a doctor before taking their child to see a RD. "I mean it would just kind of be hard for me to believe. Like I guess I would want some pretty clear, like, reasons why we would need to do that."

\subsubsection{Theme 4: Perceived Behavioral Control.}

The mothers in the study expressed varying factors that influenced their children's diets. Mothers felt like they had a lot of control over their child's diet up until the 2-yearold mark. At that point in time, more outside factors started to influence what the child consumed.

\subsection{SUBTHEME 4.1: ACCEPTANCE.}

The mothers agreed that the toddler age range was a precarious time when it came to how likely a toddler would accept new and novel foods. It seems that children would freely accept and try new foods up until a certain point, but then they become adamant 
about eating only a few foods or being a "picky eater" as many mothers described their children as being, "Picky choices these days. It definitely narrows the scope of what I can give her." Mothers felt limited by the variety of foods that their toddlers would accept and some felt that it was more important to simply get their child to eat anything rather than be concerned with the nutritional balance of the meal. "You want them to be healthy. You want them to have some sort of nutrition during the day, but I also want them to eat."

\subsection{SUBTHEME 4.2: SCARCITY OF TIME AND RESOURCES.}

It was regularly shared that one of the biggest feeding challenges that the mothers experienced was the lack of time they could commit to meal preparation. Many said that it was hard to dedicate time to cooking when they had such limited time with their families at the end of the day, so they looked for ways to prepare fast, balanced, and acceptable meals on a regular basis. "Sometimes you only have 20 minutes when everyone is home and sometimes it's not even that. Everyone is going different directions and it's hard trying to coordinate time when I work late.” It appeared that convenience and speed took precedent over the health of the meal for some, even though they valued nutrition and health for their families. "When considering what to make I would consider convenience/fast and then health. But convenience first, right?"

\subsection{SUBTHEME 4.3: OUTSIDE INFLUENCES.}

Participants expressed high levels of stress when describing the decisions and actions surrounding feeding their toddlers. Stress seemed to surround the lack of control they had over their toddlers' diets when their child was out of the home or with other 
adults, such as grandparents or daycare workers. "I stress about what she's eating at the daycare! When I look at the menu that comes home I'm like "WHAT?!? This is not a meal!" That adds another level of stress because I cannot control what others serve her." Grandparents were also often mentioned as outside influencers that valued enjoyment over nutrition when providing food to their grandchildren. Additional stress came when mothers felt a discrepancy between their desire to provide balanced meals and their need to provide food that their child would actually accept. "It's stressful when it becomes a battle. She wants dessert and I'm like, "you cannot have dessert until you eat this, and this, and this." You know, so there's some stress in that fight trying to get all of the nutrients in her."

\subsection{Discussion}

The aim of the current study was to explore, using a TPB framework, the influences on mothers' toddler feeding decisions. These influences included attitude, subjective norms, and perceived behavioral control. These constructs were derived from discussions about what sources of nutrition information mother's use and what sources of nutrition information mothers trust. In this study, it was found that mothers positively and negatively receive and accept information from a variety of sources, that they have many strong emotions associated with the act of feeding that are deeply rooted in their roles as mothers, and that mothers' toddler feeding decisions were strongly influenced by the TPB constructs.

Mothers predominantly expressed positive attitudes towards their maternal role in feeding by providing wholesome options to their toddlers and encouraging a healthy diet. 
Additionally, they valued nutrition and were confident in their nutritional knowledge. These findings are consistent with previous research that highlighted positive maternal attitudes towards the importance of good childhood nutrition and self-confidence in having adequate nutrition knowledge (Duncanson et al., 2013; Hamel \& Smith, 2013).

However, while mothers had overall positive attitudes towards the concept of nutrition, they also had strong negative attitudes about the actual act of feeding their children. These emotions included stress, guilt, responsibility, and purpose. These feelings ran deep and appeared to be engrained in their roles as mothers. This concept is consistent with the social factor of parental role construction. This role is defined by parents' beliefs regarding child rearing, child development, and what is expected of them as parents (Hoover-Dempsey \& Sandler, 1995). Parental role construction has been found to have a direct influence on mothers' behavioral intentions to provide their children with a balanced diet and to limit discretionary choices (Spinks \& Hamilton, 2016). Further research is needed to see if the addition of the parental role construction construct strengthens the standard TPB framework in regard to toddler feeding behaviors.

Mothers in the current study saw feeding their children as an innate responsibility of mothering and that if they failed in that regard then they had failed as a mother. These findings are consistent with previous research where parents felt like feeding competence was paramount in the parental role and could predict healthy eating behavioral intentions of mothers (Duncanson et al., 2013; Spinks \& Hamilton, 2015). Mothers also felt responsible for giving their toddlers the opportunity to try new foods, to provide a variety of nutritious options, and to cultivate a positive home eating environment. This feeling of responsibility could be effectively used in health promotion campaigns. Future 
approaches could capitalize on this motherly role and provide information and resources that validate what the mother is currently doing and build her confidence in these skills for the future.

While mothers in this study felt a distinct desire to provide a healthy diet for their family, they struggled to define exactly what a 'healthy diet' consisted of for a toddler. Mothers looked to varying sources to find guidance on nutrition and felt positive and negative influences on their decision making from these varying sources. They felt perceived social pressures to feed their children nutritious diets from both formal and informal sources. Many conducted their own research using websites or by asking friends. Participants consistently cited social media websites as being credible sources (depending on who posted the item) and used varying websites such as blogs and kidfriendly recipe sites. These results are consistent with previous research findings that parents rely heavily on the internet for child health information and they believe the internet is as credible as many other sources of information (Duncanson et al., 2013; Moseley, Freed, \& Gould, 2011; Sebelesfsky, Karner, Voitl, Klein, Voitl, \& Bock, 2015) Additionally, parents of young children have identified that online reading in their home was their preferred way of receiving nutrition information (Dexter, Frank, \& Seguin, 2016).

While mothers in the current study did reach out to friends often, they rarely asked family members for help, did not believe that family had much of an influence on their toddler feeding decisions, and often commented that their own upbringing often included unhealthy meals and junk food. This finding conflicts with previous research where family was one of the most consistently used and highly influential sources of 
nutrition information throughout toddlerhood (Carruth \& Skinner, 2001; Cash, Desbrow, Leveritt, \& Ball, 2014). These findings suggest that the social expectations and subjective norms from sources beyond the nuclear family (websites, friends, and social media) might have a stronger influence on mothers' feeding decisions than family pressures. Future research is needed to determine if the information mothers receive online is accurate or if it is leading to misinformation. The results from this study also support the idea that more evidence-based nutrition websites should be promoted in means that mothers would prefer, such as social media, since it is a common and preferred source of nutrition information for mothers.

Pediatricians were a primary source of nutrition information for mothers in this study, which is consistent with previous findings (Bianco, Zucco, Nobile, Pileggi, \& Pavia, 2013; Chezem, Friesen, \& Clark, 2001). Mothers were often given a handout at each well-child visit, yet that was the extent to the nutrition guidance they generally received. Most pediatricians did not freely offer nutrition information and appeared uninformed when asked specific nutrition questions. This concept has been supported previously in the literature (Hernandez, Cheng, \& Serwint, 2010; Paul et al., 2009). When the pediatrician did not bring up nutrition related topics, mothers automatically assumed that their toddler was healthy. Most healthcare professionals do not discuss nutrition and feeding with parents unless they assess that there is a problem with growth (Paul et al., 2009). This is especially true in children younger than 3 years of age, even if there is a weight problem (Hernandez et al., 2010). This could be a concern since past research has shown that mothers are more likely to initiate a conversation about feeding their child with family and friends than with a healthcare professional (Chezem et al., 
2001) and they might feel like there is not a problem if their pediatrician does not initiate a conversation. When pediatricians did give advice, most mothers appeared to have skepticism and were not willing to follow the advice completely. Additionally, while mothers were mostly pleased with their pediatricians and trusted their guidance, they did not feel like the pediatrician was well educated on nutrition topics.

In comparison to the findings about the pediatrician, most mothers saw the registered dietitian as the nutrition expert. It was universally agreed that a registered dietitian (RD) or nutritionist was someone that was trained in food and nutrition and that could provide reputable information about feeding a toddler. However, mothers unanimously agreed that they would be offended if their toddler was referred to a RD. Several stated that this would mean that they failed at one of their most basic responsibilities as a mother, which was to care and provide for their child. It appears that the subjective norm surrounding seeing a specialist (like a dietitian) has very negative connotations and is not seen as an opportunity to improve knowledge or skills.

Mothers' perceived behavioral control was impacted by pressure to provide nutritious meals and an enjoyable eating environment. Participants felt constrained by their toddlers' pickiness and the lack of time they had to prepare meals. Several also mentioned that healthy food costs more money and that their toddlers did not typically like healthier options, so this meant that they wasted the more expensive food. This is consistent with previous research that found that parents' barriers to providing healthy diets often included time and financial pressures (Kahlor et al., 2011; White et al., 2011). These concerns added to the level of stress and guilt that the mothers felt surrounding the act of toddler feeding. 


\subsubsection{Limitations}

This study used a qualitative approach to fill an important gap in the literature to better understand the underlying behavioral beliefs related to maternal toddler feeding decisions through a theoretical lens. However, there are several limitations to consider when interpreting the findings. First, it is important to note that the study was limited by the collection of data from three sites, which consisted of a self-selected, homogenous sample that was highly educated, affluent, and had a high self-rating of nutrition knowledge. Second, consistent with all qualitative studies, the findings cannot be generalized to the population as a whole. Finally, a third limitation is the fact that the primary researcher was a registered dietitian and the participants were made aware of this distinction. Therefore, some of the results could be different if the focus group facilitator was not a healthcare provider since some questions focused on the role of healthcare providers as sources of nutrition information. Even with these limitations, the study was able to generate rich, in-depth data to help guide the creation of a theoretically based measure for future research.

\subsection{Implications for Research and Practice}

While a study of this size and nature cannot be generalized, there are several findings that could have an impact on practice. These findings suggest some unmet needs and provide information to develop and test effective strategies to better support mothers while they navigate making good decisions for feeding their toddlers. An area of possible intervention would be for reputable, professional organizations to capitalize on mothers' interest to use social media to find nutrition information and to make appealing websites or social media profiles. This could help improve mothers' attitudes towards the positive aspects of toddler feeding, influence the subjective norms that are acceptable 
surrounding toddler nutrition, and increase perceived behavioral control by providing realistic suggestions and tips for managing these challenging years. Since it appears that most mothers turn to social media on a regular basis, this could be a valuable avenue of reputable information dissemination for health professionals.

It is clear that pediatricians should receive more training on effectively communicating about toddler nutrition so they can put more emphasis on providing agespecific nutrition advice during child well visits. Research should be conducted with these professionals to see where their education or skills could be strengthened. Another option would be for RDs to work directly with and in the offices of pediatricians. This could help normalize the idea of seeing a RD by making it just another stop for a family during their healthcare visit. This would help alleviate mothers' concern about pediatricians not being educated on nutrition topics and would help solidify the importance of nutrition by having it be a consistent message from healthcare providers at each visit. It could also help break the stigma of being referred to a specialist and hopefully normalize the behavior of seeking out additional knowledge and skills surrounding toddler feeding.

More research is needed to better understand the direct impact that the TPB has on maternal toddler feeding decisions. These topics need to be explored through quantitative methods to assess the measurable influences between the constructs and behavioral intentions. Additionally, this quantitative approach could help further develop and refine existing measures. These future research endeavors could provide useful information to pinpoint when and how to promote optimal nutrition for toddlers. These data could also help shape future health campaigns and the dissemination of sound 
nutrition information, which could hopefully increase maternal confidence regarding toddler feeding. 


Question
1. Tell me about how important nutrition is to you when
providing food to your toddler?

a. Why do you feel this way?

2. What are your responsibilities as a mother in feeding your toddler?

3. What are some of strengths of your toddler's current eating habits?

4. If you were to compare the eating habits of your toddler with the dietary guidelines, how do you think they would compare? Why did you say better or worse?

5. If you were to compare the eating habits of your toddler with other toddlers his/her age, how do you think they would compare? Why did you say better or worse?

6. Where does your main source of nutrition information come from?

c. Can you list some sources where you look for toddler nutrition information?

i. Have you used any of the following sources of information about feeding your child?

1. Television (what programs)

2. Magazines (what magazines)

3. Internet (what sites)

4. Others

d. Can you list some people that you ask for toddler nutrition information?

i. Have you talked to any of the following persons about how to feed your child?

1. Relatives

2. Friends

3. Health professionals
a. Doctors
b. Nurses
c. Physician Assistant
d. Registered Dietitians

Theory of Planned

Behavior Construct or

Variable of Interest

Attitude toward behavior

Attitude toward behavior

Attitude toward behavior

Subjective norm

Subjective norm

Subjective Norms

7. Others (church, daycare, etc). 
Table 4.1 (continued)

8. How would you feel if your toddler was referred to a Subjective Norms registered dietitian?

9. What sources have you found to be extremely helpful Subjective Norms in regard to information on feeding your toddler?

10. What sources do you trust in regard to information on Subjective Norms feeding your toddler?

11. What do you think are the main influences on what your toddler eats?

Perceived behavioral control

12. What is the main challenge that you experience in regard to feeding your toddler?

Perceived behavioral control

13. What are some parts of your toddler's eating habits Behavioral intention that you would like to change? 
Table 4.2 Sociodemographic Characteristics of Study Participants

\begin{tabular}{ll} 
Age & $\mathrm{n}(\%)$ \\
\hline $25-29 \mathrm{y}$ & $2(13)$ \\
$30-34$ y & $7(47)$ \\
$35-39$ y & $6(40)$ \\
\hline Education Level & $\mathrm{n}(\%)$ \\
\hline Bachelor's degree & $10(67)$ \\
Graduate degree & $5(33)$ \\
\hline Employment Status & $\mathrm{n}(\%)$ \\
\hline Working & $9(60)$ \\
Non-working & $6(40)$ \\
\hline Household Income Level & $\mathrm{n}(\%)$ \\
\hline \$0 - \$49,999 & $4(27)$ \\
\$50,000 - \$89,999 & $2(13)$ \\
Over \$90,000 & $9(60)$ \\
\hline Number of Children & $\mathrm{n}(\%)$ \\
\hline 1 & $3(20)$ \\
\hline & $7(47)$ \\
\hline & $3(20)$ \\
\hline Children's Ages & $2(13)$ \\
\hline 2 years old & $\mathrm{n}(\%)$ \\
\hline y years old & $5(15)$ \\
\hline
\end{tabular}


Table 4.3 Quotes by Theme

\begin{tabular}{|c|c|}
\hline Number & Subtheme/Example Quotation \\
\hline Theme 1 & Attitude: \\
\hline 1.1 & Positive Maternal Role in Feeding \\
\hline 1.1.1 & $\begin{array}{l}\text { I feel like I started eating better when we had kids because then it's not } \\
\text { just your life and your body that you're ruining. }\end{array}$ \\
\hline 1.1 .2 & $\begin{array}{l}\text { I kind of feel like trying to get those good habits in of having a well- } \\
\text { balanced meal for her has a positive impact on us too. }\end{array}$ \\
\hline 1.2 & Negative Maternal Role in Feeding \\
\hline 1.2.1 & $\begin{array}{l}\text { So yeah, I'm like so proud of my son when he goes and makes the } \\
\text { choice for the veggie tray and to my daughter I'm like why are you } \\
\text { choosing cookies? I don't know, I probably failed with one of those. } \\
\text { Oh man. }\end{array}$ \\
\hline 1.2.2 & $\begin{array}{l}\text { One thing that comes to mind is if we're traveling or even just busy. I } \\
\text { feel like we do not make good choices around that even though it is my } \\
\text { job. }\end{array}$ \\
\hline 1.2 .3 & $\begin{array}{l}\text { I can totally agree with what you're saying about the pickiness and } \\
\text { going through this phase where I only want to eat } X, X \text {, and } X \text { and that } \\
\text { makes me feel bad as a mom. }\end{array}$ \\
\hline Theme 2 & Subjective Norms: Positively Accepted \\
\hline 2.1 & Social Media \\
\hline 2.1 .1 & $\begin{array}{l}\text { Wellness Mama blog. I don't know if anyone else follows her, but I } \\
\text { mean I feel like she posts something, it must be true! (laughs) I mean, I } \\
\text { don't know if I agree with everything, but for the most part it's very in } \\
\text { line with my thinking. }\end{array}$ \\
\hline 2.1 .2 & $\begin{array}{l}\text { If you like that person on social media then it's [what they posted] } \\
\text { more valid. (Laughter and agreement from group) }\end{array}$ \\
\hline 2.2 & Pediatricians \\
\hline 2.2.1 & $\begin{array}{l}\text { I don't feel like I've gone into them [a child's well visit with the } \\
\text { pediatrician] wanting his help with nutrition. I mean it's just been like, } \\
\text { "I think my kid's healthy? You confirm that!" Um, but, yeah, I don't } \\
\text { know. In my mind, that wouldn't be my source of nutrition } \\
\text { information. }\end{array}$ \\
\hline 2.2.2 & $\begin{array}{l}\text { I really like our pediatrician and I feel like he keeps, and I do } \\
\text { appreciate the fact that he even keeps food as a piece of the puzzle, as a } \\
\text { piece of health }\end{array}$ \\
\hline 2.3 & Registered Dietitians \\
\hline 2.3.1 & $\begin{array}{l}\text { And I feel like a dietitian would be more apt to researching all of these } \\
\text { things and would be able to give a more concise answer than somebody } \\
\text { that has to know everything. So I feel like that would be helpful. }\end{array}$ \\
\hline 2.3.2 & $\begin{array}{l}\text { So if there was a nutritionist that could say, "you need to eat this" or } \\
\text { whatever or however they're good about doing that. I feel it just gives } \\
\text { more clout or weight. You know, like they're the expert on foods! }\end{array}$ \\
\hline Theme 3 & Subjective Norms: Negatively Accepted \\
\hline 3.1 & Pediatricians \\
\hline
\end{tabular}


Table 4.3 (continued)

3.1.1 I'm not trying to say that doctors don't have anything good to say about it, but I just feel like I don't really want to discuss it with them. I feel like I know what I'm doing.

3.1.2 My pediatrician, I don't really care for him, but since we're probably going to leave I'm just kind of sticking it out, but I don't care for him because I feel like I've asked questions and he doesn't provide me with anything. I feel like everybody gets the printout, you know? Even just like really basic information, he had his nurse print him something off. But I feel like I didn't really feel validated in asking, so that's kind of like I was like well I guess you're not going to help me, I'm going to turn to these other things.

3.2 Registered Dietitians

3.2.1 My friend actually had that (child was referred to dietitian). I think that her child was overweight at like 5 or 6 . And like she was offended by it, she was like "oh, God".

3.2.2 (Reaction to if their child was referred to a registered dietitian) I've FAILED! (laughs with others) No really, I've done something wrong if my child needs a specialist, someone who is trained in this. You know, I've done something wrong.

3.2.3 It (being referred to a dietitian) would be kind of annoying, perhaps, to be kind of called out or whatever. Um, I don't know if it's a stigma or what that is or why that would elicit those feelings as opposed to just encouraging guidance, but I do think it is laden with an emotional response.

\section{Theme $4 \quad$ Perceived Behavioral Control}

$4.1 \quad$ Acceptance

4.1.2 Giving them what they will eat since it is somewhat limited.

4.1.3 For me it's about what the kids will actually eat. It's convenience. What the other kids are eating.

4.2 Scarcity of Time and Resources

4.2.1 Part of it for me is a time issue. When I have an hour and a half in the evening with my girls to get them fed, get them ready to go to school or daycare the next day, fill out any forms... I'm like making a lunch is just one more thing that I don't have time to do. Honestly, I'd rather clean the bathroom than pack a lunch (laughs). I HATE packing lunches!

4.2.2 Cost is the biggest influence. I wouldn't necessarily buy all the foods I buy unless they were on sale.

4.2.3 I feel like it caused a lot of stress before because, kind of like what you were saying, you only have so much time with your kids at the end of the day and before you know it, its bedtime! So, I can't be spending all this time putting lunch together when I should be spending time with her. 
Table 4.3 (continued)

4.2.4 You asked about stress before, and yes, I would say that it is stressful being a fulltime mom. You know, when you get home you have two hungry kids and your husband is home and hungry as well. Trying to pull something together quickly that is nutritious and balanced

$4.3 \quad$ Outside influences

4.3.1 My mom will say, "Your daughter is really an eater." Well, she's 3 so she's only eating what you give her. Stop giving her those things.

4.3.2 That adds another level of stress because I cannot control what others serve her.

4.3.4 That adds another level of stress because I cannot control what they (daycare) serve. 


\section{CHAPTER 5. FACTORS THAT INFLUENCE MATERNAL FEEDING DECISIONS FOR TODDLERS: EXTENDING THE THEORY OF PLANNED BEHAVIOR}

\subsection{Introduction}

Health officials have warned that today's children could be the first generation to have a predicted lower life expectancy than that of their parents due to the impact of obesity on longevity and quality of life (Olshanskey et al., 2005). National data show that $8.1 \%$ of children under age 2 years have high weight-for-length (at or above the 95th percentile) and $22.8 \%$ of children aged 2-5 are categorized as overweight or obese (Ogden, Carroll, Kit, \& Flegal, 2014). Obesity during the early years of life substantially increases the risk for obesity later in life (Freedman et al., 2005; Ong et al., 2009). Currently in the United States toddlers' diets are not well balanced and may contribute to excessive weight gain in the first few years of life (Briefel et al., 2010; Butte et al., 2010; Siega-Riz et al., 2010). Establishing healthy eating behaviors is vital in the early years to help combat the development of obesity and other chronic diseases (Birch \& Ventura, 2009).

Parents have significant influence over their young children's weight-related outcomes, including nutrient intake and eating behaviors (Brown, Ogden, Vogele, \& Gibson, 2008; Loth, MacLehose, Larson, Berge, \& Neumark-Sztainer, 2016). Mothers are the dominant parent regarding food decisions and purchases in the home (ByrdBredbenner, Abbott, \& Cussler, 2008). Their influence on the diets of their young children may be seen in the types of foods available, role modeling of healthy dietary intake, meal and snack structure, and the creation of a healthy eating environment (Birch, 1999; Mitchell, Farrow, Haycraft \& Myer, 2013). Children are more willing to accept a 
healthy diet if parents use encouraging behavior at meal times (Horodynski, Strommel, Brophy-Herb, Xie, \& Weatherspoon, 2010; Schwartz, Scholtens, Lalanne, Weenen, \& Nicklaus, 2011). While parents do value feeding their children a healthy, balanced diet, it has been reported to be one of the most difficult parental responsibilities (Campbell, Hesketh, Silverii, \& Abbott, 2010; Carruth, Ziegler, Gordon, \& Barr, 2004). The incongruence between parental attitudes and beliefs and intentions related to toddler feeding needs to be further explored.

In an effort to determine what influences a mother's decisions about toddler feeding, the Theory of Planned Behavior (TPB) was utilized as the guiding framework for this research. According to the theory, behavior is the direct result of intention. In turn, intention is impacted by attitude toward the behavior, subjective norms about what important others think about performing the behavior, and perceived behavioral control over performing the behavior (Ajzen, 2002). Parents believe that optimal nutrition is important for their child's health; however, they have reported that providing a balanced diet is one of the most challenging experiences in parenthood (Campbell et al., 2010; Champion, Giles, \& Moore, 2010). Providing a healthy diet could be difficult to achieve because of a lack of parental perceived control over the child feeding experience (Duncanson, Burrows, Holman, \& Collins, 2013). The factors that impact mothers' decisions about toddler feeding needs to be further studied. This theory is appropriate for the current study because it has been shown to be a reliable predictor of intentions and behavior for a variety of dietary behaviors.

The TPB has commonly been used to study dietary behaviors in several population groups. Specific to prediction of diet, a recent meta-analysis of the TPB 
found that the constructs of the theory could explain $21.2 \%$ of the variance found among dietary behaviors. The meta-analysis also found that short-term behaviors and those assessed by self-report were better predicted, which are both characteristics of the current study (Rosemary, McEachan, Conner, Taylor, \& Lawton, 2011). A recent TPB study examining factors that impact mothers' decisions towards healthy eating for their children found that attitude, subjective norm, and perceived behavioral control predicted intention and behavior for healthy eating. The addition of a variable, parental role construction, was also a significant predictor in that study of maternal intentions to feed their children a healthy diet (Spinks \& Hamilton, 2016). When considering other heath behaviors, it was found the addition of the parental role construction variable to the TPB constructs strengthened the theory's ability to explain the variance in parental decisions to limit child screen time (Hamilton, Spinks, White, Kavanagh, \& Walsh, 2016) and to use sun-protective behaviors (Thomson, White, \& Hamilton, 2012).

Parental role construction has been shown to be influential in a wide variety of topics for parental decision-making regarding their children's health behaviors (Hamilton et al., 2016; Keech, Hatzis, Kavanagh, White, \& Hamilton, 2018; Spinks \& Hamilton, 2016; Thomson et al., 2012). If a parent believes that their role is active and important in the promotion of health behaviors for their children then they are more likely to partake in the protective behaviors (Hamilton, Kirkpatrick, Rebar, White, \& Haggar, 2017; Ice, Neal, \& Cottrell, 2014; Thomson et al, 2012).

This construct was added to the study because of findings from focus groups in the initial stage of research that demonstrated how seriously mothers see the job of feeding their child as a central tenant of maternal responsibility. The mothers described a 
deep level of commitment and strong emotions when talking about their role in regard to feeding their child. The consensus was that feeding a toddler a nutritious diet was a central duty of mothering and if they did not meet this requirement then they had failed in one of their basic maternal roles (Combs et al., 2019). It is important to study the impact of role construction on mothers' decision-making because these roles seem to be associated with health behaviors.

The first aim of the current study was to use the TPB to assess factors affecting a mother's behavioral intentions to provide their toddlers with a healthy diet. The second aim of the current study was to see if the addition of the parental role construction variable strengthened the TPB's ability to significantly predict the mother's behavioral intention to provide their toddler with a healthy diet. Using the TPB and past research, it was hypothesized that attitude, subjective norm, perceived behavioral control, and parental role construction would predict a mother's intention to provide a healthy diet for her toddler.

\subsection{Methods}

\subsubsection{Research Design and Participants}

This cross-sectional study targeted mothers of at least one child between the ages of 12-48 months. Males (fathers) were excluded, because it is supported in the literature that mothers are the dominant parent regarding food decisions and purchases in the home (Byrd-Bredbenner, Abbott, \& Cussler, 2008). All participants were over the age of 18 and spoke English. Additionally, the survey respondents were not limited to a particular geographical region because of the nature of the online survey. A sample of 148 mothers 
aged 18-47 years, with at least one child aged 1-3 years participated in the study. Table 5.1 presents demographic information for the participants.

\subsubsection{Procedures}

In an effort to recruit mothers from varied socioeconomic backgrounds, education levels, and geographic locations, the entry points for sampling were Lexington-Fayette County Health Departments, Central Kentucky Community Action Council sites, a Northern Kentucky Mother's Group, and ResearchMatch. The survey was distributed via these organizations' listservs and websites. The survey distribution process, which took place in May 2018, included initiating pre-survey contact with the initial entry points, distribution of the online survey link, follow-up contact to the group, and a final second survey request to the group. Specifically, an invitation email provided by the researcher was forwarded to potential participants from key personnel at each site that included a summary of the study and an anonymous link to the web survey. There was also a message at the end of the email requesting that the participants forward the survey link to others they know that fit the inclusion criteria.

The survey was administered through Qualtrics, an online survey management system. The survey could have been taken using a variety of digital tools, including computers, tablets, or cell phones. The survey took most participants 10-15 minutes to complete. Two qualifying questions were included at the beginning of the survey and if individuals did not meet the criteria, they were taken to the end of the survey and did not respond to additional survey items. As an incentive to participate, individuals were provided with the opportunity to enter a prize drawing to win 1 of $8 \$ 50$ gift cards by 
following a link provided at the end of the survey that took them to a separate form where they could enter in their contact information.

\subsubsection{Measures}

The survey for this study was developed using results from prior focus groups (Combs, Ickes, \& McMullen, 2019) and a previously validated survey (Spinks \& Hamilton, 2016) that fit the theoretical basis of this study. An initial phase of qualitative research was conducted that served as a backbone and provided individualized insight into the creation of the measure used for the quantitative research. The survey was pilot tested with a group of four mothers of toddlers before dissemination to check for face validity and to ensure that the survey had appropriate readability. The survey was also shared with two nutrition experts to ensure face and content validity.

\subsubsection{Theory of Planned Behavior Constructs.}

The survey measured behavioral intention of mothers to provide meals that include a wide variety of the five food groups in appropriate amounts to their toddlers as the dependent variable. Independent variables of the TPB constructs (attitude, subjective norms, and perceived behavioral control) were measured based on procedures outlined by Ajzen (2007). Finally, the additional construct of parental role construction was included and measured based on procedures of prior research (Spinks \& Hamilton, 2016).

The main outcome behavior of the tool was modified slightly from "ensure that my child eats a wide variety of foods from the five food groups according to the recommended serves" to "ensure that my child eats a wide variety of foods from the five food groups in appropriate amounts." This change was made based on focus group 
findings (Combs et al., 2019) and based on the fact that the United States Dietary Guidelines do not have set serving size recommendations for children younger than 2 years of age.

The number of questions for each construct from the Theory of Planned Behavior varied. Each question was scored using a 7 point Likert-type scale on a "strongly disagree" to "strongly agree" or "bad" to "good" dimension. For each scaled question, higher scores indicated higher levels of agreement or more positive responses.

\subsection{ATTITUDE}

Four items comprised the attitude subscale. Participants ranked the specified behavior as being good/bad, favorable/unfavorable, desirable/undesirable, and beneficial/harmful. Participants evaluated each outcome on a 7-point scale from positive (7) to negative (1) with a possible range of $4-28$.

\subsection{SUBJECTIVE NORM}

Three questions comprised the subjective norm subscale. Participants responded to the following three questions: "Most people who are important to me would approve of me ensuring that my toddler eats a wide variety of foods from the five food groups in appropriate amounts EVERY DAY”; “The people in my life whose opinions I value would think that my ensuring my toddler eats a wide variety of foods from the five food groups in appropriate amounts EVERY DAY is desirable"; and "Those people who are important to me think that I should ensure my toddler eats a wide variety of foods from the five food groups in appropriate amounts EVERY DAY'. Participants evaluated each outcome on a 7-point scale from strongly agree (7) to strongly disagree (1) with a possible range of $3-21$. 


\subsection{PERCEIVED BEHAVIORAL CONTROL}

Two questions comprised the perceived behavioral control subscale, which included: "It is mostly up to me whether I ensure that my toddler eats a wide variety of foods from the five food groups in appropriate amounts EVERY DAY" and "I am confident that I will ensure that my toddler eats a wide variety of foods from the five food groups in appropriate amounts EVERY DAY". Participants evaluated each outcome on a 7-point scale from strongly agree (7) to strongly disagree (1) with a possible range of 2 14.

\subsection{BEHAVIORAL INTENTION}

Three questions comprised the behavioral intention subscale. These questions included: "I intend to ensure that my toddler eats a wide variety of foods from the five food groups in appropriate amounts EVERY DAY"; "I plan to ensure that my toddler eats a wide variety of foods from the five food groups in appropriate amounts EVERY DAY"; and "I expect that I will ensure that my toddler eats a wide variety of foods from the five food groups in appropriate amounts EVERY DAY". Participants evaluated each outcome on a 7-point scale from strongly agree (7) to strongly disagree (1) with a possible range of $3-21$.

\subsection{PARENTAL ROLE CONSTRUCTION}

Three questions comprised the parental role construction subscale, which included: "I believe it is my responsibility as a parent to make sure that my child eats a wide variety of foods from the five food groups in appropriate amounts EVERY DAY in the next week"; "It is an important part of my role as a parent to make sure that my child 
eats a wide variety of foods from the five food groups in appropriate amounts EVERY DAY in the next week"; and "As a parent, it is my job to make sure that my child eats a wide variety of foods from the five food groups in appropriate amounts EVERY DAY in the next week". Participants evaluated each outcome on a 7-point scale from strongly agree (7) to strongly disagree (1) with a possible range of $3-21$.

\subsubsection{Demographics.}

A section of demographic questions was included to garner important information about the participants completing the survey. Information gathered included: maternal age, maternal education (high school diploma/GED, associate's degree, bachelor's degree, graduate/professional degree, or other), maternal employment (full-time, parttime, stay-at-home mom, student, or other), maternal relationship status (single (never married), married, divorced/separated, or other), household income, maternal race (American Indian/Alaska Native, Asian, Black/African American, Native Hawaiian/Pacific Islander, White, or other), current WIC participation (yes, no, or prefer not to answer), current SNAP participation (yes, no or prefer not to answer), maternal weight/height, child's weight/height, child's age, child's gender, and total number of children in the household.

\subsubsection{Statistical Analysis}

Descriptive statistics were used to identify the demographic data of the sample population. Internal consistency reliability of the measure was assessed using Cronbach's alpha. The determinants of intention per the TPB were explored using descriptive statistics and multiple linear regression. Initial analyses were completed to check that the assumptions of multiple linear regression were met. The VIF values were 
above 0.1 and the Tolerance values were well below 10, the Durbin-Watson statistic was within an acceptable range, and the scatterplot of standardized residual on standardized predicted value was acceptable. The software package used for these analyses was IBM SPSS Statistics for Windows, Version 24.0. For statistical testing, the significance level was set to 0.05 .

\subsection{Results}

\subsubsection{Participant Characteristics}

The final sample consisted of 148 mothers that completed the survey. The mean age of the sample was $32.83(S D=6.16)$ years (range $21-53$ years). The majority of participants were married (87.2\%), had earned a college degree or higher (79.7\%), held part-time or fulltime employment, $(60.8 \%)$, and were White $(90.3 \%)$. When rating their own toddler's diet, $86 \%$ of mothers rated it as good, very good, or excellent .When rating their current nutrition knowledge, $88 \%$ of mothers rated it as good, very good, or excellent. Demographic information for the sample can be found in Table 5.1.

\subsubsection{Questionnaire Reliability}

The measures of attitude, subjective norm, perceived behavioral control, parental role construction, and behavioral intention demonstrated acceptable levels of internal consistency reliability, with $\alpha$ coefficients of $0.885,0.838,0.501,0.949$, and 0.870 respectively. 


\subsubsection{Theory of Planned Behavior Constructs}

The survey measured constructs of the TPB and the additional construct of parental role construction. Table 5.2 lists the means and standard deviations of the subscales for each construct. Additionally, the questions used to create each subscale, along with the corresponding means and standard deviations are listed. Based on scaled scores, the mothers in the study reported moderately high levels of behavioral intention (5.82), subjective norms (5.88), and perceived behavioral control (5.56). Mothers reported very high levels of positive attitudes (6.68) and very high levels of parental role construction (6.35).

Bivariate correlations show that all four constructs were significantly correlated with intention. Parental role construction was the strongest correlate of maternal intention. Table 5.3 provides the bivariate correlations among TPB variables.

\subsubsection{Multivariate Linear Regression}

Table 5.4 lists the results of the multiple regression for mothers' behavioral intentions to feed their toddler a balanced diet. The initial predictors for model 1 were three constructs of the TPB and the criterion variable was the mother's intention to feed her toddler a balanced diet. The analysis indicated that the overall model was significant, $\mathrm{F}(3,152)=42.22, \mathrm{p}<.01$. The sample multiple correlation coefficient was .74 and adjusted R2 of the analysis was .53 indicating that approximately $53 \%$ of the variance of the mother's intention in the sample can be accounted for by the linear combination of the three constructs of the TPB. In this initial analysis, attitude toward the behavior $(B=.20$, $\mathrm{p}<.01)$, subjective norm $(\mathrm{B}=.20, \mathrm{p}<.01)$, and perceived behavioral control $(\mathrm{B}=.55, \mathrm{p}$ 
$<.01)$ were statistically significant predictors of maternal intention to feed their toddler a balanced diet.

After considering the TPB variables alone, the variable of parental role construction was added to the second model to see if addition strengthened the TPB's ability to significantly predict the mother's behavioral intention. The analysis indicated that the model with the addition of the parental role construction construct was significant, $\mathrm{F}(3,128)=40.96, \mathrm{p}<.01$. The sample multiple correlation coefficient was .78 and adjusted R2 of the analysis was .59 indicating that approximately $59 \%$ of the variance of the mother's intention in the sample can be accounted for by the linear combination of the three constructs of the TPB with the addition of the PRC variable. In this analysis, attitude toward the behavior $(\mathrm{B}=.14, \mathrm{p}<.05)$, perceived behavioral control $(\mathrm{B}=.38, \mathrm{p}<.01)$, and parental role construction $(\mathrm{B}=.35, \mathrm{p}<.01)$ were statistically significant predictors of maternal intention to feed their toddler a balanced diet. Table 5.4 provides the results of the hierarchical multiple regression for maternal behavioral intention.

\subsection{Discussion}

The current study was original in using an extended version of the TPB to understand maternal feeding behavior for toddlers. The results of this study support the use of the theory in identifying predictors of maternal decision making for feeding their toddlers nutritionally balanced meals. The TPB model predicted $53 \%$ of the variance in mother's behavioral intention surrounding the toddler feeding behavior of providing meals that include a wide variety of the five food groups in appropriate amounts. 
Furthermore, the second model added the variable of parental role construction to see if it strengthened the TPB's ability to significantly predict the mother's behavioral intention. The addition of the parental role construction variable added $6 \%$ more predictive power to the second model.

This study suggests that the TPB is an appropriate fit for working with mothers of young children and health behaviors, which has also been supported in past research (Spinks \& Hamilton, 2016; Andrews, Silk, \& Eneli, 2010, Swanson et al., 2011). In line with the theory, attitude, subjective norm, and perceived behavioral control predicted mothers' behavioral intentions in the initial model. However, when the extended model was tested, parental role construction, attitude, and perceived behavioral control were significant predictors of mothers' behavioral intentions. These findings help identify variables that could be targeted in future interventions and health campaigns directed at mothers of young children.

\subsubsection{Attitudes}

Mothers in this study had very positive attitudes towards the healthy eating behavior of providing their toddler with meals that include a wide variety of the five food groups in appropriate amounts. This finding is consistent with past research that has shown that mothers have strong positive attitudes toward promoting healthy diets in their young children (Hamel \& Smith, 2013; Spinks \& Hamilton, 2015; Vichayanrat et al., 2018) and they feel like good nutrition is important (Duncanson et al., 2013). It appears that mothers have positive views of healthy eating and value the behavior, and while it is a significant predictor, it is not as strong of a predictor of behavioral intention as some of 
the other constructs. This could indicate that there are other factors that intervene between beliefs and actions.

\subsubsection{Subjective Norm}

Subjective norm was the weakest predictor of maternal behavioral intention in both models in the current study. In the context of this study, subjective norm was based on who was considered an important influencer to the mother and whose opinions the mother valued. This could have been healthcare providers, family members, or other friends with toddlers. It has been suggested that if parents believe that their child's feeding practices are better than others in their peer group then they may be less motivated to provide their own child with a healthy diet (Duncanson et al., 2013). In the current study, $86 \%$ of mothers rated their own toddler's diet as good, very good, or excellent. Therefore, the mothers in the sample might believe that their toddler's diet is better than others and they might not be impacted by others' opinions.

This finding does contradict past research that found that when a parent is making a health decision for a child then perceived social pressures can be a strong predictor in parental decision making (Hamilton et al., 2012, 2013). However, mothers of toddlers have stated that they often rely on their "motherly instinct" rather than on family members' opinions, healthcare provider recommendations, or national guidelines (Combs et al., 2019), which might help explain why the impact of those outside referents were the weakest predictor in the current study. 


\subsubsection{Perceived Behavioral Control}

The variable of PBC was measured by looking at the mother's confidence level in her ability to control her toddler's nutrition. Mothers in the current study reported moderate perceived behavioral control in regard to providing their toddlers with meals that include a wide variety of the five food groups in appropriate amounts. Mothers of young children report low control over their children's diets due to outside factors that can impact their child's intake, such as daycares or grandparents (Combs et al., 2019). Additional reported extrinsic factors include food advertising and other children (Duncanson et al., 2013) and limited time and toddler acceptance (Vichayanrat et al., 2018). When looking at mothers of older children, PBC was the strongest predictor of mothers encouraging a healthy diet (Hamel \& Smith, 2013), which was also supported in this study as it was the strongest predictor in both models. Therefore, future health promotion efforts could benefit from approaches that could help build a mother's confidence in her ability to provide a nutritious diet for her toddler.

Going against the theoretical principles of the TPB, one past study showed that the higher the maternal PBC, the lower a mother's intent is to encourage a healthy diet for their child (Hamel \& Smith, 2013). This was not supported in the current study considering that PBC was the strongest predictor of maternal intention to feed their toddler balanced meals. Past research has shown that maternal control of the diet is higher in mothers of younger children (Campbell et al., 2010). This could be an area of future research since the mothers of young children in the current study already reported moderate levels of PBC. 


\subsubsection{Parental Role Construction}

Feeding competence is paramount to the parental role (Duncanson et al., 2013). It is integral to a mother's role to feed their child a healthy diet, give them the opportunity to try new foods, be a positive role model for healthy eating behaviors, and monitor food intake (Combs et al., 2019; Duncanson et al., 2013). The importance of role construction as an influencer in maternal decision making was supported in this study, as the addition of the variable strengthened the overall predictive ability of the TPB. It also had the highest positive correlation with the mothers' behavioral intent. Parental role construction can have a positive effect on maternal decision making.

This finding is consistent with other recent studies that support the idea that parental role construction has an impact on a variety of health behaviors for children, such as healthy eating (Ice, Neal, \& Cottrell, 2014), restriction of screen time (Hamilton, Spinks, White, Kavanagh, \& Walsh, 2016), and sun-protective behaviors (Hamilton, Cleary, White, \& Hawkes, 2015; Thomson, White, \& Hamilton, 2012). It is important to note that parental role construction is an internal belief that a mother holds about their maternal responsibilities. It is interesting that this internal belief was a stronger predictor than the external pressures measured from the subjective norm construct. Mothers placed more value in the internal expectations they set for themselves rather than the external expectations that others might place on the mother. It appears that exploring and encouraging this positive parental role that mothers have created for themselves surrounding healthy eating behaviors could be an effective approach for future health campaigns. 


\subsubsection{Limitations}

Research is limited on what guides maternal decision making surrounding toddler feeding behavior. The current study serves as an initial step, using a theoretical basis, to better understand what predictors influence maternal intention to feed toddlers nutritionally balanced meals. While this first step is important to help fill a gap in the literature, several limitations are also present. One such limitation is the fact that the majority of participants were white, married, and highly educated. This could have been due to the sampling methods used. This homogenous sample might not provide data that is transferable to different groups of mothers.

Additionally, the dependent variable in the study was the mother's self-reported behavioral intention rather than her actual behavior. The testing of the TPB would be strengthened if the actual maternal behavior of feeding her toddler balanced meals was measured in addition to the behavioral intention. Finally, the survey used could be strengthened through further measure development and testing with various populations.

\subsection{Implications for Research and Practice}

The current study provides several unique contributions to the nutrition education and health promotion research. First, the study used the TPB to examine its predictive capability for maternal intention to feed toddlers nutritionally balanced meals. To the authors' knowledge, no theoretically-based research studies have been conducted in the United States with this specific target audience. Second, this is the first study in the United States to use an extended version of the TPB with mothers of toddlers to see the

predictive power of the model is strengthened. Finally, this study focused on mothers of 
toddlers, which is a group of individuals that have not been studied extensively because of the lack of standardized dietary guidelines for this age group.

Future research needs to investigate this population more since this is a pivotal time in the establishment of the child's eating behaviors and could have a large impact on their long-term health outcomes. Future studies are needed with larger, more diverse samples. Additionally, since a mother's self-efficacy to provide a healthy diet declines during the first few years of a child's life (Campbell et al., 2010), it could be important to complete this study in mothers of older children to see if the TPB constructs still predict behavioral intention or changes over time. These findings could help inform health promotion programs on when to intervene and exactly which areas to focus on during the interventions to be most successful. It appears that health promotion efforts should aim to increase the mother's sense of behavioral control and parental responsibility rather than focusing on the benefits of healthy eating. Health promotion programs could be more successful if they provide tangible ways to help overcome perceived barriers and, in turn, increase a mother's belief in her own ability to provide her young child with a balanced diet. 
Table 5.1 Demographics

\begin{tabular}{ll}
\hline Age & $\mathrm{n}(\%)$ \\
\hline$<30 \mathrm{y}$ & $29(19)$ \\
$31-39 \mathrm{y}$ & $114(74)$ \\
$>40 \mathrm{y}$ & $10(7)$ \\
\hline
\end{tabular}

Education Level n (\%)
n

\begin{tabular}{ll}
\hline High school diploma or GED & 20 (13)
\end{tabular}

Associate degree

$16(11)$

Bachelor's degree $\quad 56(38)$

Graduate degree $\quad 56(38)$

\begin{tabular}{ll}
\hline Employment Status & n $(\%)$
\end{tabular}

Working (full-time) 74 (50)

Working (part-time) 21 (14)

Stay-at-home mom 49 (33)

Student 4 (3)

$\begin{array}{ll}\text { Ethnicity } & \mathrm{n}(\%)\end{array}$

Hispanic, Latino, or Spanish Origin 4 (3)

Not of Hispanic, Latino, or Spanish 143 (97)

Origin 
Table 5.1 (continued)

\begin{tabular}{|c|c|}
\hline Race & $\mathrm{n}(\%)$ \\
\hline American Indian or Alaska Native & $1(0.68)$ \\
\hline Asian & $1(0.68)$ \\
\hline Black or African American & $5(3)$ \\
\hline White & $138(93)$ \\
\hline Other & $4(3)$ \\
\hline Number of Children & $\mathrm{n}(\%)$ \\
\hline 1 & $45(30)$ \\
\hline 2 & $68(46)$ \\
\hline 3 & $25(17)$ \\
\hline 4 & $10(7)$ \\
\hline Marital Status & $\mathrm{n}(\%)$ \\
\hline Single (never-married) & $9(6)$ \\
\hline Married & $129(87)$ \\
\hline Divorced or separated & $6(4)$ \\
\hline Other & $4(3)$ \\
\hline Currently Receive WIC & $\mathrm{n}(\%)$ \\
\hline
\end{tabular}


Table 5.1 (continued)

\begin{tabular}{|c|c|}
\hline Yes & $13(9)$ \\
\hline No & $134(91)$ \\
\hline Currently Receive SNAP & $\mathrm{n}(\%)$ \\
\hline Yes & $5(3)$ \\
\hline No & 143(96) \\
\hline Current Nutrition Knowledge Rating & $\mathrm{n}(\%)$ \\
\hline Poor & 1(1) \\
\hline Fair & $18(11)$ \\
\hline Good & $60(38)$ \\
\hline Very Good & $56(36)$ \\
\hline Excellent & $21(14)$ \\
\hline Current Toddler Nutrition Rating & $\mathrm{n}(\%)$ \\
\hline Poor & $5(3)$ \\
\hline Fair & $17(11)$ \\
\hline Good & $57(37)$ \\
\hline Very Good & $66(42)$ \\
\hline Excellent & $11(7)$ \\
\hline
\end{tabular}


Table 5.2 Means and standard deviations of TPB Constructs

\begin{tabular}{|c|c|c|}
\hline $\begin{array}{c}\text { TPB } \\
\text { Construct }\end{array}$ & Measurement & Mean (SD) \\
\hline \multirow[t]{4}{*}{$\begin{array}{l}\text { Behavioral } \\
\text { Intention }\end{array}$} & $\begin{array}{l}\text { Participants evaluate each outcome on a 7-point scale } \\
\text { from strongly agree (7) to strongly disagree (1) for } \\
\text { three questions with a possible total of } 21 \text { points. }\end{array}$ & $17.48(3.07)$ \\
\hline & $\begin{array}{l}\text { I intend to make sure that my toddler eats a wide } \\
\text { variety of foods from the five food groups in } \\
\text { appropriate amounts EVERY DAY. }\end{array}$ & $5.89(1.18)$ \\
\hline & $\begin{array}{l}\text { I plan to make sure that my toddler eats a wide } \\
\text { variety of foods from the five food groups in } \\
\text { appropriate amounts EVERY DAY. }\end{array}$ & $5.95(1.09)$ \\
\hline & $\begin{array}{l}\text { I expect that I will make sure that my toddler eats a } \\
\text { wide variety of foods from the five food groups in } \\
\text { appropriate amounts EVERY DAY. }\end{array}$ & $5.73(1.14)$ \\
\hline \multirow[t]{5}{*}{ Attitude } & $\begin{array}{l}\text { Participants evaluate each outcome on a } 7 \text {-point } \\
\text { scale from positive ( } 7 \text { ) to negative (1) for four } \\
\text { questions with a possible total of } 28 \text { points. }\end{array}$ & $26.70(2.96)$ \\
\hline & $\begin{array}{l}\text { For me to make sure that my toddler eats a wide } \\
\text { variety of foods from the five food groups in } \\
\text { appropriate amounts every day in the next week } \\
\text { would be"... Bad (1) vs. Good (7) }\end{array}$ & $6.57(1.44)$ \\
\hline & $\begin{array}{l}\text { For me to make sure that my toddler eats a wide } \\
\text { variety of foods from the five food groups in } \\
\text { appropriate amounts every day in the next week } \\
\text { would be"... Unfavorable (1) vs. Favorable ( } 7 \text { ) }\end{array}$ & $6.60(1.42)$ \\
\hline & $\begin{array}{l}\text { For me to make sure that my toddler eats a wide } \\
\text { variety of foods from the five food groups in } \\
\text { appropriate amounts every day in the next week } \\
\text { would be"... Undesirable (1) vs. Desirable (7) }\end{array}$ & $6.64(1.41)$ \\
\hline & $\begin{array}{l}\text { For me to make sure that my toddler eats a wide } \\
\text { variety of foods from the five food groups in } \\
\text { appropriate amounts every day in the next week } \\
\text { would be"... Harmful (1) vs. Beneficial ( } 7 \text { ) }\end{array}$ & $6.79(0.56)$ \\
\hline
\end{tabular}


Table 5.2 (continued)

Subjective

Norm
Participants evaluate each outcome on a 7-point scale from strongly agree (7) to strongly disagree (1) for three questions with a possible total of 21 points for this portion.

Most people who are important to me would approve of me making sure that my toddler eats a wide variety of foods from the five food groups in appropriate amounts EVERY DAY.

The people in my life whose opinions I value would think that my making sure my toddler eats a wide variety of foods from the five food groups in appropriate amounts EVERY DAY is desirable.

Those people who are important to me think that I should make sure my toddler eats a wide variety of foods from the five food groups in appropriate amounts EVERY DAY.

Perceived Participants evaluate each outcome on a 7-point scale behavioral from strongly agree (7) to strongly disagree (1) for control two questions with a possible total of 14 points.

It is mostly up to me whether I make sure that my toddler eats a wide variety of foods from the five food groups in appropriate amounts EVERY DAY.

I am confident that I will make sure that my toddler eats a wide variety of foods from the five food groups in appropriate amounts EVERY DAY.

Parental Role Participants evaluate each outcome on a 7-point scale Construction from strongly agree (7) to strongly disagree (1) for three questions with a possible total of 21 points.
$17.65(3.25)$

$19.05(2.61)$ 
Table 5.2 (continued)

I believe it is my responsibility as a parent to make

sure that my child eats a wide variety of foods from

the five food groups in appropriate amounts EVERY

DAY in the next week.

It is an important part of my role as a parent to make sure that my child eats a wide variety of foods from the five food groups in appropriate amounts EVERY DAY in the next week.

As a parent, it is my job to make sure that my child eats a wide variety of foods from the five food groups in appropriate amounts EVERY DAY in the next week. 
Table 5.3 Bivariate Correlations among Variables

\begin{tabular}{lccccc}
\hline Variable & Intention & Attitude & $\begin{array}{c}\text { Subjective } \\
\text { Norm }\end{array}$ & PBC & PRC \\
\hline Intention & & $.382^{* *}$ & $.479 * *$ & $.672^{* *}$. & $687^{* *}$ \\
Attitude & $.382^{* *}$ & & $.198^{*}$ & $.353^{* *}$ & $.303^{* *}$ \\
Subjective & $.479 * *$ & $.198^{*}$ & & $.520^{* *}$ & $.461^{* *}$ \\
Norm & & & & & $.680^{* *}$ \\
PBC & $.672^{* *}$ & $.303^{* *}$ & $.461^{* *}$ & & \\
PRC & $.687^{* *}$ & $.353^{* *}$ & $.520^{* *}$ & $.680^{* *}$ & \\
\hline
\end{tabular}

**Correlation is significant at the 0.01 level (2-tailed).

* Correlation is significant at the 0.05 level (2-tailed). 
Table 5.4 Summary of Regression Analysis for Variables Predicting Mothers' Intentions to Feed Their Toddler a Balanced Diet $(\mathrm{N}=148)$

Model $1 \quad$ Model 2

Variable

\begin{tabular}{llllll}
\hline$B$ & $S E B$ & $\beta$ & $B$ & $S E B$ & $\beta$
\end{tabular}

Attitude

0.21

0.07

$.20 * *$

0.15

0.07

$.14^{*}$

Subjective Norm

0.18

0.06

$.20 * *$

0.11

0.06

.12

Perceived

0.68

0.08

$.55 * *$

0.46

0.10

$.38 * *$

Behavioral Control

Parental Role

0.41

0.10

$.35 * *$

Construction

$R^{2}$

.53

.59

$F$ for change in $R^{2}$

$42.22 * *$

$40.96 * *$

$* p<.05 * * p<.01$. 


\section{CHAPTER 6. CONCLUSIONS AND RECOMMENDATIONS}

The purpose of the study was to gain a better understanding of what factors impact maternal feeding decisions regarding toddler nutrition behaviors. This was a two-

phased mixed methods study. The aim of the initial qualitative study was to explore, using a Theory of Planned Behavior (TPB) framework, the influences on mothers' toddler feeding decisions. These influences included attitude, subjective norms, and perceived behavioral control. These constructs were derived from discussions about what sources of nutrition information mothers use and what sources of nutrition information mothers trust. The aim of the subsequent quantitative study was to use the TPB to assess factors affecting a mother's behavioral intentions to provide their toddler with a healthy diet and to see if the addition of the parental role construction variable strengthened the TPB's ability to significantly predict the mother's behavioral intention to provide their toddler with a healthy diet.

\subsection{Summary of Results}

The first study used a qualitative approach to gather data from three focus groups that consisted of mothers of toddlers, which included 15 participants in total. Qualitative thematic analysis was used to define prominent themes discovered through the focus group findings. Four major themes emerged from the data analysis: (1) attitudes (subthemes: positive towards maternal role of feeding and negative towards the maternal role of feeding); (2) subjective norms positively accepted (subthemes: social media, pediatricians, and registered dietitians); (3) subjective norms negatively accepted 
(subthemes: pediatricians and registered dietitians); (4) perceived behavioral control (subthemes: acceptance, scarcity of time and outside influences).

Mothers predominantly expressed positive attitudes towards their maternal roles in feeding of providing wholesome options to their toddlers and they sought to encourage a healthy diet. Additionally, they valued nutrition and were confident in their nutritional knowledge. However, while mothers had overall positive attitudes towards the concept of nutrition, they also had strong negative attitudes about the actual act of feeding their children. These emotions included stress, guilt, responsibility, and purpose. Their perceived behavioral control was also impacted by pressure to provide nutritious meals and an enjoyable eating environment. These feelings run deep and appear to be engrained in their roles as mothers.

Mothers in the current study saw feeding their children as an innate responsibility of mothering and that if they failed in that regard then they failed as a mother. These findings were consistent with previous research where parents felt like feeding competence was paramount in the parental role and could predict healthy eating behavioral intentions of mothers (Duncanson et al., 2013; Spinks \& Hamilton, 2015). This feeling of responsibility could be effectively used in future health promotion campaigns.

Mothers looked to varying sources to find guidance on nutrition and felt positive and negative influences on their decision making from these varying sources. Their subjective norms were impacted by the perceived social pressures they felt to feed their children nutritious diets from both formal and informal sources. Many conducted their own research using websites or by asking friends. Participants consistently cited social 
media websites as being credible sources (depending on who posted the item) and used varying websites such as blogs and kid-friendly recipe sites.

Pediatricians were a primary source of nutrition information for mothers in this study, which is consistent with previous findings (Chezem, Friesen, \& Clark, 2001; Bianco, Zucco, Nobile, Pileggi, \& Pavia, 2013). When pediatricians did give advice, most mothers appeared to have skepticism and were not willing to follow the advice completely. Additionally, while mothers were mostly pleased with their pediatricians and trusted their guidance, they did not feel like the pediatrician was well educated on nutrition topics. In comparison to the findings about the pediatrician, most mothers saw the registered dietitian (RD) as the nutrition expert. However, mothers unanimously agreed that they would be offended if their toddler was referred to a RD. Several stated that this would mean that they failed at one of their most basic responsibilities as a mother, which was to care and provide for their child. It appears that the normative expectation surrounding seeing a specialist (like a RD) has very negative connotations and is not seen as an opportunity to improve knowledge or skills.

Mothers' perceived behavioral control was impacted by pressure to provide nutritious meals and an enjoyable eating environment all within the constraints of daily pressures. Participants felt limited by their toddlers' pickiness and the lack of time they had to prepare meals. Several also mentioned that healthy food costs more money and that their toddlers did not typically like healthier options, so this meant that they wasted the more expensive food. This is consistent with previous research that found that parents' barriers to providing healthy diets often included time and financial pressures 
(Kahlor et al., 2011; White et al., 2011). These concerns added to the level of stress and guilt that the mothers felt surrounding the act of toddler feeding.

Formative research on beliefs is necessary to gain a deeper understanding of behaviors. Beliefs are important to explore since they can be used to create effective health messages that address concerns and feelings that surround the behavior. The first stage of research provided a better understanding of factors that influence mothers' decisions surrounding toddler feeding. An online survey was created using data gathered from the exploratory focus groups and a previously validated survey (Spinks \& Hamilton, 2016) that fit the theoretical basis of this study and provided more meaningful output on which to complete data analysis. The survey utilized the TPB to assess the connections between the constructs and the mothers' behavioral intentions surrounding toddler feeding. Additionally, because of the finding from the initial stage of research that mothers hold deep feelings about feeding that appear to be engrained in their roles as mothers, the social factor of parental role construction was also included in the survey to see if the addition of the variable strengthened the TPB's ability to predict maternal intention.

The final sample consisted of 148 mothers that completed the survey. The mean age of the sample was $32.83(S D=6.16)$ years. The majority of participants were married (87.2\%), had earned a college degree or higher $(79.7 \%)$, held part-time or fulltime employment, $(60.8 \%)$, and were White $(90.3 \%)$. The survey measured constructs of the TPB and the additional construct of parental role construction. Bivariate correlations showed that all four constructs were significantly correlated with intention 
and each other. Parental role construction was the strongest correlate of maternal intention.

The TPB model predicted $53 \%$ of the variance in mother's behavioral intention surrounding the toddler feeding behavior of providing meals that include a wide variety of the five food groups in appropriate amounts. In this initial analysis, attitude toward the behavior, subjective norm, and perceived behavioral control were statistically significant predictors of maternal intention to feed their toddler a balanced diet. Of these variables, perceived behavioral control was the most salient predictor.

After considering the TPB variables alone, the variable of parental role construction was added to the second model to see if the addition strengthened the ability to significantly predict the mother's behavioral intention. The analysis indicated that the second model with the addition of the parental role construction construct was significant and the model predicted $59 \%$ of the variance of the mother's intention. Therefore, the addition of the parental role construction variable added $6 \%$ more predictive power to the model. In this analysis, attitude toward the behavior, perceived behavioral control, and parental role construction were statistically significant predictors of maternal intention to feed their toddler a balanced diet. Of these variables, perceived behavioral control was again the most salient predictor.

Research is limited on what guides maternal decision making surrounding toddler feeding behavior. The current study serves as an initial step, using a theoretical basis, to better understand what influences maternal intention to feed toddlers nutritionally balanced meals. Results support the TPB as a prominent decision making model for mothers' feeding decisions for their toddlers. While attitude and perceived behavioral 
control were significant predictors of maternal behavioral intention, subjective norm was not a significant predictor. Mothers in the study received nutrition information from a variety of sources, most notably the pediatrician and social media. However, it appears that the expectations set forth by these external sources did not directly impact a mother's behavioral intention, which is important to note since internal expectations did directly impact a mother's behavioral intention. The maternal role reflects an internal, personal responsibility for behaviors in regard to caring for children. Parental role construction has been shown to positively impact maternal decision-making surrounding the act of toddler feeding and is strongly correlated with maternal intention to feed a toddler a wellbalanced diet. By extending the TPB model to include parental role construction, it can provide better insight into maternal decision making for toddler nutrition.

\subsection{Strengths}

The current study provides data to help fill a gap in the literature surrounding the influences on maternal decisions for toddler feeding. One major strength includes using a theoretical framework to shape the entire study. By utilizing the TPB, the current study provides a better understanding of how this theory can be effectively applied to maternal feeding behavior topics. The results demonstrate that this theory can be used to create future health promotion programs that can have an impact on the mothers' behavioral intentions.

Additionally, by collecting data from mothers of toddlers, the current study provides valuable insight into this window of time during the toddlers' transitional diet period. This is a pivotal time in the development of eating behaviors, so the results from 
this study shed light on how to most effectively support mothers' decisions, which could have a large impact on the long-term nutrition behaviors of their children.

Finally, the current study used a mixed methods approach, which provided a deeper understanding of the topic at hand. The exploratory design was used to find out new knowledge about a topic where little was currently known. Qualitative design provided rich data that helped gain a deeper understanding of maternal perceptions and emotions, which can inform health professionals and future interventions. Additionally, findings from the qualitative approach can inform the development of future theoretically grounded measures. The findings from the quantitative portion of the study identified which constructs had the greatest impact on behavioral intentions, which can be used by future health educators to focus interventions on certain areas that would have the strongest influence on the target behavior. The integration of both qualitative and quantitative methods can provide more confidence in the results and the conclusions drawn from the study.

\subsection{Limitations}

Research is limited on what guides maternal decision making surrounding toddler feeding behavior. The current study serves as an initial step, using a theoretical basis, to better understand what predictors influence maternal intention to feed toddlers nutritionally balanced meals. While this first step is important to help fill a gap in the literature, several limitations are also present. Limitations for the current study include the fact that the findings from the research are not able to be extrapolated to a larger population because of the nonrandom sampling design, however they are acceptable for 
this research since it was exploratory. It is important to note that the initial qualitative study was limited by the collection of data from three sites, which consisted of a selfselected, homogenous sample that was highly educated, affluent, and had a high selfrating of nutrition knowledge. However, this type of design still provided sufficient information for the objectives because it aided in meeting the purpose of the research, which used a non-experimental, exploratory design.

A limitation specific to the qualitative study was the fact that the primary researcher was a registered dietitian and the participants were made aware of this distinction. Therefore, some of the results could have been different if the focus group facilitator was not a healthcare provider since some questions focused on the role of healthcare providers as sources of nutrition information. Even with these limitations, the study was able to generate rich, in-depth data to help guide the creation of a theoretically based measure for future research.

Furthermore, mothers that were interested in health and nutrition might have been more likely to participate in both stages of the research since sampling was not randomized. This interest could have influenced the knowledge and resources the mother uses in regard to nutrition information, which could impact the results. Access to a computer and the internet was required to complete the online survey, so this could have eliminated possible participants or certain groups resulting in non-response error. Because the survey was distributed via the internet, respondents might have been more likely to be comfortable using the internet and might be more likely to use it for their main source of information. 
Specific to the quantitative study, the dependent variable in the study was the mother's self-reported behavioral intention rather than her actual behavior. The testing of the TPB would be strengthened if the actual maternal behavior of feeding their toddler balanced meals was measured in addition to the behavioral intention. The measure used could be strengthened through further measure development and testing with various populations. Overall, this study used a mixed methods approach to fill an important gap in the literature to better understand the underlying behavioral beliefs related to maternal toddler feeding decisions through a theoretical lens.

\subsection{Implications for Researchers and Health Promotion Professionals}

The current study provides several unique contributions to the nutrition education and health promotion research. First, the study used the TPB to examine its predictive capability for maternal intention to feed toddlers nutritionally balanced meals. To the authors' knowledge, no theoretically-based research studies have been conducted in the United States with this specific target audience. Second, this is the first study in the United States to use an extended version of the TPB that included parental role construction with mothers of toddlers to see the predictive power of the model is strengthened. Finally, this study focuses on mothers of toddlers, which is a group of individuals that have not been studied extensively because of the lack of standardized dietary guidelines for this age group.

While a study of this size and nature cannot be generalized, there are several findings that could have an impact on practice. These findings suggest several unmet needs and provide information to develop and test effective strategies to better support 
mothers while they navigate making good decisions for feeding their toddlers. An area of possible intervention would be for reputable, professional organizations to capitalize on mothers' interest to use social media to find nutrition information. This could help improve mothers' attitudes towards the positive aspects of toddler feeding, influence the normative expectations surrounding toddler nutrition, and increase perceived behavioral control by providing realistic suggestions, tips, and skill building for managing the challenging toddler years. Since it appears that most mothers turn to social media on a regular basis, this could be a valuable avenue of reputable information dissemination for health professionals.

When considering main sources of nutrition information, it is clear that pediatricians should receive more training on effectively communicating about toddler nutrition so they can put more emphasis on providing age-specific nutrition advice during child well visits. Research should be conducted with these professionals to see where their education or skills could be strengthened. Another option would be for registered dietitians to work directly with and in the offices of pediatricians. This could help normalize the idea of seeing a dietitian by making it just another stop for a family during their healthcare visit. This would help alleviate mothers' concern about pediatricians not being educated on nutrition topics and would help solidify the importance of nutrition by having it be a consistent message from healthcare providers. It could also help break the stigma of being referred to a specialist and hopefully normalize the behavior of seeking out additional knowledge and skills surrounding toddler feeding. Health promotion professionals could also help lessen this stigma by regularly discussing the role of a registered dietitian with participants and by supporting mothers to actively seek out 
nutrition information from a variety of reputable sources. Working with a trained nutrition professional could also improve a mother's confidence and skills, which could, in turn, strengthen her view of her role as a good mother.

Future research needs to investigate this population more since this is a pivotal time in the establishment of the child's eating behaviors and could have a large impact on their long-term health outcomes. Future studies are needed with larger, more diverse samples. Beliefs identified in the current study could serve as the basis for the creation of theoretically-based interventions. Interventions should be developed for this particular audience that use the TPB to test its ability in changing maternal feeding behaviors. These interventions should focus on increasing mothers' perceived behavioral control over the act of toddler feeding and should also highlight the idea of parental role construction, which could add a novel approach to the health campaign and strengthen its impact.

Additionally, since a mother's self-efficacy to provide a healthy diet declines during the first few years of a child's life (Campbell, Hesketh, Silverii, \& Abbott, 2010), it could be important to complete this study in mothers of older children to see if the TPB constructs still predict behavioral intention or changes over time. More research is needed to better understand the direct impact that the TPB has on maternal feeding decisions as children age. Additional qualitative and quantitative studies could help further develop and refine existing measures. These future research endeavors could provide useful information, such as which behavioral beliefs to pinpoint at certain points in time. These data could also help shape the emphases of future health campaigns and the dissemination of sound nutrition information, which could hopefully increase the 
level of maternal perceived behavioral control and confidence regarding toddler feeding behaviors.

These findings could help inform health promotion programs on when to intervene and exactly which areas to focus on to be most successful. It appears that health promotion efforts should aim to increase the mother's sense of behavioral control and parental responsibility rather than focusing on the benefits of healthy eating. This feeling of responsibility could be effectively used in health promotion campaigns. Future approaches could capitalize on this motherly role and provide information and resources that validate what the mother is currently doing and build her confidence in these skills for the future.

\subsection{Conclusions}

Results support the TPB as a prominent decision making model for mothers' feeding decisions for their toddlers. As a whole, mothers positively and negatively receive and accept information from a variety of sources, they have many strong emotions associated with the act of feeding that are deeply rooted in their roles as mothers, and mothers' toddler feeding decisions were strongly influenced by the TPB constructs. It appears that health promotion efforts should aim to increase the mother's sense of behavioral control and parental responsibility rather than focusing on the benefits of healthy eating. Health promotion programs should provide tangible ways to help mothers overcome perceived barriers and, in turn, increase mothers' beliefs in their ability to provide toddlers with a balanced diet. This area has much promise for future research, most notably looking deeper at the importance of the mothers' constructed roles 
for themselves and gaining a better understanding of how health professionals can improve the delivery of sound nutrition information to mothers in a way that they prefer and trust to increase mothers' level of perceived behavioral control over the act of toddler feeding. 


\section{APPENDICES}

\section{Appendix A}

\section{Table A1}

Statistical Plans for Univariate Analysis

\begin{tabular}{|c|c|c|}
\hline $\begin{array}{l}\text { Study Question or } \\
\text { Considerations }\end{array}$ & $\underline{\text { Statistical Test }}$ & Exact Variables \\
\hline $\begin{array}{l}\text { Description of study } \\
\text { population }\end{array}$ & Frequencies & $\begin{array}{l}\text { - } \text { Level of maternal education } \\
\text { - Maternal employment status } \\
\text { - } \text { Maternal relationship status } \\
\text { - } \text { WIC participation (yes/no) } \\
\text { - SNAP participation (yes/no) } \\
\text { - Maternal knowledge of child's weight } \\
\text { - } \text { (yes/no) } \\
\text { - } \text { (yes/no) } \\
\text { - } \text { Mothild's weight status } \\
\text { - Mernal knowledge of child's height } \\
\text { - }\end{array}$ \\
\hline $\begin{array}{l}\text { Description of study } \\
\text { population }\end{array}$ & $\begin{array}{l}\text { Means/Standard } \\
\text { Deviation }\end{array}$ & $\begin{array}{l}\text { - Number of children } \\
\text { - Child's age } \\
\text { - Mother's age } \\
\text { - Child's weight } \\
\text { - Mild's height } \\
\text { - Mother's weight } \\
\text { Mother's height }\end{array}$ \\
\hline $\begin{array}{l}\text { Which person do mothers } \\
\text { reach out to the most? }\end{array}$ & $\begin{array}{l}\text { Frequencies } \\
\text { Mode }\end{array}$ & $\begin{array}{l}\text { - Person mothers reaches out to the } \\
\text { most }\end{array}$ \\
\hline $\begin{array}{l}\text { Which relative do mothers } \\
\text { reach out to the most? }\end{array}$ & $\begin{array}{l}\text { Frequencies } \\
\text { Mode }\end{array}$ & $\begin{array}{l}\text { - Relative mothers reaches out to the } \\
\text { most }\end{array}$ \\
\hline $\begin{array}{l}\text { Which relative do mothers } \\
\text { trust the most? }\end{array}$ & $\begin{array}{l}\text { Frequencies } \\
\text { Mode }\end{array}$ & - Relative mothers trusts the most \\
\hline $\begin{array}{l}\text { Which healthcare } \\
\text { professional do mothers } \\
\text { reach out to the most? }\end{array}$ & $\begin{array}{l}\text { Frequencies } \\
\text { Mode }\end{array}$ & $\begin{array}{l}\text { - Healthcare professional mothers } \\
\text { reaches out to the most }\end{array}$ \\
\hline $\begin{array}{l}\text { Which healthcare } \\
\text { professional do mothers trust } \\
\text { the most? }\end{array}$ & $\begin{array}{l}\text { Frequencies } \\
\text { Mode }\end{array}$ & $\begin{array}{l}\text { - Healthcare professional mothers } \\
\text { trusts the most }\end{array}$ \\
\hline $\begin{array}{l}\text { Which media sources do } \\
\text { mother's use? }\end{array}$ & $\begin{array}{l}\text { Frequencies } \\
\text { Mode }\end{array}$ & - Media sources mothers use \\
\hline $\begin{array}{l}\text { Which media source do } \\
\text { mothers trust the most? }\end{array}$ & $\begin{array}{l}\text { Frequencies } \\
\text { Mode }\end{array}$ & - Media source mothers trust the most \\
\hline
\end{tabular}




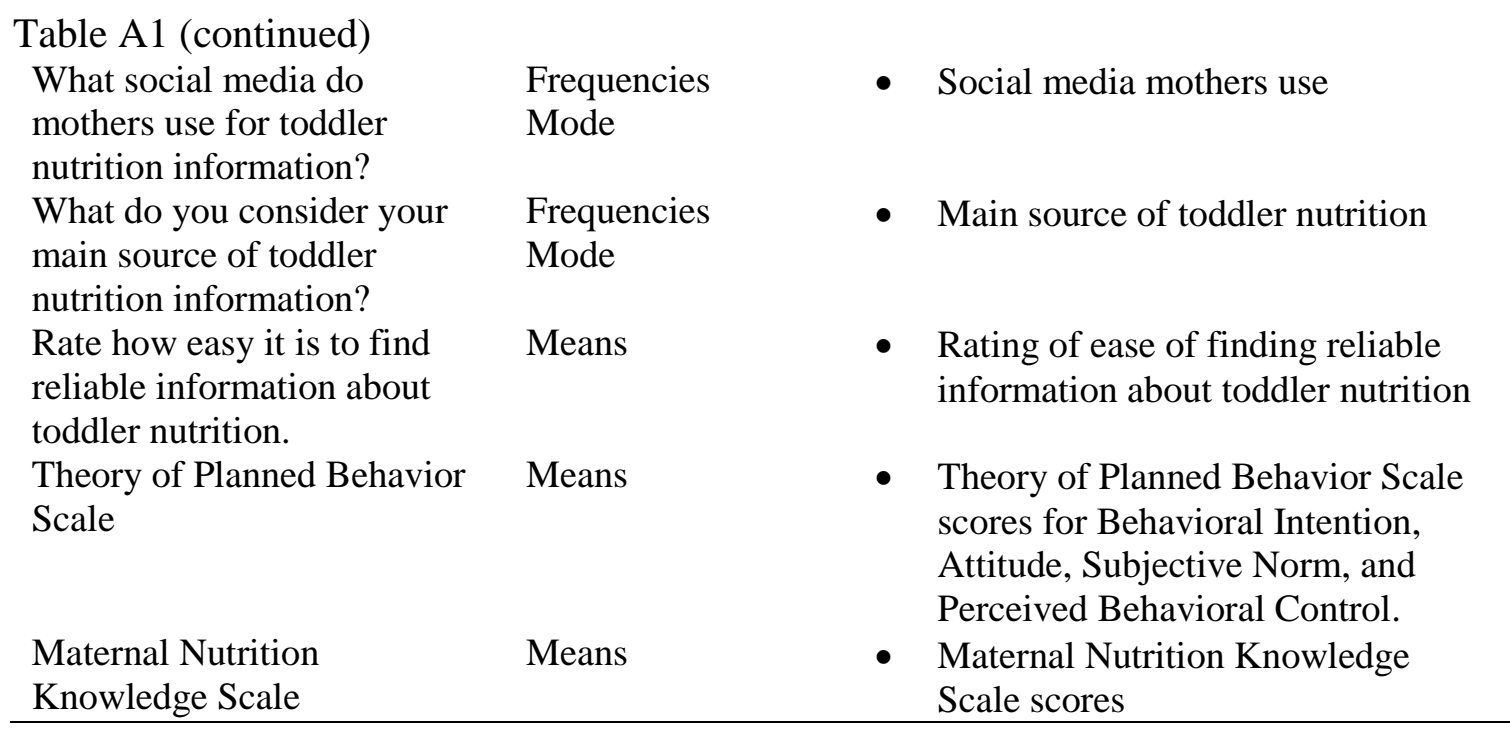


Statistical Plans for Multivariate Analysis

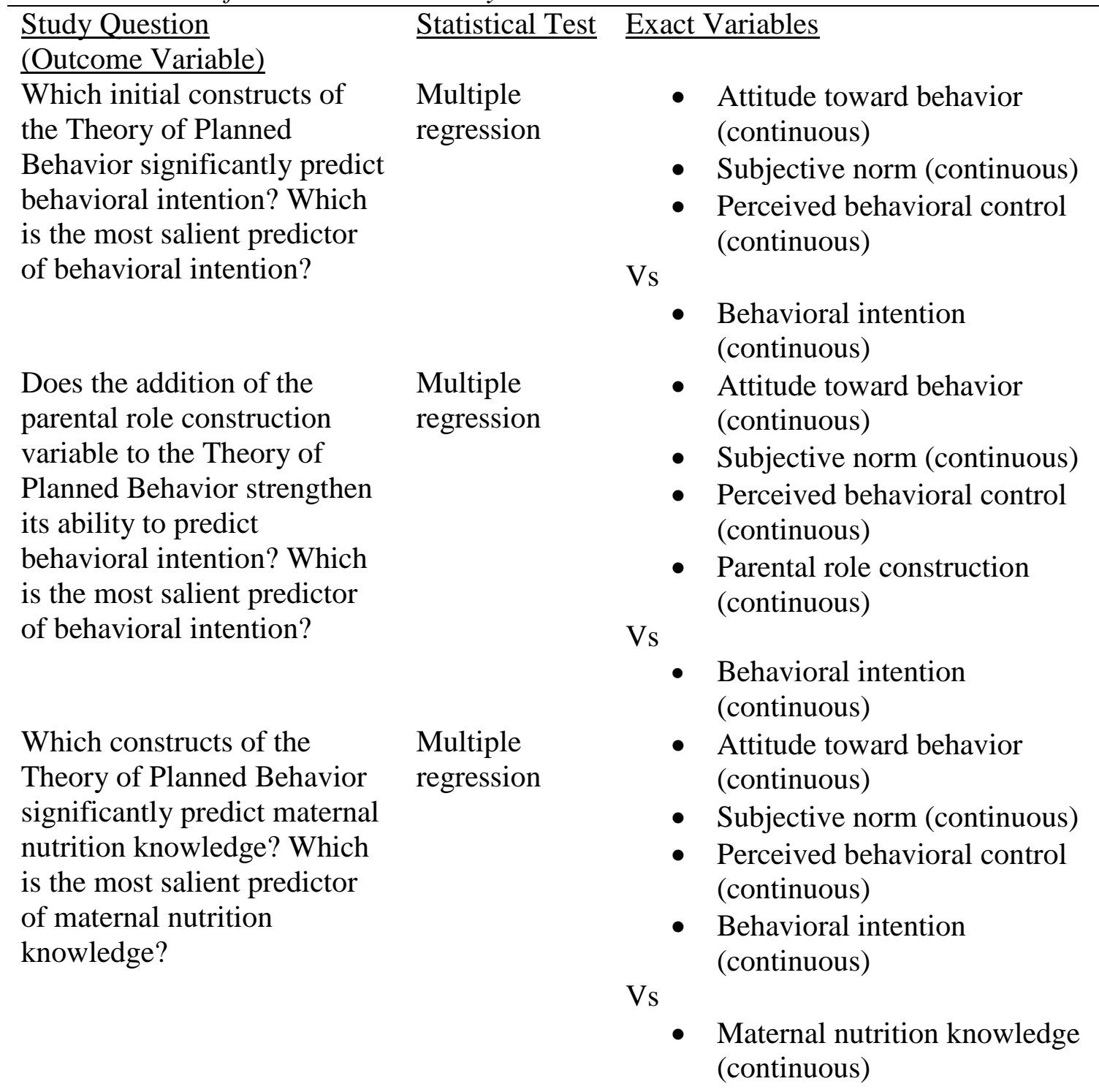




\section{Appendix B}

\section{Toddler Nutrition Survey}

\section{Introduction}

Q1 Thank you so much for taking the time to complete this survey. This survey is intended to find out what sources of toddler nutrition information you use and how those sources might impact feeding decisions. For this survey, a toddler is defined as a child between the ages of 1-3 years old. The information gathered through this survey could help develop more effective ways of delivering nutrition information to mothers in the future. All of the information that you provide is anonymous and confidential.

If you have any questions, suggestions, or concerns please contact Liz Combs at elmars2@uky.edu or 859-257-9209. Thank you!

Q2 Prior to commencing the survey please provide your responses to the following two questions. These questions will enable us to determine whether you are able to participate in the study. Inclusion criteria include being 18-years or older, being the mother of at least one child that is currently between the ages of 1-3 years of age, and able to read English.

Q3 Currently, are you 18 years or older?

Yes

No

\section{Skip To: End of Survey If Q3 = No}

Q4 Are you the mother of at least one child that is currently between the ages of 1-3 years?

Yes

No 


\section{Sources of Toddler Nutrition Information}

Q5 Do you reach to any of the following when you have a question about your toddler's diet?

\begin{tabular}{|c|c|c|}
\hline & Yes & No \\
\hline \multicolumn{3}{|l|}{ Doctors } \\
\hline \multicolumn{3}{|l|}{ Dentist } \\
\hline \multicolumn{3}{|l|}{ Nurses } \\
\hline \multicolumn{3}{|l|}{ Personal Trainer } \\
\hline \multicolumn{3}{|l|}{ Physician's Assistant } \\
\hline \multicolumn{3}{|c|}{ Registered Dietitians/Nutritionists } \\
\hline \multicolumn{3}{|l|}{ Coworkers } \\
\hline \multicolumn{3}{|l|}{ Daycare workers } \\
\hline \multicolumn{3}{|l|}{ Friends } \\
\hline \multicolumn{3}{|l|}{ Family/Relatives } \\
\hline Other: Please list below & & \\
\hline
\end{tabular}


Q6 Do you reach out to any of the following relatives when you have a question about your toddler's diet?

\begin{tabular}{l|c|}
\hline Husband or partner & Yes \\
Your mother & No \\
Your father & \\
Mother-in-law & \\
Father-in-law & \\
Sister & \\
Brother-in-law \\
Cousin \\
Sister-in-law
\end{tabular}


Q7 If you receive advice from your relatives regarding your toddler's diet, which individual's advice do you TRUST the most? Select one.

I do not receive advice from relatives regarding how to feed my toddler.

Husband or partner

Your mother

Your father

Mother-in-law

Father-in-law

Sister

Brother

Sister-in-law

Brother-in-law

Other: Please list 


\section{Healthcare Professional Sources of Toddler Nutrition Information}

Q8 If you receive advice from health care professionals about your toddler's diet, which individual's advice do you TRUST the most? Select one.

I do not receive advice from health care professionals regarding how to feed my toddler.

Dentist

Doctor

Nurse

Personal trainer

Physician's Assistant

Registered Dietitian/Nutritionist

Other: Please list

Skip To: $Q 10$ If Q8 = I do not receive advice from health care professionals regarding how to feed my toddler.

Q9 Please choose the answer that best describes your response towards the following statements. 
Rate your satisfaction with the toddler nutrition information you receive from the following health care professionals.

\begin{tabular}{|c|c|c|c|c|c|}
\hline & $\begin{array}{c}\text { Very } \\
\text { Dissatisfied }\end{array}$ & Dissatisfied & Satisfied & $\begin{array}{c}\text { Very } \\
\text { Satisfied }\end{array}$ & $\begin{array}{l}\text { I do not } \\
\text { receive } \\
\text { toddler } \\
\text { nutrition } \\
\text { information } \\
\text { from this } \\
\text { source. }\end{array}$ \\
\hline \multicolumn{6}{|l|}{ Dentist } \\
\hline \multicolumn{6}{|l|}{ Doctor } \\
\hline \multicolumn{6}{|l|}{ Nurse } \\
\hline \multicolumn{6}{|l|}{ Personal Trainer } \\
\hline Physician's Assistant & & & & & \\
\hline $\begin{array}{c}\text { Registered } \\
\text { Dietitian/Nutritionist }\end{array}$ & & & & & \\
\hline
\end{tabular}

Q10 Please choose the answer that best describes your agreement with the following statement:

"I wish that my health care providers talked to me more about toddler nutrition."

Strongly agree

Somewhat agree

Neither agree nor disagree

Somewhat disagree

Strongly disagree 
Q11 What topics regarding toddler nutrition do you wish your health care provider talked to you about? List as many as you like.

Topic 1

Topic 2

Topic 3

Topic 4

Topic 5

\section{End of Block}

\section{Media Sources of Toddler Nutrition Information}

Q12 Where do you look for toddler nutrition information? Select all that apply.

Books

Internet/Websites

Magazines

Newspapers

Radio

Television

Other: Please list

I do not look to the media for information regarding how to feed my toddler. 
Q13 Please choose the answer that best describes your response towards the following statements.

Rate your satisfaction with the toddler nutrition information you receive from the following sources.

\begin{tabular}{|c|c|c|c|c|c|}
\hline & $\begin{array}{c}\text { Very } \\
\text { Dissatisfied }\end{array}$ & Dissatisfied & Satisfied & $\begin{array}{c}\text { Very } \\
\text { Satisfied }\end{array}$ & $\begin{array}{l}\text { I do not } \\
\text { receive toddler } \\
\text { nutrition } \\
\text { information } \\
\text { from this } \\
\text { source. }\end{array}$ \\
\hline \multicolumn{6}{|l|}{ Books } \\
\hline \multicolumn{6}{|l|}{ Internet/Websites } \\
\hline \multicolumn{6}{|l|}{ Magazines } \\
\hline \multicolumn{6}{|l|}{ Newspapers } \\
\hline Radio & & & & & \\
\hline Television & & & & & \\
\hline
\end{tabular}


Q14 If you receive information from media sources about your toddler's diet, which source do you TRUST the most? Select one.

\section{Books}

Internet/Websites

Magazines

Newspapers

Radio programs

Television

\section{Block 5}

Display This Question:

If Where do you look for toddler nutrition information? Select all that apply. = Internet/Websites

Q15 Do you use any of the following social media websites to find out information on toddler nutrition?

\begin{tabular}{c|cc} 
& Yes & No \\
\hline Facebook & & \\
Pinterest & & \\
Twitter & & \\
Instagram & & \\
Other & & \\
& & \\
& &
\end{tabular}


Block 7

Q16 What would you consider your main source of toddler nutrition information? Select one.

Health Care Professionals

Family/Relatives

Friends

Books

Internet/Websites

Magazines

Newspapers

Radio

Television

Other

\section{Block 9}

Q17 The following set of questions ask about your attitude towards ensuring that your toddler eats a wide variety of foods from the five food groups in appropriate amounts. The five food groups include: fruits, vegetables, grains, protein, and dairy.

Q18

For the statements below, please select your answer along each scale based on the adjectives listed. 
For me to ensure that my toddler eats a wide variety of foods from the five food groups in appropriate amounts every day in the next week would be:

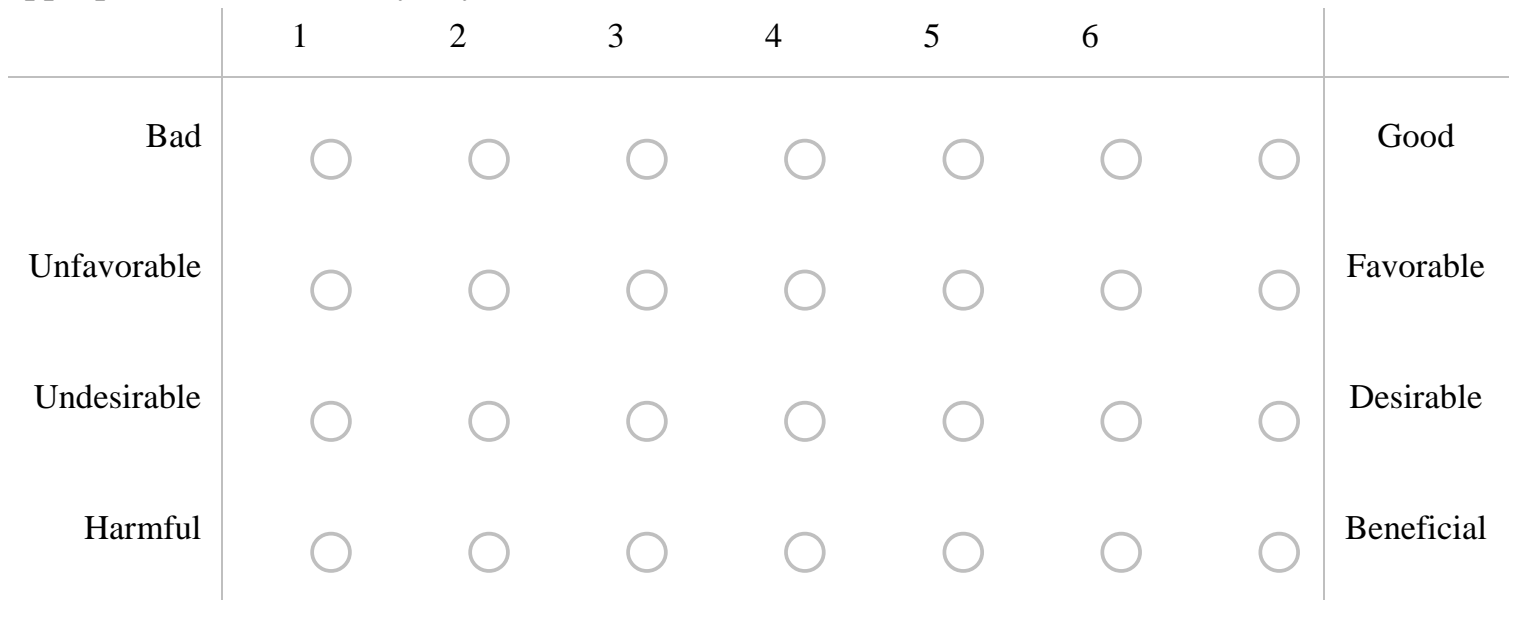


Q19 Please rate your level of agreement with each of the following statements: 


\begin{tabular}{cccccc} 
Strongly & \multicolumn{9}{c}{$\begin{array}{c}\text { Neith } \\
\text { Disagree } \\
\text { disagree }\end{array}$} & $\begin{array}{c}\text { Somew } \\
\text { hat } \\
\text { disagree }\end{array}$ & $\begin{array}{c}\text { agree } \\
\text { nor } \\
\text { disagr } \\
\text { ee }\end{array}$ & $\begin{array}{c}\text { Somew } \\
\text { hat }\end{array}$ \\
& & \multicolumn{2}{c}{ Agree } & Strongly \\
agree
\end{tabular}

I intend to ensure that my toddler eats a wide variety of foods from the five food groups in appropriate amounts EVERY DAY.

It is mostly up to me whether I ensure that my toddler eats a wide variety of foods from the five food groups in appropriate amounts EVERY DAY.

Most people who are important to me would approve of me ensuring that my toddler eats a wide variety of foods from the five food groups in appropriate amounts EVERY DAY.

I plan to ensure that my toddler eats a wide variety of foods from the five food groups in appropriate amounts EVERY DAY.

I expect that I will ensure that my toddler eats a wide variety of foods from the five food groups in appropriate amounts EVERY DAY.

I am confident that I will ensure that my toddler eats a wide variety of foods from the five food groups in appropriate amounts EVERY DAY.

The people in my life whose opinions I value would think that my ensuring my toddler eats a wide variety of foods from the five food groups in appropriate amounts EVERY DAY is desirable. 
Those people who are important to me think that I should ensure my toddler eats a wide variety of foods from the five food groups in appropriate amounts EVERY DAY.

Q20 I believe it is my responsibility as a parent to ensure that my child eats a wide variety of foods from the five food groups in appropriate amounts EVERY DAY in the next week.

\begin{tabular}{c|cccccc} 
& $\begin{array}{c}\text { Strongly } \\
\text { disagree }\end{array}$ & Disagree & $\begin{array}{c}\text { Somewhat } \\
\text { disagree }\end{array}$ & $\begin{array}{c}\text { Neither } \\
\text { agree nor } \\
\text { disagree }\end{array}$ & $\begin{array}{c}\text { Somewhat } \\
\text { agree }\end{array}$ & $\begin{array}{c}\text { Agree } \\
\text { agree }\end{array}$ \\
$\begin{array}{c}\text { Please } \\
\text { select your } \\
\text { agreement } \\
\text { with the } \\
\text { statement } \\
\text { above. }\end{array}$ & & & & \\
\end{tabular}

Q21 It is an important part of my role as a parent to ensure that my child eats a wide variety of foods from the five food groups in appropriate amounts EVERY DAY in the next week.

\begin{tabular}{c|ccccccc} 
& $\begin{array}{c}\text { Strongly } \\
\text { disagree }\end{array}$ & Disagree & $\begin{array}{c}\text { Somewhat } \\
\text { disagree }\end{array}$ & $\begin{array}{c}\text { Neither } \\
\text { agree nor } \\
\text { disagree }\end{array}$ & $\begin{array}{c}\text { Somewhat } \\
\text { agree }\end{array}$ & Agree & $\begin{array}{c}\text { Strongly } \\
\text { agree }\end{array}$ \\
\hline $\begin{array}{c}\text { Please } \\
\text { select your } \\
\text { agreement } \\
\text { with the } \\
\text { statement } \\
\text { above. }\end{array}$ & $\bigcirc$ & 0 & & & & & \\
& & & & & & \\
\end{tabular}


Q22 As a parent, it is my job to ensure that my child eats a wide variety of foods from the five food groups in appropriate amounts EVERY DAY in the next week.

\begin{tabular}{c|ccccccc} 
& $\begin{array}{c}\text { Strongly } \\
\text { disagree }\end{array}$ & Disagree & $\begin{array}{c}\text { Somewhat } \\
\text { disagree }\end{array}$ & $\begin{array}{c}\text { Neither } \\
\text { agree nor } \\
\text { disagree }\end{array}$ & $\begin{array}{c}\text { Somewhat } \\
\text { agree }\end{array}$ & Agree & $\begin{array}{c}\text { Strongly } \\
\text { agree }\end{array}$ \\
\hline $\begin{array}{c}\text { Please } \\
\text { select your } \\
\text { agreement } \\
\text { with the } \\
\text { statement } \\
\text { above. }\end{array}$ & & & & & & \\
\end{tabular}

Q23 Think of other mothers you know with a toddler for the following questions:

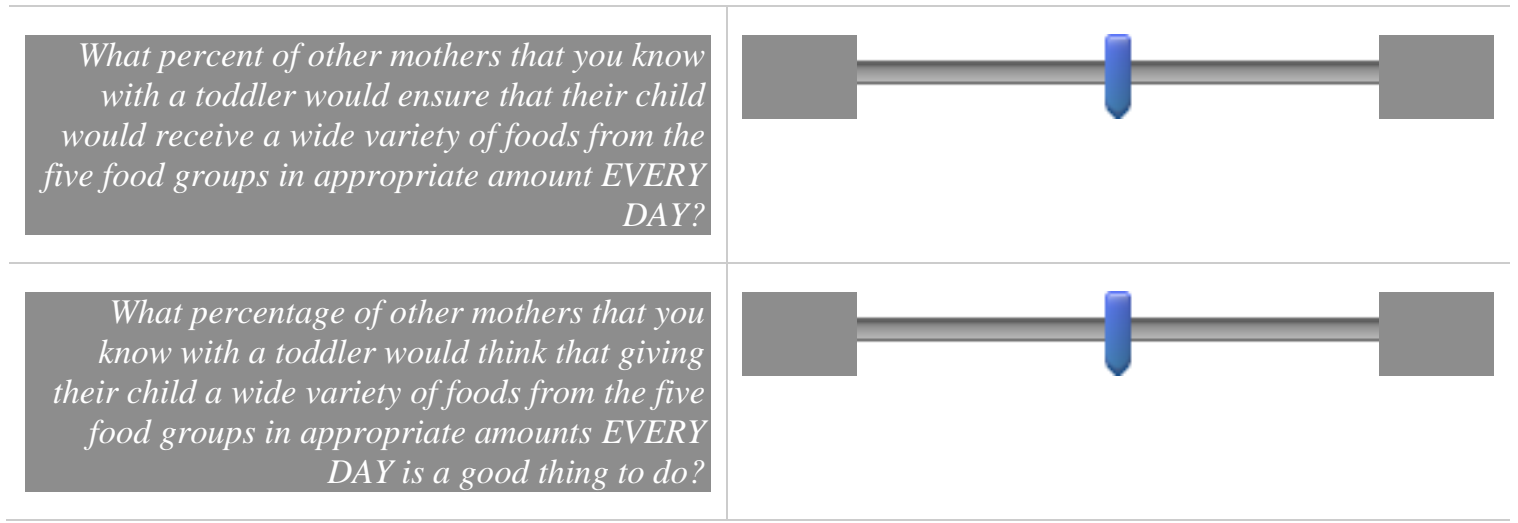

End of Block

\section{Block 8}

Q24 What do you think are the main influences on your toddler's diet? 
Q25 What are the challenges or frustrations that you have in regards to your toddler's diet?

\section{Nutrition Knowledge}

Q26 Please choose the answer that best describes your response towards the following questions.

\begin{tabular}{|c|c|c|c|c|}
\hline & Very Poor & Poor & Good & Very Good \\
\hline $\begin{array}{l}\text { How would you } \\
\text { rate your current } \\
\text { nutrition } \\
\text { knowledge } \\
\text { regarding toddler } \\
\text { nutrition? }\end{array}$ & & & & \\
\hline $\begin{array}{l}\text { How would you } \\
\text { rate your toddler's } \\
\text { current diet? }\end{array}$ & & & & \\
\hline $\begin{array}{l}\text { How would you } \\
\text { rate your current } \\
\text { diet? }\end{array}$ & & & & \\
\hline
\end{tabular}


Q27 Please choose the answer that best describes your feelings towards the following statements.

\begin{tabular}{|c|c|c|c|c|}
\hline & Strongly Disagree & Disagree & Agree & Strongly Agree \\
\hline $\begin{array}{l}\text { It is very easy to } \\
\text { find reliable } \\
\text { information about } \\
\text { toddler nutrition. }\end{array}$ & & & & \\
\hline $\begin{array}{l}\text { I feel that I receive } \\
\text { conflicting } \\
\text { information about } \\
\text { toddler nutrition. }\end{array}$ & & & & \\
\hline $\begin{array}{l}\text { I follow strict } \\
\text { guidelines when it } \\
\text { comes to my } \\
\text { toddler's diet. }\end{array}$ & & & & \\
\hline $\begin{array}{l}\text { I have concerns } \\
\text { when it comes to } \\
\text { my toddler's diet. }\end{array}$ & ( & & & \\
\hline
\end{tabular}

\section{Block 10}

Q28 Please answer the following true/false questions based on toddler nutrition guidelines.

Q29 Juice should be limited to 4-6 oz per day for toddlers.

True

False

Q30 Toddlers need 2-3 snacks per day.

True

False 
Q31 Meals and snacks should always be served when the toddler is seated.

True

False

Q32 When provided with healthy options, toddlers should be allowed to control the amount of food they eat.

True

False

Q33 It can take up to 15 times before a toddler accepts a new food.

True

False

Q34 Toddlers should be drinking low fat milk once they turn 1 year old.

True

False 
Q35 It is OK to watch TV while eating a meal or snack with a toddler.

True

False

Q36 The recommended amount of protein per day for a toddler is 1-2 ounces.

True

False

Q37 An appropriate serving size for a toddler is $1 / 4$ th of an adult portion.
True
False

Q38 A toddler's diet should contain 30-40\% of calories from fat.

True

False

\section{Demographics}

Q39 The final set of questions gathers general demographic information. All of the information that you provide is anonymous. 
Q40 How many children do you have?

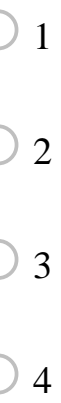

2

3

4

More than 4

\section{Display This Question:}

If How many children do you have? = 1

Q41 What is your child's current age? Please list in years.

\section{Display This Question:}

If How many children do you have? = 2

Q42 What are your children's current ages? Please list in years

Child \#1

Child \#2

\footnotetext{
Display This Question:

If How many children do you have? = 3
} 
Q43 What are your children's current ages? Please list in years.

Child \#1

Child \#2

Child \#3

Display This Question:

If How many children do you have? = 4

Q44 What are your children's current ages? Please list in years.

Child \#1

Child \#2

Child \#3

Child \#4

Display This Question:

If How many children do you have? = More than 4 
Q45 What are your children's current ages? Please list in years.

Child \#1

Child \#2

Child \#3

Child \#4

Child \#5

Child \#6

Child \#7

Child \#8

Child \#9

Child \#10

Q46 What is your current age in years? 
Q47 Which option best describes the highest academic degree that you have received?

Some high school

High school diploma or GED

Vocational/technical degree

Bachelor's degree

Graduate degree (ex: MA, MS, PhD, JD, etc.)

Other:

Q48 Which option best describes your primary current employment status?

Full-time employee

Part-time employee

Stay-at-home mom

Student

Retired

Other: 
Q49 Which option best describes your current relationship status?

\section{Single}

Married

Divorced or Separated

Widowed

Other:

Q50 What is your race?

Non-Hispanic Black

Non-Hispanic White

Hispanic

Other:

Q51 Do you currently receive WIC (Special Supplemental Nutrition Program for Women, Infants, and Children) benefits?
Yes
No
I do not want to answer this question. 
Q52 Do you currently receive SNAP (Supplemental Nutrition Assistance Program) benefits or food stamps?

Yes

No

I do not want to answer this question.

Q53 Which state do you currently live in?

\section{Skip To: Q55 If}

Q54 Which county in Kentucky do you currently live in?

Q55 Do you know your toddler's current weight?

Yes

No

I do not want to answer this question

Display This Question:

If Do you know your toddler's current weight? = Yes

Q56 Please list your toddler's current weight (in pounds) below: 
Q57 Do you know your child's current height?

Yes

No

I do not want to answer this question.

Display This Question:

If Do you know your child's current height? = Yes

Q58 Please list your toddler's current height (in inches) below: 
Appendix C

\section{Focus Groups Questions for Mothers of Young Children}

Welcome

Hello, my name is Liz Combs from the University of Kentucky Department of

Kinesiology and Health Promotion. I am asking mothers of young children to take part in a 30-45 minute focus group about where you get nutrition information from, what sources of nutrition information you trust, and how those choices affect your child-feeding practices. You have previously agreed to participate in the focus group by signing an informed consent form. The information gathered is aimed to help us understand how sources of nutrition knowledge may be influencing child-feeding practices. This project will help to develop a survey that will explore similar topics. Participation is voluntary and all responses will remain confidential. Only the researcher will know who participated, and data will be summarized, not connecting individuals to their responses. You may also choose to withdraw from the study at any time if you are uncomfortable.

\section{Guidelines}

1. No right or wrong answers, only differing points of view

2. You don't need to agree with others, but you must listen respectfully as others share their views

3. We ask that you turn off your phones. If you cannot and if you must respond to a call, please do so as quietly as possible and rejoin us as quickly as you can.

4. My role as moderator will be to guide the discussion

You've probably noticed the microphone. I'm tape recording the session because we don't want to miss any of your comments. People often say very helpful things in these discussions and I can't write fast enough to get them all down. We will be on a first name basis tonight, and I won't use any names in my reports. You may be assured of complete confidentiality.

Well, let's begin. I've placed name cards on the table in front of you to help us remember each other's names. Let's find out some more about each other by going around the table. Tell us your name and a little bit about your children.

\section{Questions:}

2. How important is nutrition to you when providing food to your toddler?

a. Why do you feel this way?

3. What are your responsibilities as a mother in feeding your toddler?

4. What do you think are the main influences on what your toddler eat?

5. What are some of strengths of your toddler's current eating habits? 
6. What are some parts of your toddler's eating habits that you would like to change?

7. What is the main challenge that you experience in regards to feeding your toddler?

8. Where does your main source of nutrition information come from?

a. Can you list some sources where you look for toddler nutrition information?

i. Have you used any of the following sources of information about feeding your child?

1. Television (what programs)

2. Newspapers (what newspapers)

3. Magazines (what magazines)

4. Internet (what sites)

5. Others

b. Can you list some people that you ask for toddler nutrition information?

i. Have any of the following persons talked to you about how to feed your child?

1. Relatives

2. Friends

3. Health professionals

a. Doctors

b. Nurses

c. Registered Dietitians

d. Nutritionists

4. Others (church, daycare, etc).

9. What resources have you found to be extremely helpful in regards to information on feeding your toddler?

10. Could you summarize some of the advice you receive from these sources regarding feeding your toddler?

11. What are the main nutrition guidelines for toddlers that you are aware of?

12. If you were to compare the eating habits of your toddler with the dietary guidelines, how do you think they would compare? Why did you say better or worse?

13. If you were to compare the eating habits of your toddler with other toddlers his/her age, how do you think they would compare? Why did you say better or worse? 
14. Are there any nutrition topics that you wish you had more information on?

Concluding Remarks:

"Of all the things we discussed, what to you is the most important?"

After the brief oral summary the question asked is: "Is this an adequate summary?"

The moderator reviews the purpose of the study and then asks the participants: "Have we missed anything? 
Appendix D

\section{Recruitment Email to Site Coordinators}

Thank you agreeing to help with the distribution of a survey about sources of toddler nutrition information used by mothers. I am asking mothers of young children (12 months-36 months old) to take part in an online survey that includes questions about where they get nutrition information from, what sources of nutrition information they trust, and some demographic information. The information gathered is aimed to help us at the University of Kentucky, Department of Kinesiology and Health Promotion understand how sources of nutrition knowledge may be influencing child-feeding practices and how sources of nutrition information are being used. The information gathered through this survey could help develop more effective ways of delivering nutrition information to mothers in the future.

How can you help? Please forward the confidential/secure volunteer survey, to all participants in your program. We have provided a draft email for your consideration below that may be used to help recruit participants to participate in the volunteer survey. It should take participants approximately $10-15$ minutes to complete and, again, their responses will be of great value to our efforts. You will also receive a summary of the results for your program from the University of Kentucky team.

Implementation timeline:

1. Send out $1^{\text {st }}$ round of emails to all program participants on January 15, 2018.

2. Send out $2^{\text {nd }}$ round of emails to all program participants on January 22, 2018.

3. Send out thank you email to all program participants on January 29, 2018.

If you have any questions, suggestions, concerns, or complaints before, during or after this process, you can contact the investigator, Liz Combs at elmars2@uky.edu. If you have any questions about your rights in this research, contact the staff in the Office of Research Integrity at the University of Kentucky between the business hours of $8 \mathrm{am}$ and 5pm EST, Mon-Fri. at 859-257-9428 or toll free at 1-866-400-9428.

Thank you again for taking part in this important research.

Thank you,

Liz Combs, MS, RD, LD

EdD Candidate in Department of Kinesiology and Health Promotion

209 B Funkhouser Building

University of Kentucky

Elmars2@uky.edu

859-257-9209 
Appendix E

\section{Survey Cover Letter}

Dear Participant,

Thank you for taking the time to complete this survey about sources of toddler nutrition information used by mothers. I am asking mothers of young children (12 months-36 months old) to take part in an online survey that includes questions about where you get nutrition information from, what sources of nutrition information you trust, and some demographic information. The information gathered is aimed to help us at the University of Kentucky, Department of Kinesiology and Health Promotion understand how sources of nutrition knowledge may be influencing child-feeding practices and how sources of nutrition information are being used. The information gathered through this survey could help develop more effective ways of delivering nutrition information to mothers in the future.

The survey should take 10-15 minutes to complete. To the best of our knowledge, participating in this survey will subject you to no more risk of harm than you would experience in everyday life. If you decide to take part in the study, you can stop at any time during the survey.

If you have any questions, suggestions, concerns, or complaints before, during or after participating in the survey, you can contact the investigator, Liz Combs at elmars2@uky.edu. If you have any questions about your rights as a volunteer in this research, contact the staff in the Office of Research Integrity at the University of Kentucky between the business hours of 8am and 5pm EST, Mon-Fri. at 859-257-9428 or toll free at 1-866-400-9428.

Thank you again for taking part in this important research.

Thank you,

Liz Combs, MS, RD, LD

EdD Candidate in Department of Kinesiology and Health Promotion

209 B Funkhouser Building

University of Kentucky

Elmars2@uky.edu

859-257-9209 
Appendix F

Consent to Participate in a Research Study 1. How Varying Sources of Nutrition Information Influence Mothers' Toddler Feeding
Decisions: Focus Group Findings

\section{WHY ARE YOU BEING INVITED TO TAKE PART IN THIS RESEARCH?}

You are being invited to take part in a research study about influences on mother's feeding decisions regarding their toddlers. You are being invited to take part in this research study because you are the mother of at least one child between the ages of 12 months -48 months. If you volunteer to take part in this study, you will be one of about 10-24 people to do so.

\section{WHO IS DOING THE STUDY?}

The person in charge of this study is Liz Combs of University of Kentucky Department of Kinesiology and Health Promotion. She is a doctoral student in the Kinesiology and Health Promotion Department. She is being guided in this research by Dr. Melinda Ickes.

\section{WHAT IS THE PURPOSE OF THIS STUDY?}

By doing this study, we hope to learn about where you get nutrition information from, what sources of nutrition information you trust, and how those choices affect your child-feeding practices. The information gathered is aimed to help us gain a better understanding of how childfeeding behaviors are influenced by different sources of nutrition information.

\section{ARE THERE REASONS WHY YOU SHOULD NOT TAKE PART IN THIS STUDY?}

You should not participate in this study if you are under 18 years of age, if you do not have children between 12-48 months of age, or if you do not speak fluent English.

\section{WHERE IS THE STUDY GOING TO TAKE PLACE AND HOW LONG WILL IT LAST?}

The research procedures will be conducted at the Beaumont Family YMCA, the University of Kentucky, and Asbury University. You will need to come to one of the facilities one time during the study. The duration of the visit will take 45-60 minutes. The total amount of time you will be asked to volunteer for this study is one hour over the next month.

\section{WHAT WILL YOU BE ASKED TO DO?}

You will be asked to participate in a focus group that should not take more than one hour. You will only need to go to one focus group. At the beginning of the focus group you will be asked to fill out a demographic questionnaire. During the focus group, you will be asked questions about where you get nutrition information for your toddler. If you do not want to answer a question, you do not have to. These focus group sessions will be audio recorded. 


\section{WHAT ARE THE POSSIBLE RISKS AND DISCOMFORTS?}

To the best of our knowledge, the things you will be doing have no more risk of harm than you would experience in everyday life.

In addition to the risks listed above, you may experience a previously unknown risk or side effect.

\section{WILL YOU BENEFIT FROM TAKING PART IN THIS STUDY?}

There is no guarantee that you will get any benefit from taking part in this study. Your willingness to take part, however, may, in the future, help society as a whole better understand this research topic.

\section{DO YOU HAVE TO TAKE PART IN THE STUDY?}

If you decide to take part in the study, it should be because you really want to volunteer. You will not lose any benefits or rights you would normally have if you choose not to volunteer. You can stop at any time during the study and still keep the benefits and rights you had before volunteering.

\section{IF YOU DON'T WANT TO TAKE PART IN THE STUDY, ARE THERE OTHER CHOICES?}

If you do not want to be in the study, there are no other choices except not to take part in the study.

\section{WHAT WILL IT COST YOU TO PARTICIPATE?}

There are no costs associated with taking part in the study.

\section{WILL YOU RECEIVE ANY REWARDS FOR TAKING PART IN THIS STUDY?}

You will receive nutrition brochures and handouts, a $\$ 15$ gift card, and a free meal provided during the focus group time for taking part in this study.

\section{WHO WILL SEE THE INFORMATION THAT YOU GIVE?}

Although other individuals participating in the focus group will know what was said and by whom, participants will be instructed to keep all information shared within the focus group private. Your information will be combined with information from other people taking part in the study. When we write about the study to share it with other researchers, we will write about the combined information we have gathered. You will not be personally identified in these written materials. We may publish the results of this study; however, we will keep your name and other identifying information private.

Beyond those participating in the focus group, we will make every effort to prevent anyone who is not on the research team from knowing that you gave us information, or what that information is. All transcripts of the focus groups will be kept in a locked office belonging to the primary investigator. Any electronic resources will be kept on a computer with a password log-in.

We will keep private all research records that identify you to the extent allowed by law. However, there are some circumstances in which we may have to show your information to other people. 
For example, the law may require us to tell authorities if you report information about a child being abused or if you pose a danger to yourself or someone else. Also, we may be required to show information which identifies you to people who need to be sure we have done the research correctly; these would be people from such organizations as the University of Kentucky.

\section{CAN YOUR TAKING PART IN THE STUDY END EARLY?}

If you decide to take part in the study you still have the right to decide at any time that you no longer want to continue. You will not be treated differently if you decide to stop taking part in the study.

The individuals conducting the study may need to withdraw you from the study. This may occur if you are not able to follow the directions they give you or if they find that your being in the study is more risk than benefit to you.

\section{WHAT ELSE DO YOU NEED TO KNOW?}

There is a possibility that the data collected from you may be shared with other investigators in the future. If that is the case the data will not contain information that can identify you unless you give your consent or the UK Institutional Review Board (IRB) approves the research. The IRB is a committee that reviews ethical issues, according to federal, state and local regulations on research with human subjects, to make sure the study complies with these before approval of a research study is issued.

\section{WHAT IF YOU HAVE QUESTIONS, SUGGESTIONS, CONCERNS, OR COMPLAINTS?}

Before you decide whether to accept this invitation to take part in the study, please ask any questions that might come to mind now. Later, if you have questions, suggestions, concerns, or complaints about the study, you can contact the investigator, Liz Combs at elmars2@uky.edu. If you have any questions about your rights as a volunteer in this research, contact the staff in the Office of Research Integrity at the University of Kentucky between the business hours of 8am and 5pm EST, Mon-Fri. at 859-257-9428 or toll free at 1-866-400-9428. We will give you a signed copy of this consent form to take with you.

Signature of person agreeing to take part in the study

Date

Printed name of person agreeing to take part in the study

Name of (authorized) person obtaining informed consent

Date 


\section{Appendix G}

\section{T. University of}

Intid of Contanuaben Review

Aprowil Ent.

$3 / 23 / 2019$

To

Birstedh Combs, MS, RD, LD

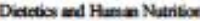

PI pheee 4: 8592575209

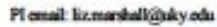

FROM. Chei-penos/Vice Oarpenen

Now Matical hatuibind Review Bearl (ARB)

SURJECT: Approval or Protocol

DATE 3/30/2018

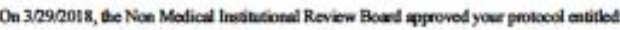

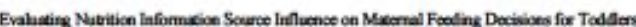

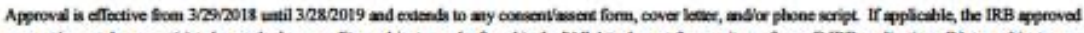

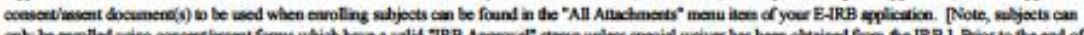

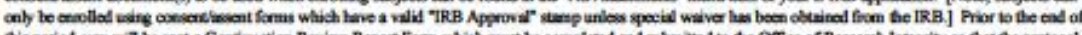

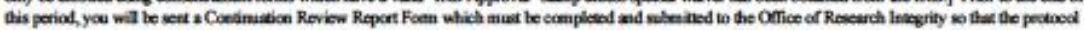

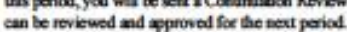

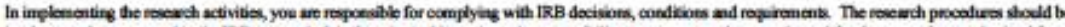

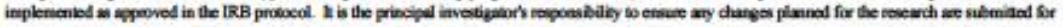

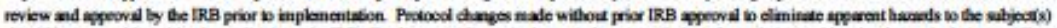

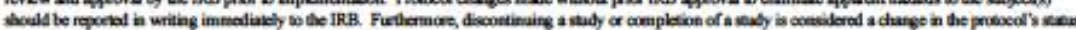

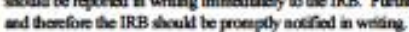

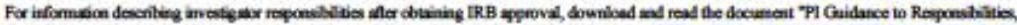

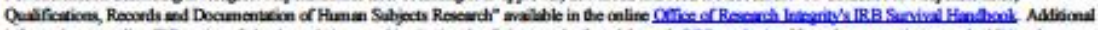

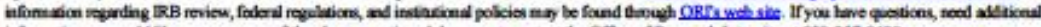

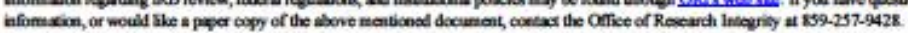




\section{Appendix $\mathrm{H}$}
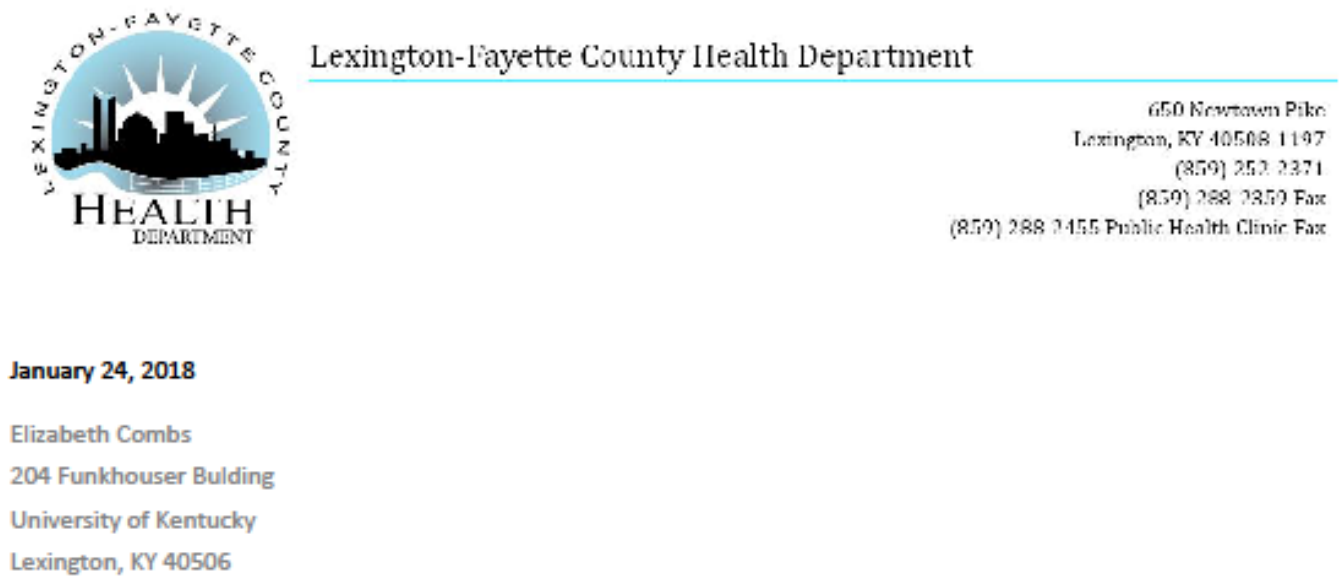

Re: Sources of Information for Mothers' Toddler Feeding Decisions: A Cross-Sectional Study of Mothers' Child Nutrition Knowledge and Feeding Using the Theory of Planned Behavior

Dear Ms. Combs:

We are pleased to inform you that your project, Sources of Information for Mothers' Toddler Feeding Decisions: A CrossSectional Study of Mothers' Child Nutrition Knowledge and Feeding Using the Theory of Planned Behavior, has been approved by the Lexington-Fayette County Health Department Institutional Review Board (IRB). This approval is for a period of one year from this letter and will require continuation approval if the research project extends beyond January $24,2019$.

Please share a summary of your results with the Lexington-Fayette County Health Department IRB when available. If you have any questions or concerns, please contact me directly at 859-899-4238.

Sincerely,

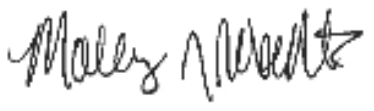

Molly J. Roberts, Chair

LFCHD IRB 


\section{BIBLIOGRAPHY}

Abbott Nutrition. (n.d.) Transitional feeding. Retrieved from

https://static.abbottnutrition.com/cms-prod/abbottnutrition-

2016.com/img/Transitionalfeeding_guide_tcm1411-57813.pdf

Academy of Nutrition and Dietetics. (2011). Nutrition and you: Trends 2011. Retrieved from http://www.eatright.org/nutritiontrends

Ajzen, I. (2002). Perceived behavioral control, self-efficacy, locus of control, and the theory of planned behavior. Journal of Applied Social Psychology, 32(4), 665683.

Ajzen, I. (2007). Theory of planned behavior. Retrieved from http://people.umass.edu/aizen/tpb.html

Alatarum. (2014) Retrieved from https://altarum.org/sites/default/files/uploadedpublication-

files/Appendix\%20B_Demographic\%20Characteristics\%20of\%20WIC\%20Famil ies_FINAL_071614.pdf

Albarracin, D., Johnson, B.T., Fishbein, M., Muellerleile, P.A. (2001). Theories of reasoned action and planned behavior as models of condom use: A meta-analysis. Psychology Bulletin, 127(1), 142-161.

Andrews, K.R., Silk, K.S., \& Eneli, I.U. (2010). Parents and health promoters: A Theory of Planned Behavior prospective on the prevention of childhood obesity. Journal of Health Communication, 15(1), 95-107. 
Astrom, A.N. \& Kiwankuka, S.N. (2006). Examining intention to control preschool children's sugar snacking: A study of carers in Uganda. International Journal of Pediatric Dentistry, 16, 10-18.

Backman, D. R., Haddad, E. H., Lee, J. W., Johnston, P. K., \& Hodgkin, G. E. (2002). Psychosocial predictors of healthful dietary behavior in adolescents. Journal of Nutrition Education and Behavior, 34, 184-193.

Barratt \& Kirwan. (2009). Cross-sectional studies. Retrieved from https://www.healthknowledge.org.uk/public-health-textbook/researchmethods/1a-epidemiology/cs-as-is/cross-sectional-studies

Beauchamp, G.K. \& Mennella, J.A. (2009). Early flavor learning and its impact on later feeding behavior. Journal of Pediatric Gastroenterology and Nutrition, 48, S25S30.

Bianco, A., Zucco, R., Nobile, C.G., Pileggi, C., \& Pavia, M. (2013). Parents seeking health-related information on the internet: Cross-sectional study. Journal of Medical Internet Research. 15, e204.

Birch, L.L. (1999). Development of food preferences. Annual Review of Nutrition, 19, 41-62.

Birch, L.L. \& Ventura, A. K. (2009). Preventing childhood obesity. What works? International Journal of Obesity, 33 (suppl. 1), S74-S81. 
Briefel, R.R., Kalb, L.M., Condon, E., Deming, D.M., Clusen, N.A., Fox, M.K., ... Reidy, K.C. (2010). The feeding infants and toddlers study 2008: Study Design and Methods. Journal of the American Dietetic Association, 110, S16 - S26.

Brown, K.A., Ogden, J., Vogele, C., \& Gibson, E.L. (2008). The role of parental control practices in explaining children's diet and BMI. Appetite, 50, 252-259.

Butte, N.F., Fox, M.K., Briefel, R.R., Siega-Riz, A.M., Dwyer, J.T., Deming, D.M., \& Reidy, K.C. (2010). Nutrient intakes of US infants, toddlers, and preschoolers meet or exceed dietary reference intakes. Journal of the American Dietetic Association, 110, S27-S37.

Byrd-Bredbenner, C., Abbott, J.M., Cussler, E. (2008). Mothers of young children cluster into 4 groups based on psychographic food decision influencers. Nutrition Research, 28(8), 506-516.

Campbell, K., Hesketh, K., Silverii, A., \& Abbott, G. (2010). Maternal self-efficacy regarding children's eating and sedentary behaviors in the early years: Associations with children's food intake and sedentary behaviors. International Journal of Pediatric Obesity, 5, 501-508.

Carruth, B.R., \& Skinner, J.D. (2001). Mothers' sources of information about feeding their children ages 2 months to 54 months. Journal of Nutrition Education, 33, 143-147.

Carruth, B.R., Ziegler, P.J., Gordon, A., \& Barr, S.I. (2004). Prevalence of picky eaters among infants and toddlers and their caregivers' decisions about offering a new food. Journal of the American Dietetic Association, 104, s57-64. 
Cash, T., Desbrow, B., Leveritt, M., \& Ball, L. (2014). Utilization and preference of nutrition information sources in Australia. Health Expectations, 18, 2288 - 2295.

Caton, S.J., Ahern, S.M., \& Hetherington, M.M. (2011). Vegetables by stealth. An exploratory study investigating the introduction of vegetables in the weaning period. Appetite, 57, 816-825.

Champion, S., Giles, L., \& Moore, V. (2010). Parental beliefs and practices contributing to overweight and obesity in children. Australas Epidemiology, 17, 21-25.

Chezem, J., Friesen, C., \& Clark, H. (2001). Sources of infant feeding information used by pregnant women. The Journal of Perinatal Education, 10, 20-26.

Christakis, D. A., \& Garrison, M.M. (2009). Preschool-aged children's television viewing in child care settings. Pediatrics 124(6):1627-1632.

Cluss, P.A., Ewing, L., King, W.C., Cohen Reis, E., Dodd, J.L., \& Penner, B. (2013). Nutrition knowledge of low-income parents of obese children. Translational Behavioral Medicine, 3, 218-225.

Combs, L., Ickes, M., \& McMullen, J. (2019). Influences on Mothers' Toddler Feeding Decisions: Focus Group Findings based on the Theory of Planned Behavior (Unpublished, doctoral dissertation). University of Kentucky, Lexington, Kentucky.

Conner, M.T. \& Sparks, P. (2005). Theory of planned behavior and health behavior. Predicting health behavior, $2^{\text {nd }}$ edition. Open University Press. 
Cooke, L.J., Wardle, J., Gibson, E.L., Sapochnik, M., Sheiham, A., \& Lawson, M. (2004). Demographic, familial and trait predictors of fruit and vegetable consumption by pre-school children. Public Health Nutrition, 7, 295-302.

Coulthard, H., Harris, G., \& Emmett, P. (2009). Delayed introduction of lumpy foods to children during the complimentary feeding period affects child's food acceptance and feeding at 7 years of age. Maternal \& Child Nutrition, 5, 75-85.

Coulthard, H., Harris, G., \& Emmett, P. (2010). Long-term consequences of early fruit and vegetable feeding practices in the United Kingdom. Public Health Nutrition, $13,2044-2051$.

Daniels, S.R. (2006). The consequences of childhood overweight and obesity. Future Child, 16, 47-67.

Dexter, B., Frank, S., \& Seguin, L. (2016). How and where parents of infants and young children want to receive information. Canadian Journal of Dietetic Practice and Research, 77, 203-205.

Duncanson, K., Burrows, T., Brett, H. \& Collins, C. (2013). Parents perceptions of child feeding: A qualitative study based on the Theory of Planned Behavior. Journal of Developmental \& Behavioral Pediatrics, 34(4), 227-236.

Dwyer-Lindgren, L., Bertozzi-Villa, A., Stubbs, R.W., Morozoff, C., Mackenbach, J.P., van Lenthe, F.J.,...Murray, C.J.L. (2017). Inequalities in life expectancy among US Counties, 1980 to 2014. Journal of the American Medical Association Internal Medicine, 177(7), 1003-1011.

Finkelstein, E.A., Graham, W.C., \& Malhotra, R. (2014). Lifetime direct medical costs of childhood obesity. Pediatrics, 133(5):854-62. 
Freedman, D. S., Khan, L. K., Serdula, M. K., Dietz, W. H., Srinivasan, S. R. \& Berenson, G. S. (2005). The relation of childhood BMI to adult adiposity: The Bogalusa Heart Study. Pediatrics, 115(1):22-27.

Gage, H., Williams, P., Von Rosen-Von Hoewel, J., Laitinen, K., Jakobik, V., MartinBautista, E., ... Raats, M. (2012). Influences on infant feeding decisions of firsttime mothers in five European countries. European Journal of Clinical Nutrition, $66,914-919$.

Gibbons, K., Graham, V., Marraffa, C. \& Henry, L. (2000). Filling the Gap- children aged between two and four years: sources of nutrition information used by families and childcare staff. Australian Journal of Nutrition and Dietetics, 57, 208-214.

Gildea, A., Sloan, S., \& Stewart, M. (2009). Sources of feeding advice in the first year of life: Who do parents value? Community Practices, 82, 27-31.

Gisel, E.G. (1991). Effect of food texture on the development of chewing of children between six months and two years of age. Developmental Medicine and Child Neurology, 33, 69-79.

Hamel, L.M. \& Smith, S.W. (2013). An investigation of the factors that influence maternal encouragement of healthy diets for preadolescent daughters. Global Journal of Medical research Microbiology and Pathology, 13, 24-33.

Hamilton, K., Cleary, C., White, K.M., \& Hawkes, A. (2015). Keeping kids sun safe: Exploring parents' beliefs about their young child's sun-protective behaviors. Pyscho-Oncology, 25(2). 
Hamilton, K., Kirkpatrick, A., Rebar, A., White, K.M., \& Hagger, M. (2017). Protecting young children against skin cancer: Parental beliefs, roles, and regret. PsychoOncology, 26, 2135-2141.

Hamilton, K., Kothe, E., Mullan, B., \& Spinks, T. (2017). The mediating and moderating role of planning on mothers' decisions for early childhood dietary behaviors. Psychology \& Health, Advanced online publication.

Hamilton, K., Spinks, T., White, K.M., Kavanagh, D.J., \& Walsh, A.M. (2016). A psychosocial analysis of parents' decisions for limiting their young child's screen time: An examination of attitudes, social norms and roles, and control perceptions. British Journal of Health Psychology, 21(2), 285-301.

Hamilton, K. \& White, K.M. (2015). Extending the Theory of Planned Behavior: The role of self and social influences in predicting adolescent regular moderate-tovigorous physical activity. Journal of Sport \& Exercise Psychology, 30(1), 56-74.

Hendricks, K., Briefel, R., Novak, T., \& Ziegler, P. (2006). Maternal and child characteristics associated with infant and toddler feeding practices. Journal of the American Dietetic Association, 106, S135 - S148.

Hernandez, R.G., Cheng, T.L., \& Serwint, J.R. (2010). Parents' healthy weight perceptions and preferences regarding obesity counseling in preschoolers: Pediatricians matter. Clinical Pediatrics, 49, 790-798.

Hernandez, R. G., Thompson, D. A., Cheng, T. L., \& Serwint, J. R. (2012). Earlychildhood obesity: How do low-income parents of preschoolers rank known risk factors? Clinical Pediatrics, 51(7), 663-670. 
Hoover-Dempsey, K.V. \& Sandler, H.M. (1995). Parental involvement in children's education: Why does it make a difference? Teachers College Record, 97(2), 310331.

Horodynski, M.A. \& Stommel, M. (2005). Nutrition education aimed at toddlers: An intervention study. Journal of Pediatric Nursing, 31, 367-372.

Horodynski, M.A., Stommel, M., Brophy-Herb, H., Xie, Y., \& Weatherspoon, L. (2010). Low-income African American and non-Hispanic White mothers' self-efficacy, "picky eater" perception, and toddler fruit and vegetable consumption. Public Health Nursing, 27(5), 408-417.

Ice, C.L., William, N.A., \& Cottrell, L. (2014). Parental efficacy and role responsibility for assisting in child's healthful behaviors. Education and Urban Society, 46(6), 699-715.

Iglowstein, I., Jenni, O. G., Molinari, L., \& Largo, R.H. (2003). Sleep duration from infancy to adolescence: Reference values and generational trends. Pediatrics, 111(2):302-307.

Institute of Medicine. (2011). Early Childhood Obesity Prevention Policies. Washington, DC: The National Academies Press, 2011.

International Food Information Council Foundation. (2017). 2017 food and health survey: "A healthy perspective: Understanding American food values". Retrieved from http://www.foodinsight.org/2017-food-and-health-survey

Kahlor, L., Mackert, M., Junker, D., \& Tyler, D. (2011). Ensuring children eat a healthy diet: A theory-drive focus group study to inform communication aimed at parents. Journal of Pediatric Nursing, 26, 13-24. 
Keech, J.J., Hatzis, D., Kavanagh, D.J., White, K.M., \& Hamilton, K. (2018). Parents' role constructions for facilitating physical activity-related behaviours in their young children. Australian Journal of Psychology, 70, 246-257.

Kourlaba, G., Kondaki, K., Grammatikaki, E., Roma-Giannikou, E. \& Manios, Y. (2009). Diet quality of preschool children and maternal perceptions/misperceptions: The GENESIS study. Public Health, 123, 738-742.

Lakshman, R., Elks, C.E., \& Ong, K.K. (2012). Childhood obesity. Circulation, 126(14), 1770-1779.

Loth, K.A., MacLehose, R.F., Larson, N., Berge, J.M., \& Neumark-Sztainer, D. (2016). Food availability, modeling, and restriction: How are these different aspects of the family eating environment related to adolescent dietary intake? Appetite, 96, 8086.

Maier, A., Chabanet, C., Schaal, B., Leathwood, P., \& Issanchou, S.N. (2008). Breastfeeding and experience with variety early in weaning increases infants' acceptance of new foods for up to two months. Clinical Nutrition, 27, 849-857.

Marquis, M., Dubeau, C., \& Thibault, I. (2005). Canadians' level of confidence in their sources of nutrition information. Canadian Journal of Clinical Nutrition, 66, 170175.

Martin, L, Leveritt, M.D., Desbrow, B., \& Ball, L.E. (2014). The self-perceived knowledge, skills, and attitudes of Australian practice nurses in providing nutrition care to patients with chronic disease. Family Practice, 31(2), 201-208. 
McKenzie, J.F., Neiger, B.L., \& Thackeray, R. (2013). Planning, implementing \& evaluating health promotion programs. Glenview, IL: Pearson Education.

Mennella, J.A. \& Beauchamp, G.K. (1998). Early flavor experiences: Research update. Nutrition Reviews, 56(7), 205-211.

Michell, G.L., Farrow, C., Haycraft, E., \& Meyer, C. (2013). Parental influences on children's eating behavior and characteristics of successful parent-focused interventions. Appetite, 60, 85-94.

Moore, A.P., Milligan, P., Rivas, C., \& Goff, L.M. (2012). Sources of weaning advice, comparisons between formal and informal advice, and associations with weaning time in a survey of UK first-time mothers. Public Health Nutrition, 15, 16611669.

Moseley, K.L., Freed, G.L., \& Goold, S. D. (2011). Which sources of child health advice to parents follow? Clinical Pediatrics, 50, 50-56.

Myers, J., Gibbons, K., Arnup, S., Volders, E., \& Naughton, G. (2015). Early childhood nutrition, active outdoor play and sources of information for families living in highly socially disadvantaged locations. Journal of Pediatric and Child Health, 51(3), 287-293.

National Association for State Community Services Programs. (n.d) Retrieved from: http://www.nascsp.org/ 
Ogden, C.L., Carroll, M.D., Kit, B.K., \& Flegal, K.M. (2014). Prevalence of childhood and adult obesity in the United States, 2011-2012. Journal of the American Medical Association, 311(8):806-814. doi:10.1001/jama.2014.732

O'Key, V. \& Hugh-Jones, S. (2010). I don't need anybody to tell me what I should be doing'. A discursive analysis of maternal accounts of (mis)trust of healthy eating information. Appetite, 54, 524-532.

Olshansky, S.J., Passaro, M.D., Hershow, M.D., Layden, J., Carnes, B.A., Brody, J.... Ludwig, D.S. (2005). A potential decline in life expectancy in the United States in the $21^{\text {st }}$ century. The New England Journal of Medicine, 352, 1138-1145.

Ong, K. K., Emmett, P., Northstone, K., Golding, J. Rogers, I. Ness, A.R., Wells, J.C., \& Dunger, D.B. (2009). Infancy weight gain predicts childhood body fat and age at menarche in girls. Journal of Clinical Endocrinology and Metabolism, 94, 15271532.

Ostry, A., Young, M. L., \& Hughes, M. (2008). The quality of nutritional information available on popular websites: a content analysis. Health education research, 23(4), 648-655.

Patrick, H. \& Nicklas, T. A. (2005). A review of family and social determinants of children's eating patterns and diet quality. Journal of the American College of Nutrition, 24, 83-92.

Paul, I., Bartok, C., Downs, D., Stifter, C., Ventura, A., \& Birch, L. (2009). Opportunities for the primary prevention of obesity during infancy. Advanced Pediatrics, 56(1), 107-133. 
Pew Research Center. (2017). Internet/broadband fact sheet. Retrieved from http://www.pewinternet.org/fact-sheet/internet-broadband/

Rosemary, R., McEachan, C., Conner, M., Taylor, N.J., \& Lawton, R.J. (2011). Prospective prediction of health-related behaviors with the Theory of Planned Behavior: A meta-analysis. Health Psychology Review, 5(2), 97-144.

Ruottinen, S., Karjalainen, S., Pienihäkkinen, K., Lagström, H., Niinikoski, H., Salminen, M.,... Simell, O. (2004). Sucrose intake since infancy and dental health in 10year-old children. Carries Research, 38, 142-148.

Ruottinen, S., Niinikoski, H., Lagström, H., Rönnemaa, T., Hakanen, M., Viikari, J., ... Simell, O. (2009). High sucrose intake is associated with poor quality of diet and growth between 13 months and 9 years of age: the special Turku Coronary Risk Factor Intervention Project. Pediatrics, 121, e1676-e1685.

Schwartz, C., Issanchou, S., \& Nicklaus, S. (2009). Developmental changes in the acceptance of the five basic tastes in the first year of life. British Journal of Nutrition, 102(9), 1375-1785.

Schwartz, C., Scholtens, P.A., Lalanne, A., Weenen, H., \& Nicklaus, S. (2011). Development of healthy eating habits early in life. Review of recent evidence and selected guidelines. Appetite, 57, 796-807.

Sebelefsky, C., Karner, D., Voitl, J. Klein, F., Voitl, P., \& Bock, A. (2015). Internet health seeking behavior of parents attending a general pediatric outpatient clinic: A cross-sectional observational study. Journal of Telemedicine and Telecare, 21, 400-407. 
Siega-Riz, A.M., Deming, D.M., Reidy, K.C., Fox, M.K., Condon, E., \& Briefel, R.R. (2010). Food consumption patterns of infants and toddlers: Where are we now?. Journal of the American Dietetic Association, 110, S38 - S51.

Simmons-Morton, B., McLeroy, K.R., \& Wendel, M.L. (2012). Behavior theory in health promotion practice and research. Burlington, MA: Jones \& Bartlett Learning.

Skinner, J.D., Carruth, B.R., Bounds, W., Ziegler, P., \& Reidy, K. (2002). Do food related experiences in the first 2 years of life predict dietary variety in schoolaged children? Journal of Nutrition Education and Behavior, 34, 310-315.

Smith, P. (2009). Viewpoint: Survey research - two types of knowledge. International Journal of Market Research, 51(6), 1-4.

Spinks, T. \& Hamilton, K. (2015). Investigating key beliefs guiding mothers' dietary decisions for their 2-3 year old. Appetite, 89, 167-174.

Spinks, T. \& Hamilton, K. (2016). Investigating mothers' decisions to give their 2-3year-old a nutritionally balanced diet. Journal of Nutrition Education and Behavior, 48, 250-257.

Sullivan, S.A., \& Birch, L.L. (1994). Infant dietary experience and acceptance of solid foods. Pediatrics, 93, 271-277.

Stang, J. (2006). Improving Eating Patterns of Infants and Toddlers. Journal of the American Dietetic Association, 106, S7-S9.

Swanson, V., Power, K.G., Crombie, I.K., Irvine, L., Kiezebrink, K., Wrieden, W., \& Slane, P.W. (2011). Maternal feeding behavior and young children's dietary 
quality: A cross-sectional study of socially disadvantaged mothers of two-year old children using the Theory of Planned Behavior. International Journal of Behavioral Nutrition and Physical Activity, 8, 65-76.

Swift, C.S. (2009). Nutrition trends: Implications for diabetes health care professionals. Diabetes Spectrum, 22, 23-25.

Thomson, C.E., White, K.M., \& Hamilton, K. (2012). Investigating mothers' decisions about their child's sun-protective behavior using the Theory of Planned Behavior. Journal of Health Psychology, 17(7), 1001-1010.

United States Department of Agriculture. (n.d.) Birth to 24 months and pregnant women. Retrieved from http://www.cnpp.usda.gov/birthto24months

United States Department of Agriculture. (2017). Women, Infants, and Children (WIC). Retrieved from https://www.fns.usda.gov/wic/women-infants-and-children-wic

Vereijken, C.M.J.L., Weenen, H., \& Hetherington, M.M. (2011). Feeding infants and young children. From guidelines to practice-conclusions and future directions. Appetite, 57, 839 - 843.

Vereecken, C., \& Maes, L. (2010). Young children's dietary habits and associations with the mothers' nutritional knowledge and attitudes. Appetite, 54, 44-51.

Vichayanrat, T., Sudha, K., Kumthanom, K., Apisuttisin, J., Uawatanasakul, N., \& Ariyakieatsakul, Y. (2018). What factors influence mothers' behavior regarding control of their children's sugary snack intake?: An application of the Theory of Planned Behavior. International Dental Journal, 68, 336-343. 
Wang, Y \& Zhang, Q. (2006). Are American children and adolescents of low socioeconomic status at increased risk of obesity? Changes in the association between overweight and family income between 1971 and 2002. American Journal of Clinical Nutrition, 84, 707-716.

Zalewski, B.M., Patro, B., Veldhorst, M., Kouwenhoven, S., Escobar, P.C., Lerma, J.C., ... Szajewska, H. (2015). Nutrition of infants and young children (one to three years) and its effect on later health: A systematic review of current recommendations (EarlyNutrition project). Critical Reviews in Food Science and Nutrition, 57, 489-500. 


\section{VITA: ELIZABETH MARSHALL COMBS}

\section{Education}

M.S. Dietetic Administration

- University of Kentucky, Lexington, KY. 2010, Summa Cum Laude

Bachelor of Science Dietetics

- University of Kentucky, Lexington, KY. 2007, Summa Cum Laude

\section{Professional Experience}

University of Kentucky, Lexington KY (2011-present)

- Lecturer, Academic Coordinator, and Coordinated Program Director, Dietetics and Human Nutrition Department

Central Baptist Hospital, Lexington, KY (2009-2011)

- Outpatient Dietitian and Health Educator

YMCA of Central Kentucky, Lexington, KY (2007-present)

- Wellness Specialist and Group Exercise Instructor

University of Kentucky, Lexington, KY (2007-2009)

- Supervised Practice Program Assistant and Teaching Assistant

Scholastic and Professional Honors

Patricia Brantley Todd School of Human Environmental Science Excellence Award in Teaching, 2017

University of Kentucky Provost's Outstanding Teaching Award, 2016

Kentucky Academy of Nutrition and Dietetics Emerging Dietetic Leader Award, 2015 Bluegrass Academy of Nutrition and Dietetics Emerging Dietetic Leader Award, 2015

Bluegrass Academy of Nutrition and Dietetics Outstanding Educator Award, 2014

\section{$\underline{\text { Professional Publications }}$}

Stephenson, T., Brewer, D., Combs, E., Koempel, A., \& McHugh, K. (2018). Experiential learning: Community nutrition class field trip to rural community with associated program planning. Journal of Nutrition Education and Behavior, 50(7S), S86-87.

Hieronymus, L.B., Combs, L.M., Coleman, E.C., Ashford, K.B., \& Wiggins, A.T. (2016). Evaluation of an education intervention in Hispanic women at risk for Gestational Diabetes Mellitus. Diabetes Spectrum.

Combs, L.M. \& Hieronymus, L.B. Navigating the Nutrition Facts Label. (2016) Weight Self-Management, March/April. 
Hieronymus, L.B., Combs, L.M., \& Gómez, M. (2015). Educational model in prenatal care to manage Gestational Diabetes Mellitus among Spanish speaking women. AADE In Practice, 3:26-32.

Stephenson, T., Mayes, L., Combs, E., \& Webber, K. (2015). Developing communication skills of undergraduate students through innovative teaching approaches, Journal of the North American Association of Colleges and Teachers of Agriculture, December. 